FACULDADE UnB GAMA - FACULDADE DE TECNOLOGIA PROGRAMA DE PÓS-GRADUAÇÃO EM INTEGRIDADE DE MATERIAIS DA ENGENHARIA

\title{
REFINAMENTO ADAPTATIVO TIPO H APLICADO À FORMULAÇÃO DE ELASTICIDADE PLANA DO MÉTODO DOS ELEMENTOS DE CONTORNO DUAL
}

RAFAELL ROCHA REBOREDO

ORIENTADOR: Dr. Éder Lima de Albuquerque CO-ORIENTADOR: Dr. Artur Antonio Portela

DISSERTAÇÃO DE MESTRADO EM INTEGRIDADE DE MATERIAIS DA ENGENHARIA

PUBLICAÇÃO: FGA.DM - N\%/2015

BRASÍLIA/DF: JULHO/2015 


\title{
UNIVERSIDADE DE BRASÍLIA \\ FACULDADE GAMA / FACULDADE DE TECNOLOGIA PROGRAMA DE PÓS-GRADUAÇÃO EM INTEGRIDADE DE MATERIAIS DA ENGENHARIA.
}

\author{
REFINAMENTO ADAPTATIVO TIPO $h$ APLICADO À FORMULAÇÃO DE \\ ELASTICIDADE PLANA DO MÉTODO DOS ELEMENTOS DE CONTORNO \\ DUAL
}

RAFAELL ROCHA REBOREDO

DISSERTAÇÃO DE MESTRADO SUBMETIDA AO PROGRAMA DE PÓS-GRADUAÇÃO EM INTEGRIDADE DE MATERIAIS DA ENGENHARIA DA FACULDADE GAMA E FACULDADE DE TECNOLOGIA DA UNIVERSIDADE DE BRASÍLIA, COMO PARTE DOS REQUISITOS NECESSÁRIOS PARA A OBTENÇÃO DO GRAU DE MESTRE EM INTEGRIDADE DE MATERIAIS DA ENGENHARIA.

APROVADA POR:

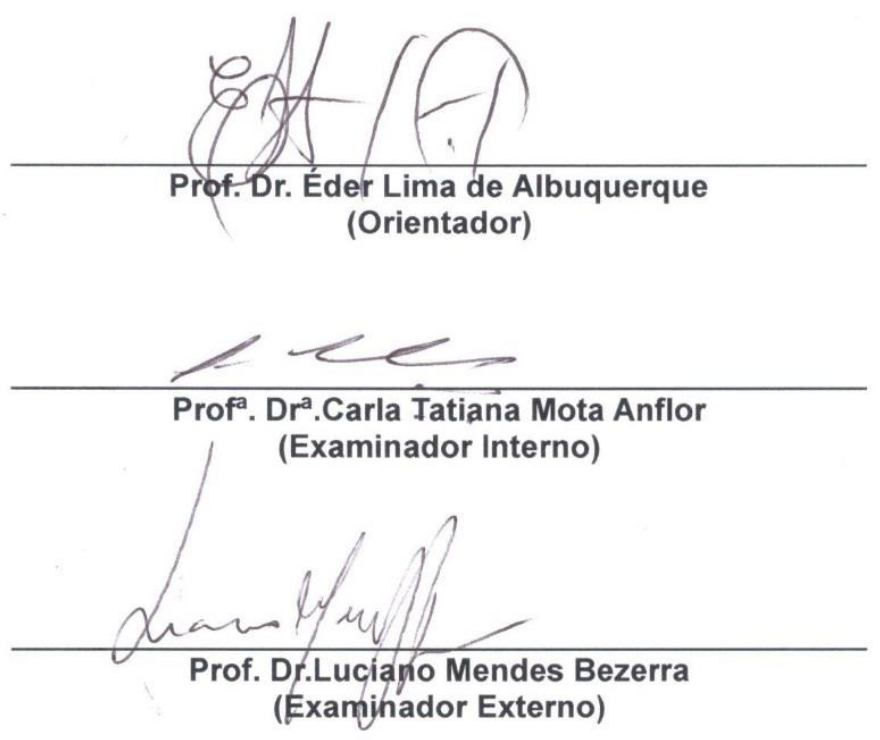

BRASÍLIA, 01 DE JULHO DE 2015. 


\section{FICHA CATALOGRÁFICA}

REBOREDO, RAFAELL ROCHA

Refinamento Adaptativo Tipo h Aplicado à Formulação de Elasticidade Plana do Método dos Elementos de Contorno Dual, [Distrito Federal] 2015.

116.p. 210 x 297 mm (FGA/FT/UnB, Mestre, Integridade de Materiais da Engenharia, 2015). Dissertação de Mestrado - Universidade de Brasília. Faculdade UnB Gama. Programa de Pós-Graduação em Integridade de Materiais da Engenharia.

$\begin{array}{ll}\text { 1. Método dos Elementos de Contorno } & \text { 2. Refinamento Adaptativo }\end{array}$

3. Estimador de Erro 4. Elasticidade Plana

$\begin{array}{ll}\text { I. FGA/FT/UnB } & \text { II. GAMA }\end{array}$

\section{REFERÊNCIA BIBLIOGRÁFICA}

REBOREDO, R. R. (2015). Refinamento Adaptativo Tipo h Aplicado à Formulação de Elasticidade Plana do Método dos Elementos de Contorno Dual. Dissertação de Mestrado em Integridade de Materiais da Integridade da Engenharia, Publicação $N^{0} 023 \mathrm{~A} / 2015$, Faculdade UnB Gama/FT/Universidade de Brasília, DF, 116.p.

\section{CESSÃO DE DIREITOS}

AUTOR: RAFAELL ROCHA REBOREDO.

TÍTULO: Refinamento Adaptativo Tipo h Aplicado à Formulação de Elasticidade Plana do Método dos Elementos de Contorno Dual.

\section{GRAU: Mestre ANO: 2015}

É concedida à Universidade de Brasília permissão para reproduzir cópias desta dissertação de mestrado e para emprestar ou vender tais cópias somente para propósitos acadêmicos e científicos. $\mathrm{O}$ autor reserva outros direitos de publicação e nenhuma parte desta dissertação de mestrado pode ser reproduzida sem a autorização por escrito do autor.

RAFAELL ROCHA REBOREDO

rafaellreboredo@gmail.com 
Ao Prof. Éder Albuquerque, que me encaminhou à pesquisa científica. Aos meus sogros Henrique e Sandra, pelo incentivo e exemplo.

À minha esposa Fernanda, pelo apoio constante e incondicional. 


\section{AGRADECIMENTOS}

Agradeço, primeiramente, à minha esposa Fernanda Lobato Miguel, pela revisão ortográfica deste texto, pelos aconselhamentos e por todo o suporte prestado durante minha então curta jornada acadêmica.

Muito obrigado também a meus sogros, Sandra e Henrique, por todo o apoio e atenção, e pelo incontestável exemplo de conduta.

Agradeço ao meu orientador, Dr. Éder Lima de Albuquerque, pela ajuda e orientação sobrecomum, sem as quais a realização deste trabalho se impossibilitaria; pela eterna e incansável disposição em tirar dúvidas e pelo comportamento exemplar que reforçam seu elevado caráter e incontestável profissionalismo.

Agradeço também ao meu co-orientador, Dr. Artur Portela, por toda inspiração que sua trajetória acadêmica a mim representa, pelos aconselhamentos e apoio prestados.

Obrigado aos professores Dra. Carla Tatiana Mota Anflor e Dr. Luciano Mendes Bezerra, membros da banca, pela atenção.

Finalmente, agradeço à CAPES pelo apoio financeiro e à UnB e FGA pela oportunidade. 
"The scientist does not study nature because it is useful to do so. He studies it, because he takes pleasure in it, and he takes pleasure in it, because it is beautiful. If nature were not beautiful, it would not be worth knowing, and life would not be worth living."

Henri Poincaré 


\section{RESUMO}

O presente trabalho apresenta um algoritmo de refinamento adaptativo tipo $h$, para ser utilizado junto à formulação de elasticidade plana do Método dos Elementos de Contorno Dual (MECD). Esse algoritmo é baseado no cálculo de indicadores de erro responsáveis pela aferição das descontinuidades da solução produzida ao longo do contorno entre elementos quadráticos descontínuos, permitindo a identificação do elemento de contorno que apresenta a maior descontinuidade para um refinamento localizado da malha. $O$ método adaptativo é validado mediante a solução de quatro problemas, dois exemplos clássicos de elasticidade plana e dois de mecânica da fratura. Para demonstrar a efetividade do algoritmo, além de um estudo de convergência, é realizada uma análise comparativa entre as soluções produzidas com as formas tradicionais do MEC e MECD e a técnica adaptativa apresentada.

Palavras chaves: Método dos Elementos de Contorno; Refinamento Adaptativo; Estimador de Erro; Elasticidade Plana; Mecânica da Fratura. 


\section{ABSTRACT}

The present work is concerned with the effective numerical implementation of the adaptive dual boundary-element method (DBEM) for two-dimensional elastic problems. The method uses a simple error estimator, based on the discontinuity of the solution across the boundaries between adjacent elements and implements the $h$ version of the adaptive mesh refinement for 2D elastic BEM formulation. In order to validate the algorithm, four problems are solved: two classical elasticity theory examples and two from fracture mechanics. To demonstrate the algorithm effectiveness, these problems are solved using both conventional BEM and DBEM and its adaptive forms.

Keywords: Boundary Element Method; Adaptive Refinement; Error Estimator; Elasticity; Fracture Mechanics. 


\section{LISTA DE FIGURAS}

2.1 Forças externas aplicadas a um tetraedro infinitesimal como a representação de

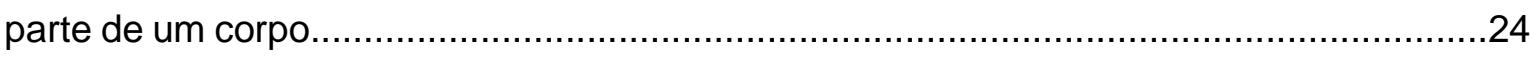

2.2 Modos de Carregamento: (a) Modo I, (b) Modo II e (c) Modo III............................ 29

2.3 Sistemas de Coordenadas na Ponta da Trinca.................................................... 30

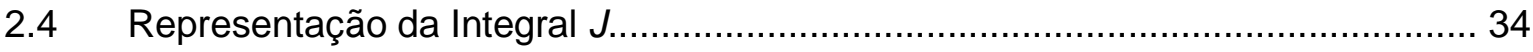

2.5 Distância do raio adotado para o cálculo da Integral J....................................... 35

3.1 Ponto fonte circundado por uma região semicircular......................................... 47

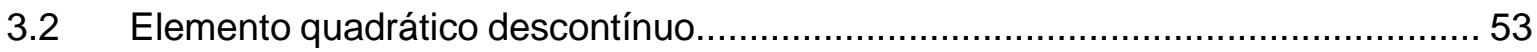

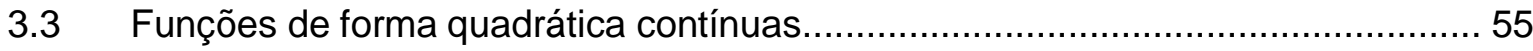

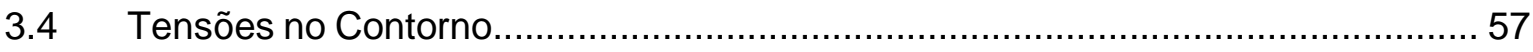

5.1 O problema matemático de quase-singularidade ............................................. 75

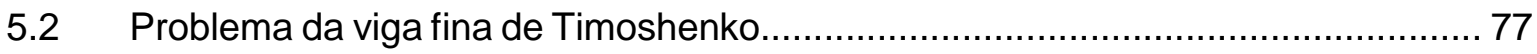

5.3 Malha inicial para o problema de viga fina....................................................... 77

5.4 Soluções obtidas com o MEC convencional e MEC adaptativo............................... 79

5.5 Esforço computacional entre os dois métodos de solução.................................. 80

5.6 O problema da placa com furo circular sob tração............................................. 82

5.7 Malha inicial do problema da placa com furo central sob tração............................ 83

5.8 Locais de aferição das tensões no furo da placa............................................... 83

5.9 Soluções obtidas com o MEC convencional e MEC adaptativo............................... 85

5.10 Esforço computacional entre os dois métodos de solução.................................... 86

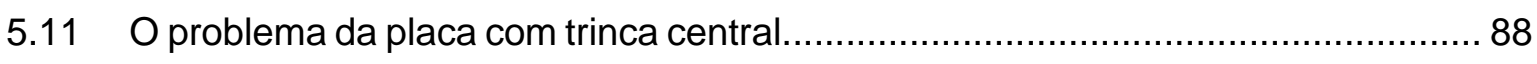

5.12 Elementos da trinca em detalhe para a $2^{\mathfrak{a}}$ iteração............................................. 90

5.13 Soluções obtidas com o MECD convencional e MECD adaptativo........................ 92

5.14 Esforço computacional entre os dois métodos de solução................................... 93

5.15 Fator de intensidade de tensão para diferentes valores de $\mathrm{a} / \mathrm{b} . \ldots \ldots \ldots \ldots \ldots \ldots \ldots \ldots . . . . . . . . . . . . . . .94$

5.16 O problema da placa com trinca de borda sob tração......................................... 95 
5.17 Elementos da trinca em detalhe para ambas as iterações.................................... 97

5.18 Soluções obtidas com o MECD convencional e MECD adaptativo.........................99

5.19 Esforço computacional entre os dois métodos de solução................................... 99

5.20 Fator de intensidade de tensão para diferentes valores de a/b........................... 100 


\section{LISTA DE TABELAS}

5.1 Resultados para o deslocamento vertical máximo - MEC convencional................ 78

5.2 Resultados para o deslocamento vertical máximo - MEC adaptativo.................... 78

5.3 Resultados para a tensão máxima na placa - MEC convencional......................... 84

5.4 Resultados para a tensão máxima na placa - MEC adaptativo.............................. 84

5.5 Valores para os indicadores de erro nas (a) $1^{\underline{a}}$ iteração e (b) $2^{\underline{a}}$ iteração................ 89

5.6 Fator de intensidade de tensão para $a / B=0,5-M E C D$ adaptativo........................ 90

5.7 Fator de intensidade de tensão para a/B=0,5 - MECD convencional................... 90

5.8 Fator de intensidade de tensão para $\mathrm{a} / \mathrm{B}=0,4-\mathrm{MECD}$ adaptativo........................ 90

5.9 Fator de intensidade de tensão para a/B=0,4 - MECD convencional.................... 91

5.10 Fator de intensidade de tensão para $a / B=0,3$ - MECD adaptativo....................... 91

5.11 Fator de intensidade de tensão para $a / B=0,3-M E C D$ convencional.................... 91

5.12 Fator de intensidade de tensão para $\mathrm{a} / \mathrm{B}=0,2$ - MECD adaptativo........................ 91

5.13 Fator de intensidade de tensão para a/B=0,2 - MECD convencional....................91

5.14 Valores para os indicadores de erro nas (a) $1^{\mathrm{a}}$ iteração e (b) $2^{\underline{a}}$ iteração................ 96

5.15 Fator de intensidade de tensão para $a / B=0,7$ - MECD adaptativo....................... 97

5.16 Fator de intensidade de tensão para a/B=0,7 - MECD convencional.................... 97

5.17 Fator de intensidade de tensão para a/B=0,6 - MECD adaptativo........................ 97

5.18 Fator de intensidade de tensão para a/B=0,6 - MECD convencional..................... 98

5.19 Fator de intensidade de tensão para $\mathrm{a} / \mathrm{B}=0,5$ - MECD adaptativo........................ 98

5.20 Fator de intensidade de tensão para $a / B=0,5-M E C D$ convencional.................... 98

5.21 Fator de intensidade de tensão para $a / B=0,4$ - MECD adaptativo....................... 98

5.22 Fator de intensidade de tensão para a/B=0,4 - MECD convencional.................... 98 


\section{LISTA DE ABREVIATURAS E SIGLAS}

MEC $=$ Métodos dos Elementos de Contorno

MECD = Método dos Elementos de Contorno Dual

$\mathrm{BEM}=$ Boundary Element Method

DBEM = Dual Boundary-element Method

MDF = Método das Diferenças Finitas

$\mathrm{MEF}=$ Método dos Elementos Finitos

ISD = identidade de Somigliana para deslocamentos

IST = identidade de Somigliana para Tensões

EIC = Equação Integral de Contorno

EICC = Equação Integral de Contorno Convencional

$\mathrm{EICH}=$ Equação Integral de Contorno Hipersingular 


\section{SUMÁRIO}

1 INTRODUÇÃO

1.1 Métodos Numéricos Aplicados a Problemas de Engenharia.................................16

1.2 Breve Histórico do Desenvolvimento do MEC …................................................17

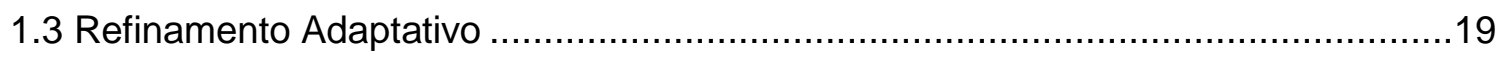

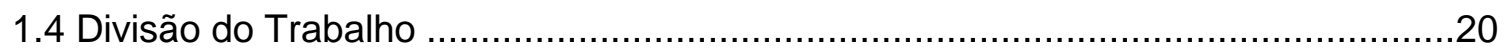

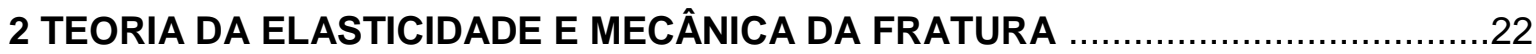

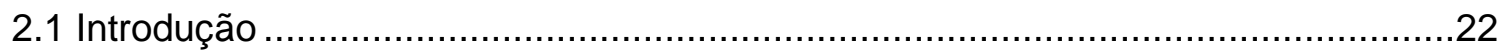

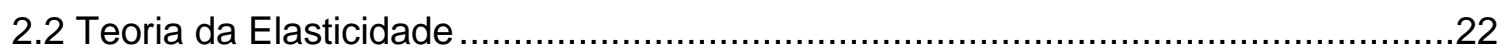

2.2.1 O Conceito deTensão ...........................................................................22

2.2.2 O Tensor de Tensões ...........................................................................23

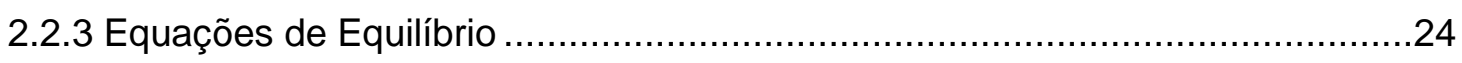

2.2.4 O Tensor de Deformação....................................................................24

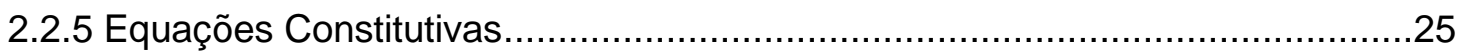

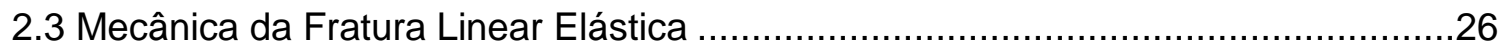

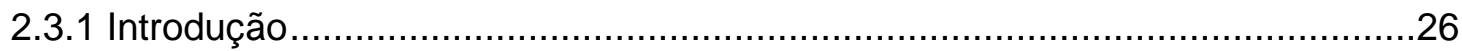

2.3.2 Breve Histórico do Desenvolvimento da Mecânica da Fratura .........................27

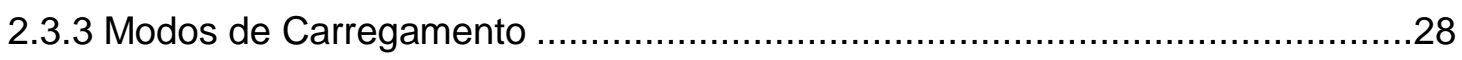

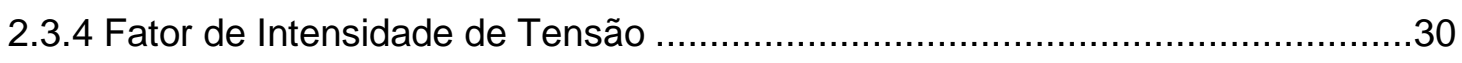

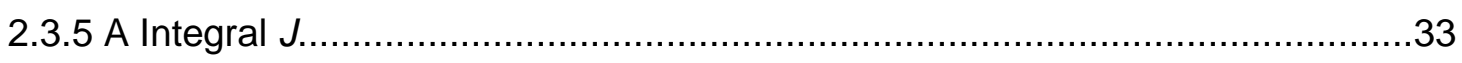

3 O MÉTODO DOS ELEMENTOS DE CONTORNO E SUA FORMULAÇÃO DUAL .......37

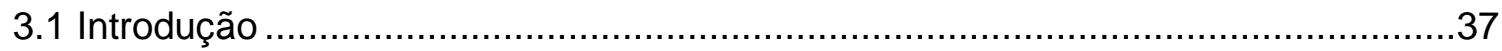

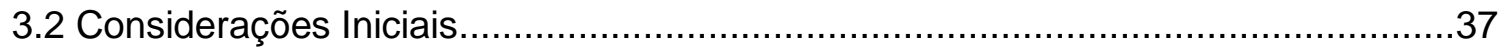

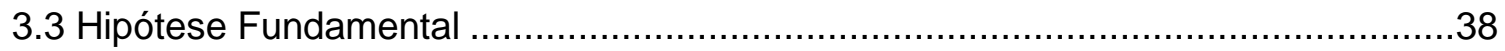

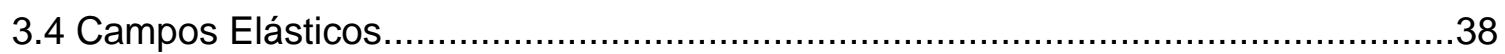

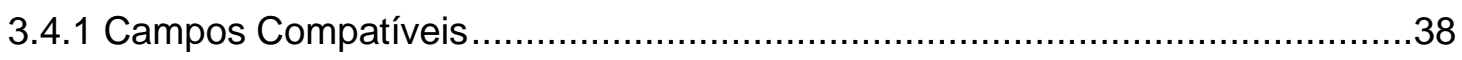

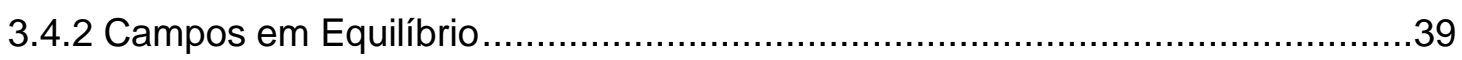

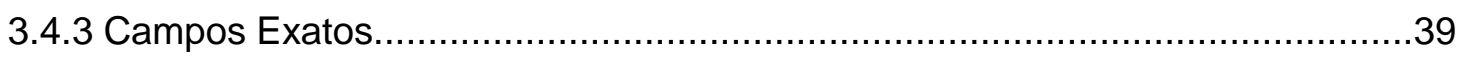

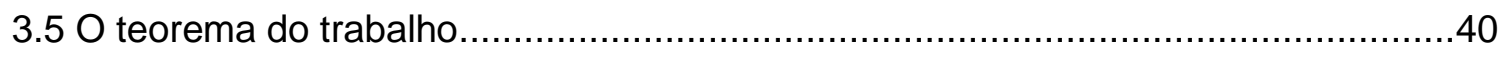

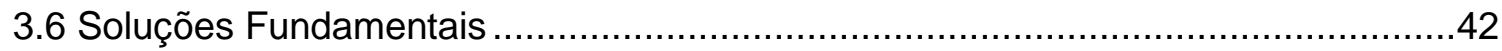

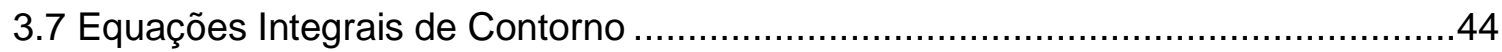


3.7.1 Equação de Deslocamento (EICC) ….....................................................44

3.7.2 Equação de Forças de Superfície $(\mathrm{EICH})$...................................................48

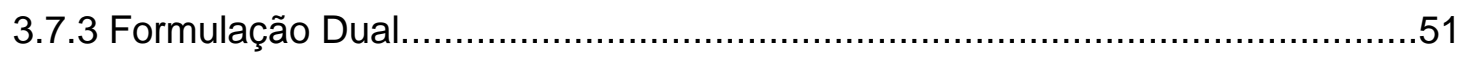

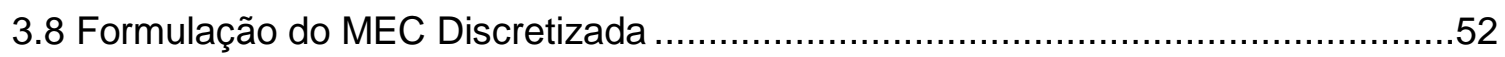

3.8.1 Elementos Quadráticos Descontínuos ......................................................52

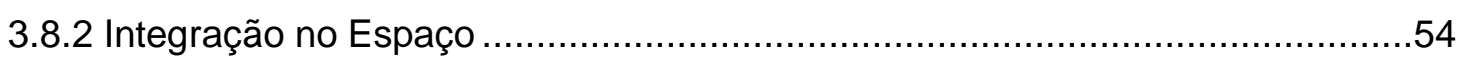

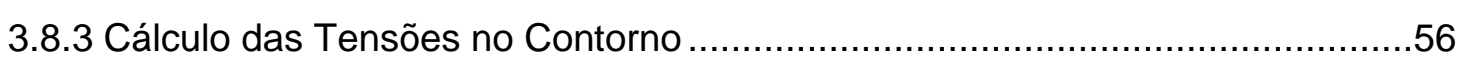

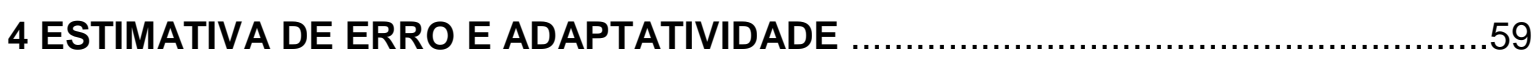

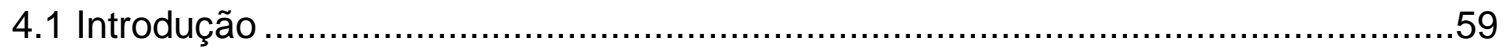

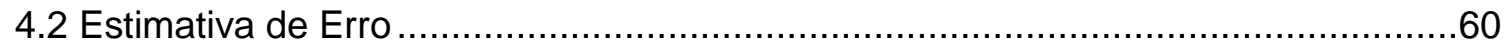

4.2.1 Tipos de Estimadores de Erro a posteriori ..................................................61

4.2.2 Estimador de Erro para Elementos de Contorno Descontínuos ......................63

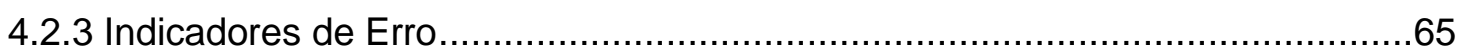

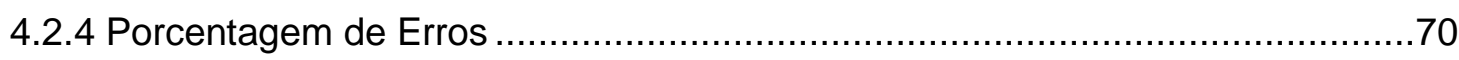

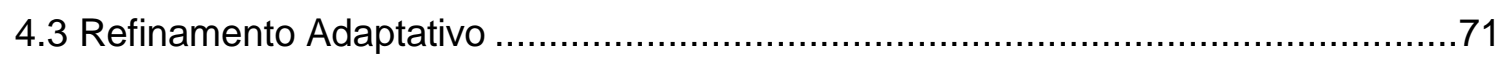

4.3.1 Tipos de Refinamento Adaptativo ....................................................... 71

4.3.2 Refinamento Adaptativo Implementado .............................................. 72

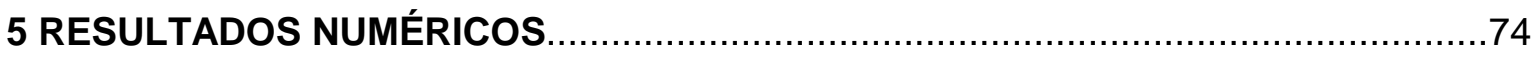

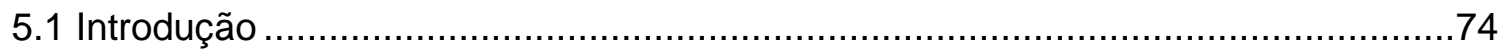

5.2 Problemas Clássicos de Elasticidade Plana .........................................................

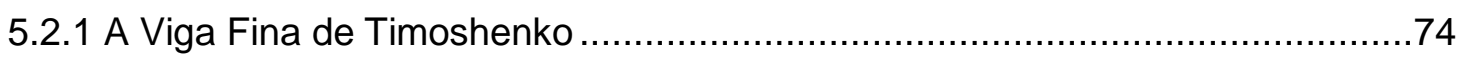

5.2.2 Placa Infinita com Furo Circular sob Tração............................................... 81

5.3 Problemas Clássicos de Mecânica da Fratura.......................................................87

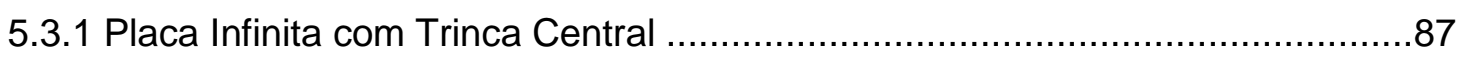

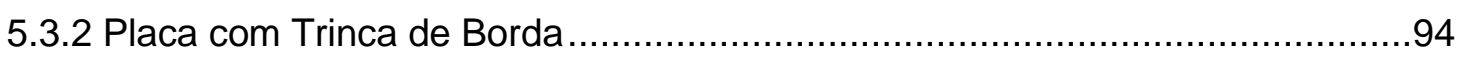

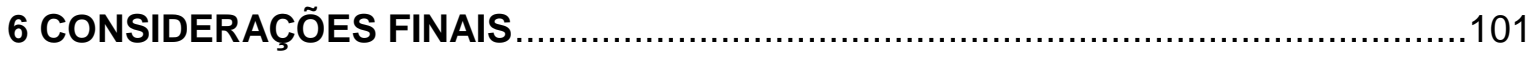

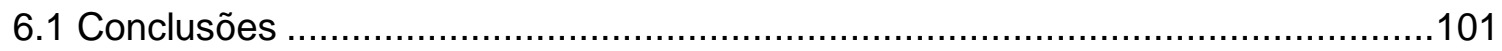

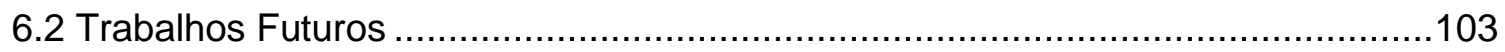

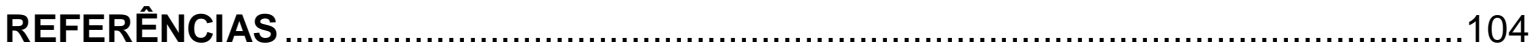

APÊNDICE A - ROTINA PARA O CÁLCULO DOS SALTOS ENTRE AS SOLUÇÕES DO CONTORNO ............................................................................................112

APÊNDICE B - ROTINA PARA O CÁLCULO DOS INDICADORES DE ERRO............114 APÊNDICE C - ROTINA PARA O CÁLCULO DAS PORCENTAGENS DE ERRO ......115 APÊNDICE D - ROTINA PARA EFETUAR O REFINAMENTO ..................................116 



\section{INTRODUÇÃO}

\subsection{MÉTODOS NUMÉRICOS APLICADOS A PROBLEMAS DE ENGENHARIA}

A busca pela solução exata de um problema de engenharia sempre norteou os trabalhos da comunidade científica desde os primórdios do desenvolvimento das ciências. Muitas das vezes, a considerável complexidade do conjunto de equações diferenciais que governam o problema torna a obtenção analítica dessa solução impraticável, ao menos que seja adotado um número significativo de simplificações, o que, por sua vez, acaba por presumir um modelo matemático incompatível com a natureza real do problema em análise. Os métodos numéricos possuem a vantagem de não demandarem a consideração dessas simplificações, permitindo análises mais realistas. Assim, problemas complexos são tratados por modelagens discretas, resultando em um sistema de equações mais simples, que pode ser facilmente resolvido por intermédio de técnicas computacionais.

O primeiro método numérico amplamente empregado na solução de problemas de mecânica dos sólidos foi o Método das Diferenças Finitas (MDF). Nesta formulação, o sistema de equações diferenciais governantes é aproximado por uma expansão truncada em série de Taylor, sendo resolvido para alguns pontos do domínio. Por ser um método de solução de equações diferenciais, centra-se no conceito de aproximar essas equações pelas chamadas diferenças finitas, tornandoas equações algébricas de fácil solução.

Embora o MDF tenha sido, de certa forma, um método pioneiro, segundo Cheng (1), o Método dos Elementos Finitos (MEF) possui o maior número de publicações registradas na plataforma Web of Science, com mais de 65 mil entradas, o que o torna o método numérico mais popular e, consequentemente, o mais versátil na solução de problemas de engenharia. A origem da formulação do MEF pode ser obtida utilizando o princípio dos trabalhos virtuais ou o cálculo variacional, necessitando da discretização de todo o domínio do problema, podendo resultar em malhas bastante complexas e de intrincada geração e representação. Desta forma, 
problemas em três dimensões serão resolvidos por intermédio de elementos de volume e problemas de 2D por elementos de área.

O Método dos Elementos de Contorno (MEC) é um dos três métodos de análise numérica mais populares. Segundo Cheng (1), os termos "boundary element" ou "boundary integral" possuem pouco mais de 10 mil entradas na Web of Science. 0 MEC é uma técnica que, diferentemente do MDF e MEF, necessita da discretização apenas do contorno do problema, o que acaba por reduzir em uma unidade a sua dimensão. A formulação do MEC se baseia na obtenção das equações integrais de contorno (EIC), deduzidas a partir da manipulação algébrica das equações diferenciais governantes do problema. No que concerne problemas de elasticidade plana, a EIC é obtida a partir da identidade de Somigliana para o deslocamento, por intermédio de um processo de limite para o contorno. O MEC faz aproximações por segmentos no contorno do corpo utilizando as chamadas funções de forma, que dão origem a um sistema de equações lineares que contém as incógnitas do problema. Tendo em vista que não há necessidade de discretização do domínio, os sistemas de equações gerados são menores que os obtidos pelo MEF, quando um mesmo problema é analisado por ambas as técnicas, naturalmente. As aproximações são feitas exclusivamente no contorno, sendo que a solução é contínua no domínio do corpo, sendo obtida a partir dos valores das quantidades calculadas no contorno, quais sejam: deslocamentos e forças superfícies.

\subsection{BREVE HISTÓRICO DO DESENVOLVIMENTO DO MEC}

\subsubsection{Formulação Elástica do MEC}

O conceito de reduzir a dimensão de um problema fazendo uso de uma equação integral de contorno foi introduzido, no que concerne à Mecânica do Contínuo, ainda no século XIX por Somigliana (2) para a teoria da elasticidade e começo do século XX por Fredholm (3) para a teoria potencial. Entretanto, foi apenas com as contribuições dos matemáticos Muskhelishvili (4), Mikhlin (5), Smirnov (6) e Kupradze (7), no começo da década de 1950, que as soluções para equações integrais singulares se estabeleceram na comunidade científica. A base da formulação indireta do MEC teve 
origem nessa mesma época, com os trabalhos de Kellogg (8), Jaswon (9), Symm (10), Massonnet (11) e Oliveira (12). O método direto, o qual atribui um significado físico às variáveis do problema matemático, se desenvolveu mediante os trabalhos de Rizzo (13) e Cruze e Rizzo (14) para a teoria da elasticidade, já no final da década de 1960. Em seguida, Lachat (15) e Lachat e Watson (16) desenvolveram, para aplicações ao MEF, uma representação paramétrica tanto para as variáveis geométricas quanto para as físicas. A equação integral de contorno para aferir a tensão de um corpo foi apresentada por Cruze (17), em 1977, entretanto, seu uso integrado ao MEC só foi permitido em 1988, por intermédio do trabalho de Hong e Chen (18).

A equação integral de contorno de deslocamento pode ser deduzida de várias formas. A formulação apresentada por Cruze e Rizzo (14) é baseada na forma interna do teorema da reciprocidade de Betti. Em outra abordagem, Aliabadi (19) apresentaram uma formulação baseada na forma externa desse mesmo teorema. A equivalência entre ambas as formulações pode ser demonstrada por intermédio do teorema do trabalho, por meio do qual a forma externa do teorema da reciprocidade de Betti é fundamentada.

Uma derivação alternativa, no que concerne à teoria potencial, foi introduzida por Brebbia e Dominguez (20), por meio do método dos resíduos ponderados. A primeira aplicação desse método para elastostática foi realizada por Portela (21), para fins de dedução da expressão generalizada do teorema do trabalho, por meio do qual a EIC para o deslocamento foi formulada, cuja dedução será apresentada com mais detalhes no Capítulo 3 deste trabalho.

\subsubsection{Formulação Dual do MEC}

Embora o MEC possa ser aplicado a problemas de elasticidade plana de forma bastante eficiente, em face de geometrias degeneradas, a utilização de uma única equação integral de contorno dá origem a um problema mal posto. O Método dos Elementos de Contorno Dual (MECD) é a técnica mais eficiente para o tratamento desse tipo de problema, tendo sido apresentado por Portela, Aliabadi e Rooke (22) em 1992.

O MECD consiste na aplicação simultânea de ambas as equações integrais de contorno, a convencional e a hipersingular - EICC e EICH, respectivamente. O pleno desenvolvimento dessa formulação teve como base os trabalhos de Hong e Chen 
Chen (23), que investigaram a equação integral calculada no sentido principal de Hadamard, a qual representa a origem da $\mathrm{EICH}$. Os mesmos autores apresentaram, em 1987, a dedução de ambas as EIC Chen e Hong (24) e Chen e Chen (25). Desde então, a EICH foi paulatinamente recebendo a atenção da comunidade científica, conforme se observa pelos trabalhos de Gray (26), Gray, Martha e Ingraffea (27) e Mi e Aliabadi (28).

Atualmente, o MECD já está bem estabelecido, possuindo uma versatilidade que o permite ser aplicado a uma sorte diferente de problemas de engenharia. Neste trabalho, a formulação elástica bidimensional do MECD será usada para resolver dois problemas contendo geometrias degeneradas: inicialmente, calcularemos o fator de intensidade de tensões para uma placa contendo uma trinca central e, em seguida, para uma placa com trinca de borda. O desenvolvimento e aplicação do MECD a esses problemas serão descritos em mais detalhes nos capítulos subsequentes. Uma revisão bibliográfica detalhada sobre o surgimento e evolução do MECD ao longo do tempo pode ser encontrada em Chen e Hong (29).

\subsection{REFINAMENTO ADAPTATIVO}

Conforme exposto anteriormente, a obtenção de uma solução exata para problemas reais de engenharia muitas vezes constitui uma tarefa extremamente complexa. Por conseguinte, a utilização de métodos numéricos no intuito de obter soluções aproximadas para esses problemas se define como uma das melhores estratégias.

Soluções aproximadas estabelecem um distanciamento compulsório, inerente ao processo de análise numérica, das soluções exatas, de modo que se faz necessário o desenvolvimento de métodos que permitam o controle desses erros de aproximação.

Normalmente, o processo de refinamento de malha na fase de discretização do problema está associado à obtenção de soluções numéricas mais precisas. Entretanto, refinar a malha significa aumentar o volume dos cálculos realizados, o que, por sua vez, representa um aumento do esforço computacional empregado, tornando a solução obtida mais dispendiosa. Nesse caso, é essencial o uso inteligente deste 
artifício - deve-se procurar o refinamento de locais que mais influenciam na convergência da solução, buscando um equilíbrio entre o custo computacional e a obtenção de soluções com menores erros agregados.

A técnica de refinamento adaptativo possui como objetivo, justamente, realizar o refinamento de modo inteligente. É baseado no conceito de estimador de erros, caracterizados em forma de algoritmos responsáveis pelo mapeamento dos erros da solução de forma localizada. Assim, é possível saber qual região do modelo discreto precisa ser refinada.

O objetivo principal deste trabalho é propor um método de refinamento adaptativo baseado em um tipo de estimador de erro que computa as descontinuidades do contorno ao longo de elementos adjacentes da malha. Esse algoritmo será incluído às formulações elásticas 2D do MEC e MECD, para elementos de contorno quadráticos descontínuos. A apresentação detalhada desse método está presente no Capítulo 4 do presente trabalho, e constitui uma extensão para problemas elásticos da formulação proposta por Portela em 2011 para problemas potenciais.

\subsection{DIVISÃO DO TRABALHO}

Este trabalho está dividido em seis capítulos distintos, relacionados a seguir:

- Capítulo 1: Introdução;

- Capítulo 2: Teoria da Elasticidade e Mecânica da Fratura. Apresenta os conceitos da teoria da elasticidade em duas dimensões, essenciais ao desenvolvimento das equações integrais de contorno, bem como introduz conhecimentos de mecânica da fratura linear elástica, pré-requisitos para a solução dos problemas de geometria degenerada presentes no Capítulo 5;

- Capítulo 3: O Método dos Elementos de Contorno e sua Formulação Dual. Apresenta o desenvolvimento da formulação elástica em duas dimensões do MEC e MECD, deduzindo as equações integrais de contorno convencional e hipersingular (EICC e EICH, respectivamente). Além disso, apresenta o equacionamento discretizado do método; 
- Capítulo 4: Estimativa de Erro e Adaptatividade. Apresenta o equacionamento para um tipo de estimador de erro baseado no cálculo das descontinuidades dos elementos de contorno, definindo, ainda, os tipos de estimadores de erro e conceitos de refinamento adaptativo;

- Capítulo 5: Resultados Numéricos. Apresenta os resultados obtidos com a técnica de refinamento adaptativo para quatro problemas distintos, sendo dois exemplos clássicos da teoria de elasticidade plana e dois exemplos de placas trincadas, próprios da mecânica da fratura;

- Capítulo 6: Conclusões. Principais conclusões e contribuições deste trabalho. 


\section{TEORIA DA ELASTICIDADE E MECÂNICA DA FRATURA}

\subsection{INTRODUÇÃO}

Uma vez que a principal meta deste trabalho é desenvolver um algoritmo de refinamento adaptativo para a formulação elástica do Método dos Elementos de Contorno (MEC), bem como para sua formulação dual (MECD), há a necessidade de validação do equacionamento implementado. Assim, foram selecionados quatro problemas, com soluções já conhecidas na literatura, para serem resolvidos, sendo dois deles contemplando corpos de geometria degenerada (trincas). A análise de corpos trincados requer a aplicação de conceitos de mecânica da fratura linear elástica, como o cálculo do fator de intensidade de tensões, cuja definição será apresentada a seguir.

Isto posto, este capítulo tem por objetivo a apresentação dos princípios fundamentais da teoria da elasticidade, bem como conceitos de mecânica da fratura, tendo em vista a natureza dos problemas apresentados no Capítulo 5 deste trabalho.

O equacionamento apresentado a seguir servirá de base para 0 desenvolvimento das formulações elásticas do MEC e MECD, a serem apresentadas no capítulo seguinte.

\subsection{TEORIA DA ELASTICIDADE}

\subsubsection{O Conceito de Tensão}

No que tange à Mecânica do Contínuo, o conceito de tensão é concebido através de certas suposições fundamentais, sem as quais a própria existência desse conceito seria impossibilitada. A primeira suposição diz respeito à situação em que uma força externa de magnitude qualquer, denotada por $\mathbf{F}$, é aplicada sobre um corpo em equilíbrio. Neste caso, suponhamos que exista um sistema de forças internas 
produzidas entre as partes desse corpo, e que tal sistema de forças internas possui a função de se equilibrar com a força $\mathbf{F}$, no sentido de manter o corpo imóvel. Essa suposição implica que o estado de cada parte do corpo não será modificado caso essa mesma parte seja substituída pela força F, a ser distribuída ao longo do contorno do corpo, chamado $S$.

Assim sendo, consideremos $d \mathbf{F}$ como sendo uma quantidade de força externa aplicada a um elemento diferencial $d S$ da interface do contorno $S$. A segunda suposição fundamental considera, pois, que, quando $d S \rightarrow 0$, o limite de $d \mathbf{F} / \mathrm{d} S$ existe. Tal limite é definido pelo vetor de força de superfície $\mathbf{t}$, aplicado a um ponto $P$ :

$$
\mathbf{t}=\lim _{d S \rightarrow 0} \frac{d \mathbf{F}}{d S}
$$

Outra suposição considera que $d \mathbf{F}$ não sofre mudanças quando o contorno $S$ é substituído por outro contorno qualquer que contenha o elemento $d S$. Considerando que no ponto $P$ do contorno essa quantidade diferencial aponta para o sentido do vetor unitário normal ao contorno, n, podemos escrever essa suposição da seguinte forma:

$$
\mathbf{t}(P, \mathbf{n})=-\mathbf{t}(P,-\mathbf{n})
$$

\subsubsection{O Tensor de Tensões}

Consideremos um tetraedro infinitesimal como a representação de uma parte de um corpo onde são aplicadas forças externas de magnitude qualquer (Fig. 2.1). De todas as faces do tetraedro, três delas são normais às direções do eixo ortogonal, sendo a quarta face, centrada em $P$, normal à direção do vetor unitário n. A teoria da elasticidade permite demonstrar que, no que concerne ao equilíbrio estático do corpo, o estado de tensão do ponto $P$ pode ser definido em termos das componentes do vetor de força de superfície, $\mathbf{t}_{i}$, definidos nas faces ortogonais do triangulo infinitesimal como Portela (30):

$$
\mathbf{t}=\mathbf{t}_{i} n_{i}
$$

Na direção $j$, a Eq. (2.3) pode ser escrita da seguinte forma:

$$
t_{j}=\sigma_{i j} n_{i}
$$


onde $t_{j}$ e $\sigma_{i j}$ representam os componentes dos vetores $\mathbf{t}$ e $\mathbf{t}_{i}$ na direção $j$, respectivamente.

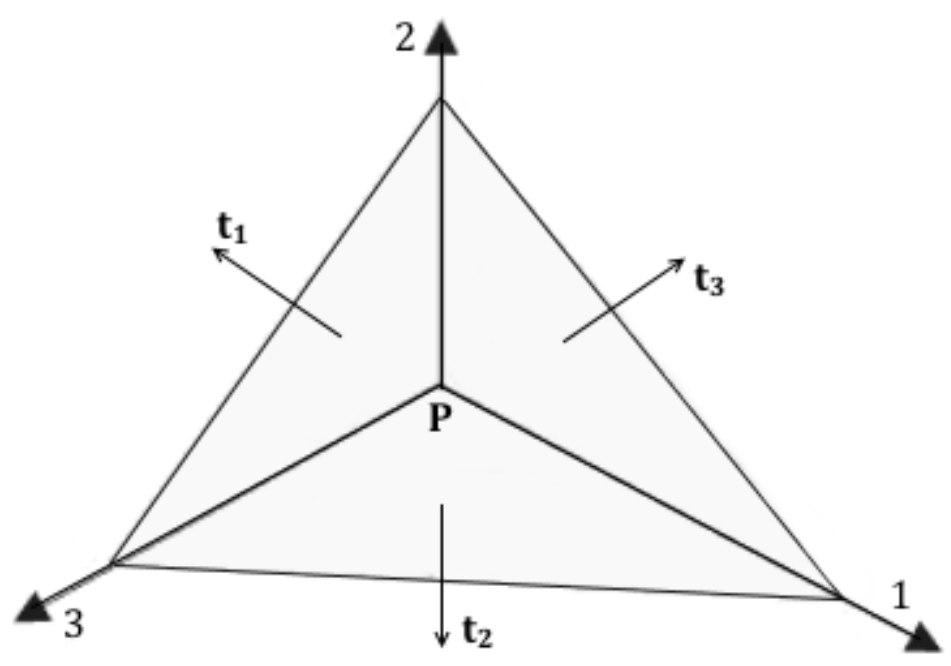

Figura 2.1 Forças externas aplicadas a um tetraedro infinitesimal como a representação de parte de um corpo

\subsubsection{Equações de Equilíbrio}

Consideremos um sistema externo de forças aplicadas a um corpo, constituído de forças de superfície aplicadas ao contorno do corpo, denotadas por $t_{i}$, e forças de corpo aplicadas ao domínio, representadas pelas quantidade $b_{i}$. O equilíbrio estático das forças é definido por:

$$
\sigma_{i j, i}+b_{j}=0
$$

A teoria da elasticidade, por intermédio do equilíbrio de momentos, permite demonstrar, ademais, que o tensor das tensões é simétrico. O sistema de equações expresso na Eq. (2.5) pode ser representado por três equações diferenciais com seis incógnitas no total. Esse sistema, parte de um problema estaticamente indeterminado, possui um número infinito de soluções, devendo existir, portanto, outro conjunto de equações com vistas à constatação da unicidade da solução do problema elástico (30).

\subsubsection{O Tensor de Deformação}

Um campo de deformação, denotado por $u_{i}$, é definido como a reação direta ao campo de tensões em um corpo deformável. Assim, o estado de deformação em qualquer ponto do corpo pode ser definido por um tensor simétrico de segunda ordem, $\varepsilon_{i j}$. Pela 
hipótese de deslocamentos infinitesimais, temos a seguinte expressão para o tensor de deformação:

$$
\varepsilon_{i j}=\frac{1}{2}\left(u_{i, j}+u_{j, i}\right)
$$

No intuito de assegurar a unicidade dos deslocamentos, as componentes do tensor de deformação não podem ser designadas arbitrariamente, devendo satisfazer certas condições de compatibilidade e integrabilidade. Assim, a equação de compatibilidade para problemas em duas dimensões (direções 1 e 2) será:

$$
\varepsilon_{11,22}+\varepsilon_{22,11}=\varepsilon_{12,12} .
$$

\subsubsection{Equações Constitutivas}

A hipótese fundamental que suporta a Teoria da Elasticidade se baseia na ideia de que, considerando qualquer ponto do corpo, os campos de tensão e deformação satisfazem uma relação definida por uma lei física, independente do tempo, que depende da constituição do material com qual o corpo é fabricado. Para o regime linear elástico, as relações de tensão e deformação podem ser definidas de acordo com as expressões:

$$
\sigma_{i j}=\frac{\partial W}{\partial \varepsilon_{i j}},
$$

onde $W$ denota a densidade de energia de deformação, que é escrita como uma função apenas das deformações do corpo, quando o material é considerado estável. A consideração de estabilidade estabelece que as variações de tensões $\left(\delta \sigma_{i j}\right)$ e deformações $\left(\delta \varepsilon_{i j}\right)$ se relacionam da seguinte forma:

$$
\delta \sigma_{i j} \delta \varepsilon_{i j}>0
$$

A função densidade de energia de deformação é definida como se segue:

$$
W=\frac{1}{2} C_{i j k l} \varepsilon_{i j} \varepsilon_{k l}
$$

onde $C_{i j k l}$ denota o tensor de constantes elásticas do material. Substituindo a Eq. (2.10) na Eq. (2.8), temos a Lei de Hooke generalizada: 


$$
\sigma_{i j}=C_{i j k l} \varepsilon_{k l}
$$

Assim, as Equações (2.10) e (2.11) permitem definir uma nova forma para a função densidade de energia de deformação:

$$
W=\frac{1}{2} \sigma_{i j} \varepsilon_{i j}
$$

Para um material isotrópico em regime linear elástico, as equações constitutivas (2.11) podem ser expressas como:

$$
\varepsilon_{i j}=\frac{1+v}{E} \sigma_{i j}-\frac{v}{E} \sigma_{k k} \delta_{i j}
$$

ou, ainda,

$$
\sigma_{i j}=\frac{E}{1+v} \varepsilon_{i j}+\frac{E v}{(1+v)(1-2 v)} \varepsilon_{k k} \delta_{i j}
$$

onde $E$ denota o módulo de elasticidade do material e $v$ a razão de Poisson.

\subsection{MECÂNICA DA FRATURA LINEAR ELÁSTICA}

\subsubsection{Introdução}

Objetivamente falando, a fratura pode ser definida como um processo de formação de novas superfícies no material. Do ponto de vista microscópico, novas superfícies são formadas devido à quebra das ligações interatômicas no sólido. Já do ponto de vista macroscópico, a fratura pode ser vista como sendo a separação da superfície de um sólido em uma ou mais partes resultando no aparecimento de trincas que crescem diante de um carregamento.

Considere uma estrutura trincada. Quanto maior a trinca, maior o concentrador de tensão relacionado, o que implicará diretamente no aumento da taxa de propagação da fissura frente a aplicação de forças externas ao corpo, diminuindo, por consequência, a resistência mecânica do material em questão. 
A Mecânica da Fratura surge para responder questões que contemplam as implicações mecânicas desse tipo de falha estrutural; questionamentos do tipo (31):

a) Qual seria o tamanho crítico de uma trinca submetida a cargas normais de serviço?

b) Quanto tempo leva para, uma vez aplicadas tais cargas, a trinca crescer até seu tamanho crítico?

c) Quantas vezes uma estrutura deve ser inspecionada para que a segurança seja sempre mantida?

Será apresentado, a seguir, um breve histórico sobre o desenvolvimento da disciplina de mecânica da fratura ao longo dos anos, bem como a definição dos principais conceitos dessa ciência, os quais permitirão a resolução dos problemas de geometria degenerada apresentados na parte final deste trabalho.

\subsubsection{Breve Histórico do Desenvolvimento da Mecânica da Fratura}

O início das pesquisas no campo da fratura começou com Leonardo da Vinci, ainda no século $\mathrm{XV}$, com investigações sobre a causa primordial do surgimento de trincas em uma estrutura. Da Vinci mediu a resistência de fios de aço e descobriu que tal propriedade comportava-se de forma inversamente proporcional ao tamanho do fio o chamado "efeito do comprimento", uma característica importante em fratura. Tais resultados, ainda que qualitativos, implicaram na conclusão de que fios maiores significavam uma maior probabilidade do material conter uma falha, ou seja, trincas no material se relacionam diretamente com a resistência mecânica do sólido.

Foi apenas cinco séculos depois que os primeiros resultados quantitativos surgiram. Em 1913, Inglis (32) determinou a magnitude do concentrador de tensões em análise a entalhes elípticos em placas planas. Finalmente em 1921, Griffith (33) conduziu uma pesquisa na qual se aplicou uma análise de tensão do mesmo furo elíptico estudado por Inglis a uma propagação instável de trinca. Usando a Primeira Lei da Termodinâmica, Griffith foi capaz de formular uma teoria que resolvia o problema ao fazer uso de um simples balanço de energia, a qual constitui a base da teoria moderna.

Após o término da Segunda Guerra Mundial, a teoria de Griffith foi expandida por outros pesquisadores da área, entre eles, o líder do grupo de estudo de Mecânica 
da Fratura do Laboratório de Pesquisa Naval americano, o Dr. G.R Irwin. A primeira grande contribuição do pesquisador americano foi aplicar a abordagem vista no Método de Griffith aos metais, incluindo a dissipação de energia da deformação plástica local ao balanço energético proposto anteriormente. Nesse mesmo período vale citar as contribuições de outros pesquisadores, como Orowan e Mott, cujos trabalhos são citados com maiores detalhes em Anderson (34).

Em 1957, Irwin (35) apresentou outra alternativa ao modelo de Griffith utilizando uma abordagem mais conveniente à análise de engenharia, a chamada taxa de alívio de energia potencial. No ano seguinte, Irwin aproveitou um artigo publicado por Westergaard (36) em 1939 para mostrar que os deslocamentos e as tensões próximas à ponta da trinca estavam relacionados por uma única constante; tal parâmetro ficou conhecido posteriormente como fator de intensidade de tensão.

Assumindo que haja uma trinca no material - hipótese primordial previamente estabelecida pela Mecânica da Fratura - existem duas formas pelas quais uma estrutura pode vir a colapsar. A primeira delas assume uma solicitação atípica e pontual; já a outra hipótese prevê a atuação de esforços cíclicos, cujas frequências e amplitudes podem ser variáveis, o que caracteriza o fenômeno de fadiga.

Os tópicos subsequentes tratarão apenas dos conceitos fundamentais de mecânica da fratura, tendo em vista que a abordagem de teorias próprias da disciplina de propagação de trincas por fadiga foge do escopo deste trabalho. Nos exemplos que contemplam geometrias degeneradas, discutidos no Capítulo 5, terão por objetivo a aferição do fator de intensidade de tensões que, como dito anteriormente, representa o principal parâmetro na análise mecânica de um corpo sólido trincado.

\subsubsection{Modos de Carregamento}

Os modos de carregamento são classificados de acordo com o movimento exercido pela superfície superior com relação à inferior, separadas pela trinca que tende a se propagar, dado o movimento de ambas as faces, de acordo com a Fig. (2.2). 


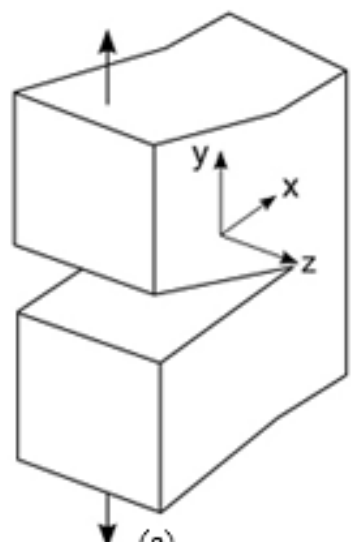

(a)

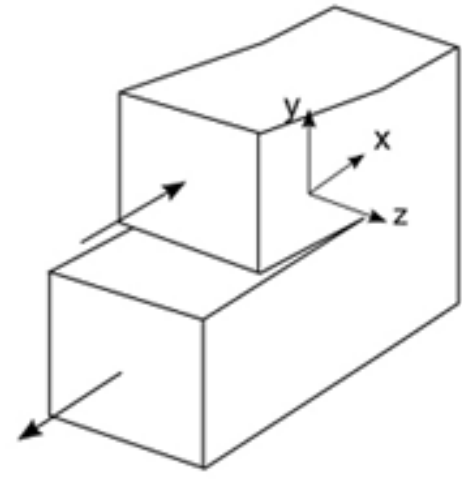

(b)

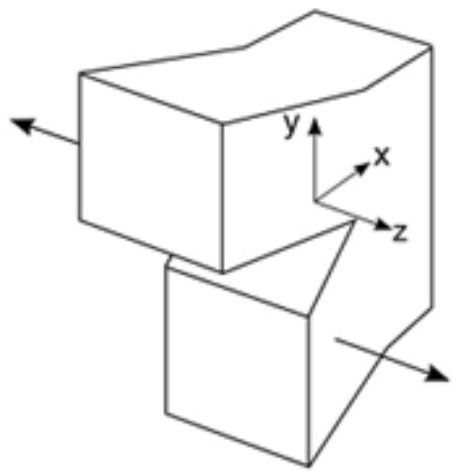

(c)

Figura 2.2 Modos de Carregamento: (a) Modo I, (b) Modo I/ e (c) Modo III. Fonte: (37)

A Fig. 2.2 expressa um corpo com uma trinca plana e um sistema de coordenadas fixo exatamente à ponta da trinca, na medida em que suas faces estejam sobre o plano x-z, sendo paralelas ao eixo x e ortogonais à $z$.

No caso de uma carga ser aplicada paralelamente ao eixo y (Fig. 2.2a), teremos o chamado modo I (modo de abertura ou tração); O modo II (modo de cisalhamento) é caracterizado por um carregamento aplicado paralelamente ao eixo x (Fig. 2.2b); já o modo III (modo de torção) acontece na situação em que o carregamento for aplicado paralelamente ao eixo z (Fig. 2.2c).

Observa-se que, em modo I, a separação dos planos que contemplam a trinca (planos $x-y$ e $x-z$ ) acontece de forma simétrica. Em modo II, a simetria só ocorre no deslizamento do plano $x-y$, procedendo antissimetricamente frente à desunião do plano x-z. Finalmente, em modo III, ambos os planos se separam de forma antissimétrica.

Diz-se que o problema é plano se as equações para o deslocamento e forças de superfície forem funções apenas das direções $x$ e y. Define-se modo misto a situação em que há a combinação de mais de um dos modos apresentados acima, na qual a solução final será dada através da superposição das soluções particulares, constatada a linearidade das equações governantes do problema.

Cumpre informar que os problemas resolvidos neste trabalho contemplaram cargas aplicas apenas em modo I. 


\subsubsection{Fator de Intensidade de Tensão}

O trabalho publicado por Westergaard (36) em 1939 introduziu uma expressão para o campo de tensões na vizinhança de uma trinca de comprimento $2 a$, carregada em modo I puro, para um material isotrópico de comportamento linear elástico. Essa expressão é enunciada da forma que se segue:

$$
\sigma_{i j}=\sigma \sqrt{\frac{a}{2 r}} f_{i j}(\theta)
$$

onde $f_{i j}(\theta)$ é uma função da coordenada polar $\theta$. Aqui, podemos observar que a Eq. (2.15) define o campo de tensões como sendo função da tensão $\sigma$ aplicada ao corpo, da dimensão da trinca e das coordenadas polares acima definidas ( $r$ e $\theta$ ) em relação à direção da ponta da trinca, conforme ilustra a Fig. (2.3):

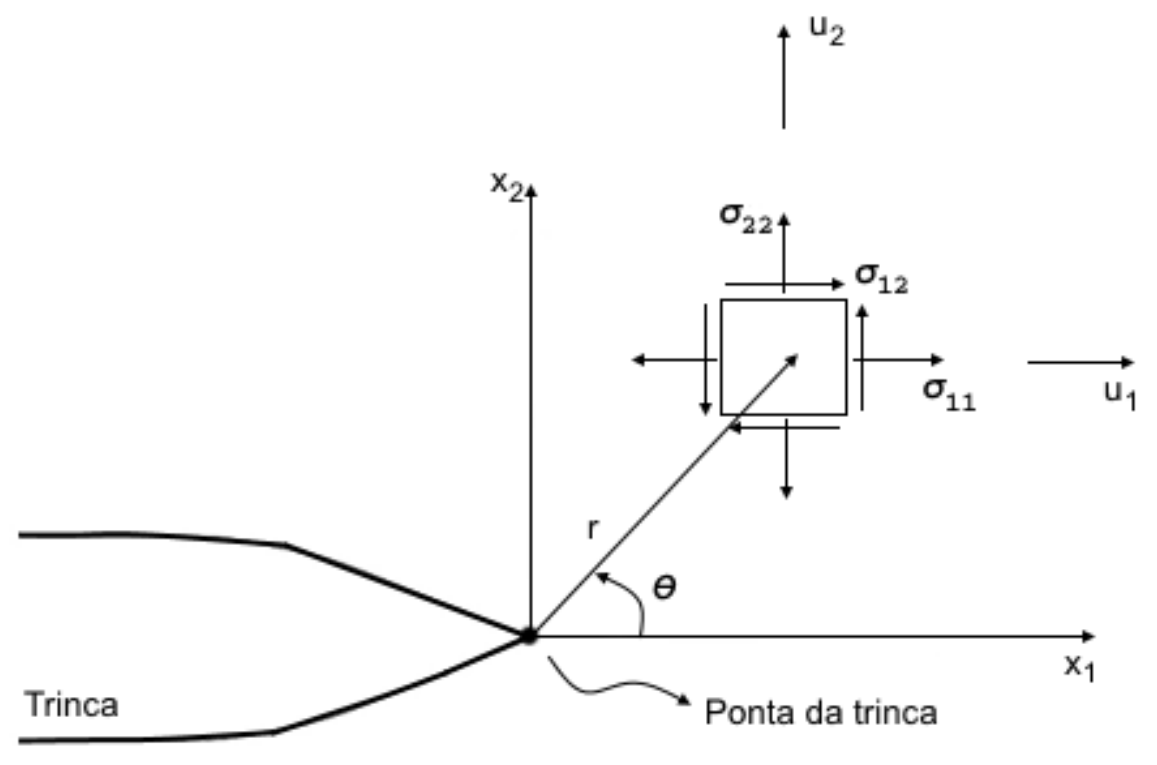

Figura 2.3 Sistemas de Coordenadas na Ponta da Trinca

Foi baseado naquele trabalho que Irwin (38) identificou um fator de proporcionalidade em associação a cada modo de fratura, os então chamados fatores de intensidade de tensão, $K_{I}, K_{I I}$ e $K_{I I I}$, em relação aos modos $I, I I$ e $I I I$, respectivamente. Assim, é possível reescrever a Eq. (2.15) na forma:

$$
\sigma_{i j}=\frac{K_{I}}{\sqrt{2 \pi r}} f_{i j}(\theta) .
$$


O fator de intensidade de tensão pode ser interpretado fisicamente como um parâmetro que define a intensidade do campo de tensões e deslocamentos nas proximidades da ponta da trinca, de forma a não depender das coordenadas polares definidas na Fig. (2.3). Desse modo, duas trincas completamente distintas, submetidas a tensões diferentes e com comprimentos diversos, apresentarão a mesma distribuição de tensões e deslocamentos uma vez que os respectivos fatores de intensidade de tensão forem idênticos.

Consideremos uma trinca de comprimento $2 a$, em uma placa submetida a uma tensão denotada por $\sigma$. Neste caso, pode-se escrever a expressão para o fator de intensidade de tensão (31):

$$
K_{I}=\beta \sigma \sqrt{a} \text {. }
$$

Comparando as dimensões das Equações (2.16) e (2.17), é possível concluir que $\beta=\sqrt{\pi}$. Assim, tem-se que:

$$
K_{I}=\sigma \sqrt{\pi a}
$$

Consideremos, agora, que a mesma placa trincada possua uma largura $W$. Quanto menor for $W$, maior será a tensão na ponta da trinca. Assim, sabemos que o fator de intensidade de tensão $K_{I}$ é inversamente proporcional à largura da placa $W$. Define-se, portanto, o fator adimensional $\beta$ como dependente de fatores geométricos do problema, ou seja:

$$
\beta=\frac{a}{W}+\frac{a}{D}+\frac{a}{R}
$$

onde $D$ denota o comprimento e $R$ a altura da placa. Substituindo a Eq. (2.19) em (2.17), após algumas manipulações algébricas, teremos:

$$
K_{I}=\beta\left(\frac{a}{L}\right) \sigma \sqrt{\pi a}
$$

onde $L$ denota o parâmetro geométrico generalizado em que $\beta$ é dependente. Conhecendo-se o fator geométrico $\beta$, bastará inquirir o parâmetro que define 0 comprimento da trinca $2 a$ e a tensão aplicada à placa para que a Eq. (2.20) possa ser resolvida. 
Para uma trinca de tamanho $2 a$ disposta no centro de uma placa considerada infinita, de largura $W$ conhecida, e finita, a solução para $K_{I}$ será da forma (39):

$$
K_{I}=\sigma \sqrt{\pi a} F(a / W)
$$

onde $F(a / W)$ é uma função dependente dos fatores geométricos do problema, possuindo inúmeras formas segundo observações empíricas, conforme demonstrado por Tada, Paris e Irwin (39). Para o caso de uma placa de largura $W$, contendo uma trinca de borda de comprimento a e submetida a mesma tração $\sigma$, o fator de intensidade de tensão em modo de abertura também pode ser calculado pela Eq. (2.21), entretanto, as formas de $F(a / W)$ serão diferentes.

Irwin (38) propôs o conceito de Taxa de Alívio de Energia Potencial, G, um parâmetro mais conveniente para a análise de engenharia, que representa o montante de energia necessário para a trinca crescer, sendo absorvida por ela para provocar tal propagação:

$$
G=-\frac{d \Pi}{d A}
$$

Embora o parâmetro acima seja referenciado como "taxa", é importante salientar que a derivada não diz respeito a uma mudança no tempo; $d \Pi$ varia com relação à área da trinca. Para uma placa infinita de espessura definida, o parâmetro $G$ pode ser reescrito na forma:

$$
G=-\frac{\pi \sigma^{2} a}{E}
$$

Os fatores de intensidade de tensão podem ser relacionados com a taxa de alívio de energia potencial (38). Assim, usando a Eq. (2.23) e os conceitos dispostos acima, escreve-se, para um material sob regime linear elástico:

$$
\begin{gathered}
G_{I}=\frac{K_{I}^{2}}{E^{\prime}}, \\
G_{I I}=\frac{K_{I I}^{2}}{E^{\prime}},
\end{gathered}
$$




$$
G_{I I I}=\frac{K_{I I I}^{2}}{2 \mu}
$$

onde $E^{\prime}=E$ para tensão plana e $E^{\prime}=E /\left(1-v^{2}\right)$ para deformação plana.

Para o caso geral, temos:

$$
G=\frac{K^{2}}{E^{\prime}}+\frac{K^{2}{ }_{I I}}{E^{\prime}}+\frac{K^{2}{ }_{I I I}}{2 \mu}
$$

Neste trabalho, as soluções dos problemas de placas trincadas terão a Eq. (2.21), juntamente às formas empíricas da função $F(a / W)$, como parâmetro de comparação para o fator de intensidade de tensão $K_{I}$ calculado numericamente por meio do MECD adaptativo, com vistas à validação do algoritmo de refinamento adaptativo desenvolvido nesta pesquisa.

\subsubsection{A Integral $J$}

Em 1961, Wells (40) estudou a propagação instável de trincas em metais. Ao testar tipos diferentes de aços estruturais a fim de medir o fator de intensidade de tensão em modo I, foi revelado que certos materiais se comportavam de forma a divergir da formulação original da Mecânica da Fratura Linear Elástica. A descoberta mostrou que a elevada dureza do material, embora fosse extremamente desejável em termos de projeto mecânico, implicava em um desajuste junto à teoria vigente. Duas formulações foram propostas para contemplar não somente os materiais de comportamento linear elástico como também os elastoplásticos: o Deslocamento de Abertura da Ponta da Trinca e a Integral J (34).

A aplicação de uma integral independente do caminho a um problema de mecânica da fratura foi obtida através do teorema da conservação da energia por Rice (41). A formulação é conhecida como Integral J.

A Integral $J$ é definida em relação a um sistema de coordenadas na ponta da trinca, como ilustrado na Figura (2.4), sendo descrita pela seguinte equação (para o caso bidimensional):

$$
J=\int_{\Gamma}\left(W n-t_{j} \frac{\partial u_{j}}{\partial x_{1}}\right) d s
$$


onde $W$ denota a densidade de energia de deformação, definida pela expressão

$$
W=\int^{\varepsilon_{k l}} \sigma_{i j} d \varepsilon_{i j}
$$

$t_{j}$ representa as forças de superfície, $n$ o vetor normal e $\Gamma$ um caminho arbitrário circundando a ponta da trinca, que deve ser percorrido no sentido anti-horário durante o processo de integração.

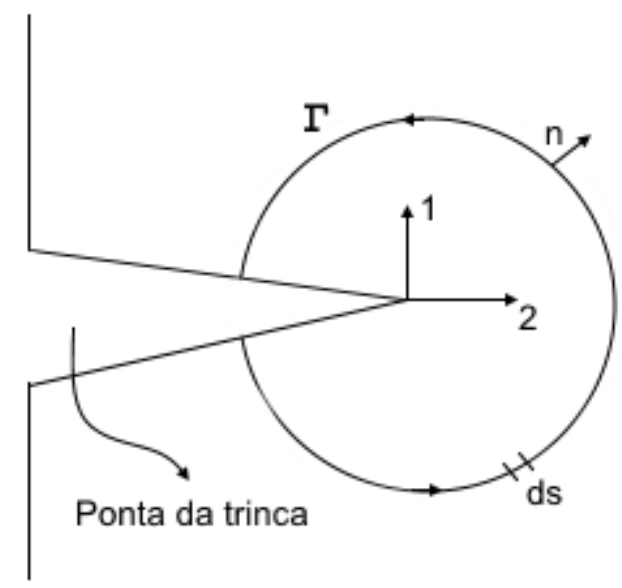

Figura 2.3 Representação da Integral J

Considerando que a Integral $\mathcal{J}$ denota a taxa de liberação de energia do material, para uma trinca em modo de abertura, utilizando a Eq. (2.24), é possível escrever:

$$
J=\frac{K_{I}^{2}}{E^{\prime}}
$$

Neste trabalho, o fator de intensidade de tensão $K_{I}$ será calculado pela técnica da Integral J. O algoritmo usado para calcular a Integral $J$ é baseado na equação:

$$
J=r \int_{-\pi}^{\pi}\left[W(r, \theta) \cos (\theta)-T_{K}(r, \theta) \frac{\partial u_{k}(r, \theta)}{\partial x}\right] .
$$

Inicialmente, devemos definir a trajetória de integração. Como a Integral $J$ independe do caminho, a implementação do cálculo da integral contemplou uma circunferência centrada no nó mais próximo à ponta da trinca, e raio $r$ conforme ilustrado na Fig. 2.5. A escolha da magnitude do raio possui a única restrição de não 
exceder os limites da placa. Desta forma, definiu-se arbitrariamente seu valor como a distância do primeiro ao quinto nó.

A Integral J é resolvida numericamente através das Fórmulas de Newton-Cotes, cuja ideia expressa um polinômio que aproxime a função desejada ao interpolar essa função em pontos igualmente espaçados. No algoritmo, foi escolhido utilizar a Regra 1/3 de Simpson Repetida, que faz uso da fórmula de Lagrange para interpolar a função com um polinômio quadrático (42).

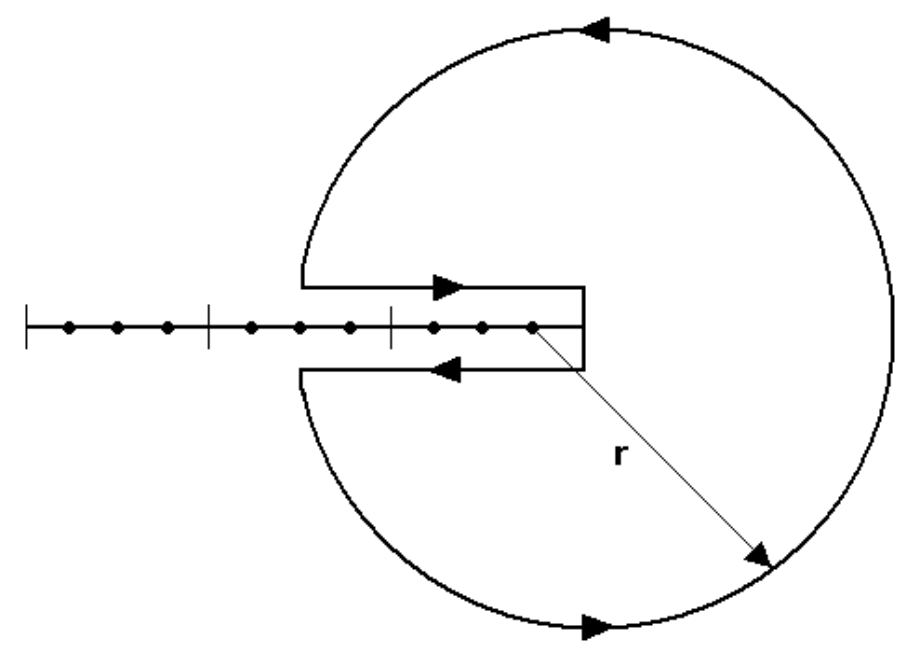

Figura 2.4 Distância do raio adotado para o cálculo da Integral $J$

Inicialmente, foi definido arbitrariamente o número de pontos para a interpolação igual a 31. Assim, a distância angular entre eles pode ser calculada através da expressão a seguir:

$$
d_{\text {pontos }}=\frac{2 \pi}{\text { número de pontos }} \text {. }
$$

Em seguida, converteu-se o sistema de coordenadas cilíndricas dos pontos no espaço para o sistema cartesiano através das expressões:

$$
\begin{aligned}
& X_{\text {ponto }}=X_{1}+r \cos (D), \\
& Y_{\text {ponto }}=Y_{1}+r \operatorname{sen}(D) .
\end{aligned}
$$

Nas Equações (2.33) e (2.34), $X_{1}$ e $Y_{1}$ denotam as coordenadas do nó correspondente à ponta da trinca e $D$ é a distância entre os pontos.

A densidade da energia de deformação $W$ é calculada da seguinte forma: 


$$
W_{i}=\sigma_{i j} \varepsilon_{i j}=\sigma_{i j} \frac{1}{2}\left(u_{i, j}+u_{j, 1}\right)=\sigma_{11} \frac{d u_{1}}{d x}-\sigma_{12} \frac{d u_{1}}{d y}+\sigma_{12} \frac{d u_{2}}{d x}+\sigma_{22} \frac{d u_{2}}{d y}
$$

O produto das forças de superfície pelo diferencial do deslocamento é calculado pela expressão:

$$
T_{k} \frac{d u_{k}}{d x}=\left(\sigma_{11} \frac{d u_{1}}{d x}+\sigma_{12} \frac{d u_{2}}{d x}\right) \cos \theta+\left(\sigma_{11} \frac{d u_{1}}{d x}+\sigma_{12} \frac{d u_{2}}{d x}\right) \operatorname{sen} \theta .
$$

Finalmente, substituindo as Equações (2.35) e (2.36) em (2.31) e discretizando essa última para ser integrada numericamente - onde os pontos de integração são dados pelas Equações (2.33) e (2.34) - temos:

$$
\begin{gathered}
J(i)=-\frac{1}{2} r\left(\sigma_{11} \frac{d u_{1}}{d x}-\sigma_{12} \frac{d u_{1}}{d y}+\sigma_{12} \frac{d u_{2}}{d x}+\sigma_{22} \frac{d u_{2}}{d y}\right) \cos \theta- \\
-r\left(\sigma_{11} \frac{d u_{1}}{d x}+\sigma_{12} \frac{d u_{2}}{d x}\right) \operatorname{sen} \theta .
\end{gathered}
$$

O valor numérico da Integral $J$ segundo a Regra 1/3 de Simpson Repetida é dada pela expressão:

$$
J=\frac{h}{3}\left[\left(J_{1}+J_{n}\right)+4\left(J_{1}+J_{2}+\ldots+J_{n-1}\right)+2\left(J_{2}+J_{4}+\ldots+J_{n-2}\right)\right],
$$

onde $n$ denota o número de pontos da integral e $h$ é a distância entre esses pontos. 


\section{O MÉTODO DOS ELEMENTOS DE CONTORNO E SUA FORMULAÇÃO DUAL}

\subsection{INTRODUÇÃO}

O Método dos Elementos de Contorno (MEC) tem por base a ideia de transformar as equações diferenciais governantes de determinado problema em equações integrais equivalentes que representam o comportamento físico do corpo em análise. A solução desse conjunto de equações integrais pode ser de forma analítica ou numérica, sendo este último o método mais comum de solução.

As equações integrais, a serem deduzidas ao longo deste capítulo, têm por característica principal a dependência apenas do contorno do corpo, o que reduz em uma unidade a dimensão do problema; significa dizer que para o caso de um problema em duas dimensões, o objeto deverá ser discretizado em elementos de contorno de apenas uma dimensão. A formulação do método depende das chamadas soluções fundamentais, que funcionam como funções de ponderação na integração. As condições de contorno são consideradas no processo de solução, e nenhuma consideração é feita no domínio do problema, apenas no contorno.

Para a solução dos problemas expostos no Capítulo 5, serão considerados tanto a formulação tradicional do MEC para problemas elásticos em duas dimensões, ou seja, a discretização da equação integral de contorno de deslocamento, deduzida a seguir, bem como a formulação dual do MEC, que utiliza ambas as equações integrais de contorno aplicadas simultaneamente em pontos fonte distintos. Todo o equacionamento que dá origem às equações integrais de contorno, bem como sua forma discretizada (MEC), está exposto a seguir.

\subsection{CONSIDERAÇÕES INICIAIS}

No intuito de definirmos o tipo de problema a ser resolvido com o equacionamento proposto a seguir, consideremos $\Omega$ como o domínio de um corpo homogêneo e $\Gamma$ como 
sendo o contorno deste domínio, sendo, ainda, subdivido em $\Gamma_{u}$ e $\Gamma_{t}$. A teoria da elasticidade, conforme demonstrado no capítulo anterior, busca determinar a distribuição das tensões $\sigma_{i j}$, deformações $\varepsilon_{i j}$ e deslocamentos $u_{i}$ ao longo do corpo, considerando restrições de deslocamento $\bar{u}_{i}$ aplicados a $\Gamma_{u}$, um sistema de carregamento externo $\bar{t}_{i}$ em $\Gamma_{t}$ e forças de corpo $b_{i}$ aplicadas ao domínio $\Omega$ do objeto.

\subsection{HIPÓTESE FUNDAMENTAL}

A teoria da elasticidade é baseada na hipótese fundamental de que, considerando qualquer ponto do corpo em análise, os tensores de tensão e deformação satisfazem a relação definida pela lei física dependente, unicamente, das propriedades do material. Para materiais isotrópicos sob regime linear elástico, estas relações constitutivas são regidas pela Lei de Hooke, expressa por meio das Equações (2.13) e (2.14).

\subsection{CAMPOS ELÁSTICOS}

Um campo elástico pode ser definido como sendo um conjunto de campos de tensões $\sigma_{i j}$, deformações $\varepsilon_{i j}$ ou deslocamentos $u_{i}$, identificados no corpo analisado. Os campos elásticos são classificados de acordo com a geometria e propriedades estáticas do corpo a qual está associado, podendo ser, segundo Portela (30), o que se segue.

\subsubsection{Campos Compatíveis}

No que concerne às restrições de deslocamento $\bar{u}_{i}$, aplicados a $\Gamma_{u}$, um campo elástico é denominado compatível se o tensor de deformações $\varepsilon_{i j}$ e vetor de deslocamento $u_{i}$ satisfizerem as equações a seguir.

$$
\varepsilon_{i j}=\frac{1}{2}\left(u_{i, j}+u_{j, i}\right) \quad \quad \text { em } \Omega,
$$


considerando, ainda, que o vetor de deslocamentos satisfaça a seguinte condição de contorno:

$$
u_{i}=\bar{u}_{i} \quad \text { em } \Gamma_{u} .
$$

Teoricamente, para cada vetor de deslocamentos, ou seja, um vetor que satisfaça a Eq. (3.2), existirá um problema enunciado de acordo com a Eq. (3.1). Destarte, para cada vetor de deslocamento cinematicamente admissível, existirá um único campo elástico compatível, o qual a ele será associado. A situação inversa, a qual um vetor de deslocamento cinematicamente admissível é gerado a partir de um tensor de deformações arbitrário, pode não observar nenhuma solução.

\subsubsection{Campos em Equilíbrio}

No que concerne o sistema de forças externas distribuídas em $\Omega$ e $\Gamma_{t}$ através das quantidades $b_{i}$ e $\bar{t}_{i}$, respectivamente, um campo elástico é dito em equilíbrio quando o tensor das tensões $\sigma_{i j}$ satisfaz as seguintes equações de equilíbrio:

$$
\sigma_{i j, i}+b_{j}=0 \quad \operatorname{em} \Omega
$$

para as seguintes condições de contorno,

$$
t_{j}=\sigma_{i j} n_{i}=\bar{t}_{j} \quad \quad \text { em } \Gamma_{t} .
$$

O problema introduzido segundo a Eq. (3.3) é matematicamente definido como estaticamente indeterminado, uma vez que, para cada sistema de forças externas, existirá um número infinito de campos elásticos em equilíbrio que o satisfaz.

\subsubsection{Campos Exatos}

No que concerne às restrições de deslocamento, $\bar{u}_{i}$ aplicado a $\Gamma_{u}$, e o sistema de forças externas distribuídas em $\Omega$ e $\Gamma_{t}$ através das quantidades $b_{i}$ e $\bar{t}_{i}$, respectivamente, um campo elástico é dito exato para o caso em que ele se encaixa, simultaneamente, nas definições apresentadas em 3.4.1 e 3.4.2, ou seja, quando são aplicadas as equações de equilíbrio definidas na Eq. (3.3) e as relações de compatibilidade expressas na Eq. (3.1), sobre um mesmo corpo em análise. Isso significa que um campo exato satisfaz as relações constitutivas expressas pelas 
Equações (2.13) e (2.14), as equações de deformação-deslocamento (3.1) e (3.2) e as equações de equilíbrio (3.3) e (3.4).

Assim, um campo exato é a solução de um problema elástico bem posto, ou seja, um problema cuja solução existe, é única e depende continuamente das condições iniciais e de contorno.

\subsection{O TEOREMA DO TRABALHO}

Seja $\Omega$ o domínio de um corpo homogêneo e $\Gamma$ o contorno deste domínio, subdivido em $\Gamma_{u}$ e $\Gamma_{t}$, considere um tensor de tensões $\sigma_{i j}^{*}$ em equilíbrio com o sistema de forças externas representado através das quantidades $\bar{t}_{i}^{*}$ e $\bar{b}_{i}^{*}$, distribuídas em $\Gamma_{t}$. e $\Omega$, respectivamente. Considere, ainda, as condições definidas pelas Equações (3.3) e (3.4). Desta forma, enuncia-se:

$$
\int_{\Omega}\left(\sigma_{i j, i}^{*}+\bar{b}_{i}^{*}\right) W_{\Omega j} d \Omega+\int_{\Gamma}\left(\sigma_{i j}^{*} n_{i}-\bar{t}_{i}^{*}\right) W_{\Gamma j} d \Gamma=0
$$

onde $W_{\Omega j}$ e $W_{\Gamma j}$ são funções arbitrárias definidas em $\Omega$ e $\Gamma_{t}$, respectivamente. Integrando a Eq. (3.5) por partes, temos:

$$
\int_{\Omega} b_{j}^{*} W_{\Omega j} d \Omega-\int_{\Omega} \sigma_{i j}^{*} W_{\Omega j, i} d \Omega+\int_{\Gamma} \sigma_{i j}^{*} n_{i} W_{\Omega j} d \Gamma+\int_{\Gamma_{t}}\left(\sigma_{i j}^{*} n_{i}-\bar{t}_{j}\right) W_{\Gamma j} d \Gamma=0 .
$$

Considere agora outro corpo com o mesmo domínio $\Omega$ e contorno $\Gamma$, subdividido em $\Gamma_{u}$ e $\Gamma_{t}$. Neste corpo, aplica-se um tensor de deformações $\varepsilon_{i j}$, compatível, segundo o definido em 3.4.1, com deslocamentos restritos $\bar{u}_{i}$ em $\Gamma_{u}$. Considere, ainda, as condições definidas pelas Equações (3.1) e (3.2). Considerando a natureza arbitrária das funções $W_{\Omega j}$ e $W_{\Gamma j}$, introduzidas pela Eq. (3.5), define-se:

$$
W_{\Omega j}=u_{j}
$$

e

$$
W_{\Gamma j}=-u_{j},
$$


e, assim, a Eq. (3.6) pode ser reescrita da seguinte forma:

$$
\int_{\Omega} b_{j}^{*} u_{j} d \Omega-\int_{\Omega} \sigma_{i j}^{*} u_{j, i} d \Omega+\int_{\Gamma_{t}} \bar{t}_{j}^{*} u_{j} d \Gamma+\int_{\Gamma_{u}} t_{j}^{*} \bar{u}_{j} d \Gamma=0 .
$$

Pela notação soma, os índices repetidos $i$ e $j$ permitem estabelecer a seguinte relação:

$$
\sigma_{i j}^{*} u_{j, i}=\sigma_{j i}^{*} u_{i, j}
$$

Considerando a simetria do tensor de tensões, a Eq. (3.10) permite:

$$
\sigma_{i j}^{*} u_{j, i}=\frac{1}{2}\left(\sigma_{i j}^{*}+\sigma_{j i}^{*}\right) u_{i, j}=\frac{1}{2} \sigma_{i j}^{*} u_{i, j}+\frac{1}{2} \sigma_{i j}^{*} u_{j, i}=\sigma_{i j}^{*} \varepsilon_{i j} .
$$

Finalmente, a Eq. (3.9) pode ser reescrita da seguinte forma:

$$
\int_{\Omega} b_{j}^{*} u_{j} d \Omega+\int_{\Gamma} t_{j}^{*} u_{j} d \Gamma=\int_{\Omega} \sigma_{i j}^{*} \varepsilon_{i j} d \Omega
$$

A Eq. (3.12) representa o teorema do trabalho. O lado esquerdo da expressão representa o trabalho das forças externas, enquanto o lado direito representa 0 trabalho relacionado às forças internas aplicadas ao corpo em análise. Segundo Portela (30), alguns conceitos e implicações importantes decorrem desse teorema:

- O teorema do trabalho foi obtido considerando dois corpos diferentes com o mesmo domínio $\Omega$ e contorno $\Gamma$. Isso significa dizer que este teorema não depende de nenhum corpo em específico - caracterizado por um conjunto determinado de relações constitutivas, mas de apenas um domínio $\Omega$ e seu contorno $\Gamma$ definidos;

- Os tensores de tensões $\sigma_{i j}^{*}$ e deformações $\varepsilon_{i j}$ são independentes, ou seja, tais campos não se relacionam de acordo com as relações constitutivas postuladas pelas Equações (2.13) e (2.14).

- O teorema do trabalho foi obtido mediante dois conjuntos diferentes de equações: equação de equilíbrio e a relação de deformação-deslocamento. Analogamente, é possível obter qualquer uma dessas três relações a partir das outras duas. 
Segundo Brebbia (43), o teorema do trabalho é a base das formulações presentes no método das diferenças finitas (MDF), método dos elementos finitos (MEF) e método dos elementos de contorno (MEC).

\subsection{SOLUÇÕES FUNDAMENTAIS}

A obtenção das soluções fundamentais provém da conceituação de um campo elástico fundamental. Esse tipo de campo é definido como um campo exato delimitado por um domínio infinito $\Omega_{\infty}$ com contorno infinito $\Gamma_{\infty}$, no qual o sistema de forças externas é expresso como um carregamento pontual aplicado em um ponto fonte $\mathbf{x}^{\prime} \in \Omega_{\infty}$. Esse carregamento pontual é matematicamente definido como:

$$
b_{i}=\delta\left(\mathbf{x}^{\prime}, \mathbf{x}\right) e_{i}
$$

onde $\delta\left(\mathbf{x}^{\prime}, \mathbf{x}\right)$ representa o delta de Dirac, $\mathbf{x}$ denota o ponto campo, e $e_{i}$ representa vetor unitário do sistema ortogonal de referência.

As funções de deslocamentos e forças de superfície do campo elástico fundamental de Kelvin são estabelecidas através das seguintes equações:

$$
u_{j}=U_{i j}\left(\mathbf{x}^{\prime}, \mathbf{x}\right) e_{i}
$$

e

$$
t_{j}=T_{i j}\left(\mathbf{x}^{\prime}, \mathbf{x}\right) e_{i}
$$

onde $U_{i j}\left(\mathbf{x}^{\prime}, \mathbf{x}\right)$ e $T_{i j}\left(\mathbf{x}^{\prime}, \mathbf{x}\right)$ representam os deslocamentos e forças de superfície na direção $j$, em um ponto campo $\mathbf{x}$, correspondente a um carregamento unitário aplicado no ponto fonte $\mathbf{x}^{\prime}$ e atuando na direção $e_{i}$. Para um problema em estado plano de deformação, as soluções fundamentais de Kelvin $U_{i j}\left(\mathbf{x}^{\prime}, \mathbf{x}\right)$ e $T_{i j}\left(\mathbf{x}^{\prime}, \mathbf{x}\right)$ foram demonstradas por Cruze (17):

$$
U_{i j}\left(\mathbf{x}^{\prime}, \mathbf{x}\right)=-\frac{1+v}{4 \pi(1-v) E}\left[(3-4 v) \ln (r) \delta_{i j}-r_{, i} r_{, j}\right]
$$


$T_{i j}\left(\mathbf{x}^{\prime}, \mathbf{x}\right)=-\frac{1}{4 \pi(1-v) r}\left\{\left[(1-2 v) \delta_{i j}+2 r_{, i} r_{, j}\right] r_{, k} n_{, k}-(1-2 v)\left(r_{, i} n_{j}-r_{, j} n_{i}\right)\right\}$,

onde $\delta_{i j}$ é o delta de Kronecker, $r\left(\mathbf{x}^{\prime}, \mathbf{x}\right)$ representa a distância entre o ponto fonte $\mathbf{x}^{\prime}$, e o ponto campo $\mathbf{x}$, definido através da expressão:

$$
r\left(\mathbf{x}^{\prime}, \mathbf{x}\right)=\sqrt{r_{i} r_{i}}
$$

onde,

$$
r_{i}=x_{i}(\mathbf{x})-x_{i}\left(\mathbf{x}^{\prime}\right)
$$

e

$$
\left.r_{i}\right|_{\mathbf{x}}=\frac{r_{i}}{r}
$$

Qualquer domínio $\Omega$ arbitrário sempre estará contido em $\Omega_{\infty}$; assim, considere que esses domínios definem corpos com as mesmas propriedades elásticas. Considere, ainda, uma carga pontual aplicada em um ponto interno aleatório de $\Omega$. As soluções fundamentais de Kelvin, que são exatas em $\Omega_{\infty}$, ainda satisfazem as relações de equilíbrio para o carregamento unitário aplicado a $\Omega$. Entretanto, esses campos não são compatíveis com as restrições de deslocamento aplicadas ao contorno $\Gamma$ de $\Omega$. Tal característica será usada pelo teorema do trabalho no desenvolvimento das equações integrais de contorno.

Pelas Equações (3.16) e (3.17), é possível notar que tanto a solução fundamental de deslocamentos quanto a de forças de superfície são singulares quando o ponto fonte tende ao ponto campo. No caso da solução fundamental de deslocamentos, a singularidade é dita fraca $(\ln (r))$. Já no caso da solução fundamental de forças de superfície, temos uma singularidade forte $(1 / r)$. As formas como essas singularidades serão tratadas serão evidenciadas a seguir. 


\subsection{EQUAÇÕES INTEGRAIS DE CONTORNO}

A dedução das equações integrais de contorno considera as condições definidas anteriormente, quais sejam a descrição de um campo elástico exato em um corpo definido por um domínio $\Omega$ e um contorno $\Gamma$, subdividido em $\Gamma_{u}$ e $\Gamma_{t}$, juntamente com as restrições de deslocamento $\bar{u}_{i}$ definidas em $\Gamma_{u}$ e sob a ação de um sistema de forças externas $\bar{t}_{i}$ e $b_{i}$, distribuídas em $\Gamma_{t}$ e $\Omega$, respectivamente. A formulação elástica das equações integrais de contorno pode ser obtida através da aplicação do teorema do trabalho para o caso em que o comportamento mecânico do material constituinte do corpo em análise é descrido pela lei de Hooke.

\subsubsection{Equação de Deslocamento (EICC)}

As equações integrais de contorno são deduzidas através do teorema do trabalho, enunciado pela Eq. (3.12), e das soluções fundamentais expressas pelas Equações (3.16) e (3.17). Inicialmente, consideremos um campo elástico exato aplicado ao corpo em análise, conforme definições postuladas em 3.4.3; ou seja, um campo elástico que satisfaça as equações de equilíbrio para o sistema de forças externas expresso pelas quantidades $\bar{t}_{i}$ e $b_{i}$, aplicados a $\Gamma_{t}$ e $\Omega$, respectivamente; e as equações de compatibilidade para as restrições de deslocamento $\bar{u}_{i}$ definidas em $\Gamma_{u}$. Esse campo, cujas definições são desconhecidas, é representado por $u_{j}, \varepsilon_{i j}$ e $\sigma_{i j}$.

No que concerne às soluções fundamentais, consideremos um campo elástico de Kelvin com as mesmas propriedades elásticas do corpo sob investigação, no qual a carga unitária é aplicada sobre um ponto fonte $\mathbf{x}^{\prime} \in \Omega$. No domínio $\Omega$, esse campo elástico se equilibra com a carga pontual, mas não satisfaz as equações de compatibilidade para as restrições de deslocamento $\bar{u}_{i}$ definidas em $\Gamma_{u}$. Esse campo, conhecido a priori, é representado por $u_{j}^{*}, \varepsilon_{i j}^{*}$ e $\sigma_{i j}^{*}$.

Conforme fora definido anteriormente, o teorema do trabalho expressa a relação entre dois campos elásticos, sendo que um desses campos é utilizado para satisfazer as equações de equilíbrio, enquanto o outro é utilizado para satisfazer as equações de compatibilidade, em um corpo definido por um domínio $\Omega$ e contorno $\Gamma$. 
Isto posto, consideremos aplicar ao teorema do trabalho a relação de equilíbrio entre o tensor das tensões $\sigma_{i j}^{*}$ e a carga unitária $b_{j}^{*}$, juntamente com a relação de compatibilidade entre o tensor de deformações $\varepsilon_{i j}$ e as restrições de deslocamento $\bar{u}_{j}$ em $\Gamma_{t}$. Assim, teremos:

$$
\int_{\Omega} \sigma_{i j}^{*} \varepsilon_{i j} d \Omega=\int_{\Omega} b_{j}^{*} u_{j} d \Omega+\int_{\Gamma_{t}} t_{j}^{*} u_{j} d \Gamma+\int_{\Gamma_{u}} t_{j}^{*} \bar{u}_{j} d \Gamma .
$$

Analogamente, quando o equilíbrio entre tensor das tensões $\sigma_{i j}$ e o sistema de forças externas, expresso pelas quantidades $\bar{t}_{j} \mathrm{e} b_{j}$, distribuídos em $\Gamma_{t} \mathrm{e} \Omega$, respectivamente, e a relação de compatibilidade entre o tensor das deformações $\varepsilon_{i j}^{*} \mathrm{e}$ os deslocamentos $u_{j}^{*}$ são aplicados ao teorema do trabalho, temos a seguinte expressão:

$$
\int_{\Omega} \sigma_{i j} \varepsilon_{i j}^{*} d \Omega=\int_{\Omega} b_{j} u_{j}^{*} d \Omega+\int_{\Gamma_{t}} \bar{t}_{j} u_{j}^{*} d \Gamma+\int_{\Gamma_{u}} t_{j} u_{j}^{*} d \Gamma
$$

O teorema de Maxwell-Betti define:

$$
\int_{\Omega} \sigma_{i j}^{*} \varepsilon_{i j} d \Omega=\int_{\Omega} \sigma_{i j} \varepsilon_{i j}^{*} d \Omega
$$

Esse teorema permite igualar as Equações (3.21) e (3.22) para obter uma única expressão, conhecida como a forma externa do teorema de Maxwell-Betti:

$$
\int_{\Omega} b_{j}^{*} u_{j} d \Omega+\int_{\Gamma} t_{j}^{*} u_{j} d \Gamma=\int_{\Omega} b_{j} u_{j}^{*} d \Omega+\int_{\Gamma} t_{j} u_{j}^{*} d \Gamma
$$

Quando as Equações (3.13), (3.14) e (3.15) são aplicadas à Eq. (3.24), após algumas operações matemáticas permitidas pelas propriedades do delta de Dirac, obtemos a expressão conhecida como identidade de Somigliana:

$$
\begin{aligned}
u_{i}\left(\mathbf{x}^{\prime}\right) & +\int_{\Gamma} T_{i j}\left(\mathbf{x}^{\prime}, \mathbf{x}\right) u_{j}(\mathbf{x}) d \Gamma(\mathbf{x})=\int_{\Gamma} U_{i j}\left(\mathbf{x}^{\prime}, \mathbf{x}\right) t_{j}(\mathbf{x}) d \Gamma(\mathbf{x})+ \\
& +\int_{\Omega} U_{i j}\left(\mathbf{x}^{\prime}, \mathbf{x}\right) b_{j}(\mathbf{x}) d \Omega(\mathbf{x}) .
\end{aligned}
$$

Conforme exposto em Betti (44), o teorema de Maxwell-Betti apresentado na Eq. (3.23) é válido para qualquer par de campos elásticos regidos pela lei de Hooke, 
o que significa dizer que nem as relações de compatibilidade, nem as de equilíbrio são exigidas para quaisquer um dos dois campos. Depreende-se, portanto, que essas relações não foram introduzidas, pois, neste estágio da formulação.

A forma externa do teorema de Maxwell-Betti, apresentado na Eq. (3.24), obtida pela aplicação da forma interna deste teorema - Eq. (3.23) ao teorema do trabalho Eq. (3.12), requer apenas que um dos campos elásticos sob análise satisfaça as relações de equilíbrio junto ao seu próprio sistema de forças externas (44), o que significa dizer que as relações de compatibilidade do campo elástico exato também não são introduzidas neste estágio da formulação.

Consideremos, finalmente, para fins de simplicidade do modelo matemático, que as forças de corpo $b_{j}$, aplicadas ao domínio $\Omega$, são nulas. Assim, a Eq. (3.25) pode ser reescrita da seguinte forma:

$$
u_{i}\left(\mathbf{x}^{\prime}\right)+\int_{\Gamma} T_{i j}\left(\mathbf{x}^{\prime}, \mathbf{x}\right) u_{j}(\mathbf{x}) d \Gamma(\mathbf{x})=\int_{\Gamma} U_{i j}\left(\mathbf{x}^{\prime}, \mathbf{x}\right) t_{j}(\mathbf{x}) d \Gamma(\mathbf{x})
$$

A Eq. (3.26) representa a identidade de Somigliana para deslocamentos (ISD). A equação integral de contorno para o deslocamento é deduzida quando o ponto fonte, até então definido no interior do domínio $\Omega$, é trazido para o contorno. Para tal, devemos considerar o caso em que $r \rightarrow 0$, sendo $r$ a distância entre o ponto fonte e o ponto campo, definido pelas Equações (3.18) e (3.19). Conforme demonstrado em Cruze (17), tal operação é realizada ao transpormos o ponto fonte para o contorno, aumentando, adicionalmente, o domínio do problema por intermédio de uma região semicircular com contorno $\Gamma_{\epsilon}^{*}$ e raio $\epsilon$, centrada no ponto fonte, como mostrado na Fig. 3.1. Nessa nova configuração, o contorno é dividido em duas partes, quais sejam: $\Gamma=$ $\left(\Gamma-\Gamma_{\epsilon}\right)+\Gamma_{\epsilon}^{*}$. A Eq. (3.26) é reescrita da seguinte forma:

$$
u_{i}\left(\mathbf{x}^{\prime}\right)+\lim _{\epsilon \rightarrow 0} \int_{\Gamma-\Gamma_{\epsilon}+\Gamma_{\epsilon}^{*}} T_{i j}\left(\mathbf{x}^{\prime}, \mathbf{x}\right) u_{j}(\mathbf{x}) d \Gamma(\mathbf{x})=\lim _{\epsilon \rightarrow 0} \int_{\Gamma-\Gamma_{\epsilon}+\Gamma_{\epsilon}^{*}} U_{i j}\left(\mathbf{x}^{\prime}, \mathbf{x}\right) t_{j}(\mathbf{x}) d \Gamma(\mathbf{x})
$$




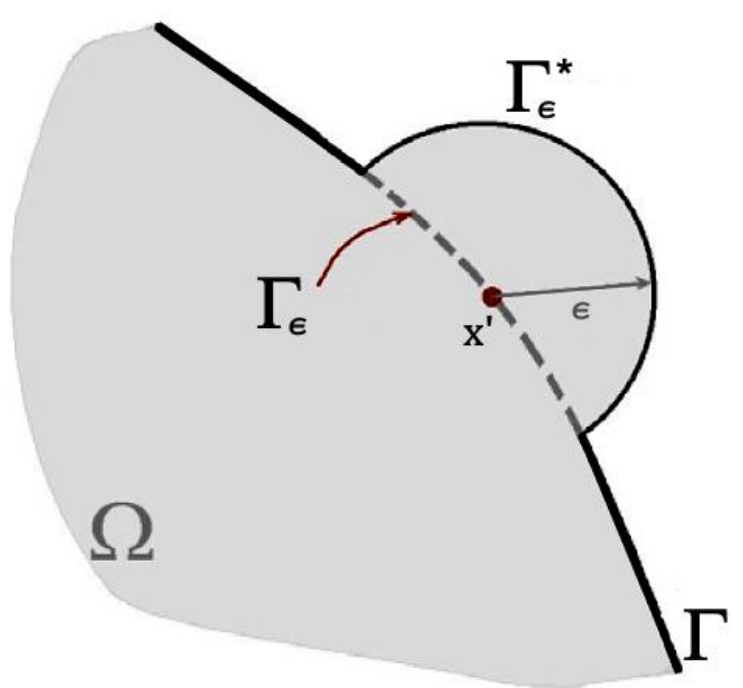

Figura 3.1 Ponto fonte localizado no contorno, circundado por uma região semicircular

A integral do lado direito da Eq. (3.27) contém um integrando de singularidade fraca da ordem $\ln (1 / r)$ e é integrável como uma integral imprópria. A integral do lado esquerdo tem uma singularidade forte, de ordem $1 / r$, que pode ser regularizada com o primeiro termo da expansão de Taylor em torno do ponto fonte, ou seja:

$$
\begin{aligned}
\lim _{\epsilon \rightarrow 0} \int_{\Gamma-\Gamma_{\epsilon}+\Gamma_{\epsilon}^{*}} T_{i j}\left(\mathbf{x}^{\prime}, \mathbf{x}\right) u_{j}(\mathbf{x}) d \Gamma(\mathbf{x})= & \lim _{\epsilon \rightarrow 0} \int_{\Gamma_{\epsilon}^{*}} T_{i j}\left(\mathbf{x}^{\prime}, \mathbf{x}\right)\left[u_{j}(\mathbf{x})-u_{j}\left(\mathbf{x}^{\prime}\right)\right] d \Gamma(\mathbf{x})+ \\
& +u_{j}\left(\mathbf{x}^{\prime}\right) \lim _{\epsilon \rightarrow 0} \int_{\Gamma_{\epsilon}^{*}} T_{i j}\left(\mathbf{x}^{\prime}, \mathbf{x}\right) d \Gamma(\mathbf{x})+ \\
& +\lim _{\epsilon \rightarrow 0} \int_{\Gamma-\Gamma_{\epsilon}} T_{i j}\left(\mathbf{x}^{\prime}, \mathbf{x}\right) u_{j}(\mathbf{x}) d \Gamma(\mathbf{x}) .
\end{aligned}
$$

Assumindo que os deslocamentos são contínuos no ponto fonte, o primeiro termo do lado direito da Eq. (3.28) é integrável e desaparece no processo de limite. O segundo termo dessa expressão representa um salto nos deslocamentos, denotado por $A_{i j}\left(\mathbf{x}^{\prime}\right) u_{j}\left(\mathbf{x}^{\prime}\right)$, onde $A_{i j}\left(\mathbf{x}^{\prime}\right)$ é uma constante que depende da geometria local e das constantes elásticas. Finalmente, o terceiro termo do lado direito da equação resulta numa integral imprópria que é calculada no sentido do valor principal de Cauchy. Assim, quando $\epsilon \rightarrow 0$, o ponto fonte tende ao contorno e, no limite, a equação (3.27) pode ser escrita na forma:

$$
c_{i j}\left(\mathbf{x}^{\prime}\right) u_{j}\left(\mathbf{x}^{\prime}\right)+\int_{\Gamma} T_{i j}\left(\mathbf{x}^{\prime}, \mathbf{x}\right) u_{j}(\mathbf{x}) d \Gamma(\mathbf{x})=\int_{\Gamma} U_{i j}\left(\mathbf{x}^{\prime}, \mathbf{x}\right) t_{j}(\mathbf{x}) d \Gamma(\mathbf{x}),
$$


onde, $c_{i j}\left(\mathbf{x}^{\prime}\right)$ é definido segundo a relação $\delta_{i j}+A_{i j}\left(\mathbf{x}^{\prime}\right)$, onde $\delta_{i j}$ é o delta de Kronecker. Para contornos suaves, $c_{i j}\left(\mathbf{x}^{\prime}\right)=\delta_{i j} / 2$. A Eq. (3.29) é dita equação integral de contorno de deslocamento, ou, equação integral de contorno convencional (EICC).

\subsubsection{Equação de Forças de Superfície (EICH)}

É sabido que a identidade de Somigliana, introduzida pela Eq. (3.26), é derivável quando aplicada em um ponto fonte $\mathbf{x}^{\prime}$ pertencente ao domínio $\Omega$. Considerando que as soluções fundamentais $U_{i j}\left(\mathbf{x}^{\prime}, \mathbf{x}\right)$ e $T_{i j}\left(\mathbf{x}^{\prime}, \mathbf{x}\right)$ são funções que dependem unicamente da distância $r$ e suas derivativas, expressas pela Eq. (3.20), pode-se reescrever a ISD da forma:

$$
u_{i, k}\left(\mathbf{x}^{\prime}\right)-\int_{\Gamma} T_{i j, k}\left(\mathbf{x}^{\prime}, \mathbf{x}\right) u_{j}(\mathbf{x}) d \Gamma(\mathbf{x})=-\int_{\Gamma} U_{i j, k}\left(\mathbf{x}^{\prime}, \mathbf{x}\right) t_{j}(\mathbf{x}) d \Gamma(\mathbf{x})
$$

O tensor de tensões $\sigma_{i j}$ é obtido através da consideração das deformações correspondentes, obtidas através da Eq. (3.30), junto às relações constitutivas expressas pela Eq. (2.14). Assim, temos:

$$
\sigma_{i j}\left(\mathbf{x}^{\prime}\right)+\int_{\Gamma} S_{k i j}\left(\mathbf{x}^{\prime}, \mathbf{x}\right) u_{k}(\mathbf{x}) d \Gamma(\mathbf{x})=\int_{\Gamma} D_{k i j}\left(\mathbf{x}^{\prime}, \mathbf{x}\right) t_{k}(\mathbf{x}) d \Gamma(\mathbf{x})
$$

A Eq. (3.31) representa a identidade de Somigliana para tensões (IST), aplicada a um ponto fonte interno $\mathbf{x}^{\prime}$. Nessa equação, $S_{k i j}\left(\mathbf{x}^{\prime}, \mathbf{x}\right)$ e $D_{k i j}\left(\mathbf{x}^{\prime}, \mathbf{x}\right)$ contém as derivadas de $T_{i j}\left(\mathbf{x}^{\prime}, \mathbf{x}\right)$ e $U_{i j}\left(\mathbf{x}^{\prime}, \mathbf{x}\right)$, respectivamente. Para um problema em estado plano de deformação, as soluções fundamentais de Kelvin $S_{k i j}\left(\mathbf{x}^{\prime}, \mathbf{x}\right)$ e $D_{k i j}\left(\mathbf{x}^{\prime}, \mathbf{x}\right)$ são definidas abaixo (17):

$$
\begin{aligned}
& D_{k i j}\left(\mathbf{x}^{\prime}, \mathbf{x}\right)=\frac{1}{4 \pi(1-v) r}\left[(1-2 v)\left(\delta_{i j} r_{, k}+\delta_{j k} r_{, i}-\delta_{i k} r_{, j}\right)+2 r_{, i} r_{, j} r_{, k}\right] n_{k}(\mathbf{x}), \\
& S_{k i j}\left(\mathbf{x}^{\prime}, \mathbf{x}\right)=\frac{1}{2 \pi(1-v) r^{2}}\left\{2 r_{, l} n_{l}\left[(1-2 v) \delta_{i j} r_{, k}+v\left(\delta_{i k} r_{, j}+\delta_{j k} r_{, i}\right)-4 r_{, i} r_{, j} r_{, k}\right]+\right. \\
& \left.+2 v\left(n_{i} r_{, j} r_{, k}+n_{j} r_{, i} r_{, k}\right)+(1-2 v)\left(2 n_{k} r_{, i} r_{, j}+\delta_{i k} n_{j}+\delta_{j k} n_{i}\right)(1-4 v) \delta_{i j} n_{k}\right\} .
\end{aligned}
$$

Analogamente à operação realizada com a ISD, transpomos o ponto fonte para o contorno, aumentando, adicionalmente, o domínio do problema por intermédio de 
uma região semicircular com contorno $\Gamma_{\epsilon}^{*}$ e raio $\epsilon$, centrada no ponto fonte, como mostrado na Fig. 3.1. O contorno é dividido em duas partes: $\Gamma=\left(\Gamma-\Gamma_{\epsilon}\right)+\Gamma_{\epsilon}^{*}$. A Eq. (3.30) é reescrita da seguinte forma:

$$
\sigma_{i j}\left(\mathbf{x}^{\prime}\right)+\lim _{\epsilon \rightarrow 0} \int_{\Gamma-\Gamma_{\epsilon}+\Gamma_{\epsilon}^{*}} S_{k i j}\left(\mathbf{x}^{\prime}, \mathbf{x}\right) u_{k}(\mathbf{x}) d \Gamma(\mathbf{x})=\lim _{\epsilon \rightarrow 0} \int_{\Gamma-\Gamma_{\epsilon}+\Gamma_{\epsilon}^{*}} D_{k i j}\left(\mathbf{x}^{\prime}, \mathbf{x}\right) t_{k}(\mathbf{x}) d \Gamma(\mathbf{x})
$$

A integral do lado direito da Eq. (3.27) contém uma singularidade forte, de ordem $1 / r$, e pode ser regularizada com o primeiro termo da expansão de Taylor em torno do ponto fonte, ou seja:

$$
\begin{aligned}
\lim _{\epsilon \rightarrow 0} \int_{\Gamma-\Gamma_{\epsilon}+\Gamma_{\epsilon}^{*}} D_{k i j}\left(\mathbf{x}^{\prime}, \mathbf{x}\right) t_{k}(\mathbf{x}) d \Gamma(\mathbf{x})= & \lim _{\epsilon \rightarrow 0} \int_{\Gamma_{\epsilon}^{*}} D_{k i j}\left(\mathbf{x}^{\prime}, \mathbf{x}\right)\left[t_{k}(\mathbf{x})-t_{k}\left(\mathbf{x}^{\prime}\right)\right] d \Gamma(\mathbf{x})+ \\
& +u_{j}\left(\mathbf{x}^{\prime}\right) \lim _{\epsilon \rightarrow 0} \int_{\Gamma_{\epsilon}^{*}} D_{k i j}\left(\mathbf{x}^{\prime}, \mathbf{x}\right) d \Gamma(\mathbf{x})+ \\
& +\lim _{\epsilon \rightarrow 0} \int_{\Gamma-\Gamma_{\epsilon}} D_{k i j}\left(\mathbf{x}^{\prime}, \mathbf{x}\right) t_{k}(\mathbf{x}) d \Gamma(\mathbf{x})
\end{aligned}
$$

Assumindo que as forças de superfícies são contínuas no ponto fonte, o primeiro termo do lado direito da Eq. (3.35) é integrável e desaparece no processo de limite. O segundo termo dessa expressão representa um salto nas forças de superfície, denotado por $A_{k i j}\left(\mathbf{x}^{\prime}\right) t_{k}\left(\mathbf{x}^{\prime}\right)$, no qual $A_{k i j}\left(\mathbf{x}^{\prime}\right)$ é uma constante que depende da geometria local e das constantes elásticas. Finalmente, o terceiro termo do lado direito da equação resulta numa integral imprópria que é calculada no sentido do valor principal de Cauchy, representada por:

$$
\int_{\Gamma} D_{k i j}\left(\mathbf{x}^{\prime}, \mathbf{x}\right) t_{k}(\mathbf{x}) d \Gamma(\mathbf{x})=\lim _{\epsilon \rightarrow 0} \int_{\Gamma-\Gamma_{\epsilon}} D_{k i j}\left(\mathbf{x}^{\prime}, \mathbf{x}\right) t_{k}(\mathbf{x}) d \Gamma(\mathbf{x}) .
$$

A integral do lado direito da Eq. (3.36) contém um integrando hipersingular, de ordem $1 / r^{2}$, e pode ser regularizada com os dois primeiros termos da expansão de Taylor em torno do ponto fonte, ou seja:

$$
\begin{aligned}
& \lim _{\epsilon \rightarrow 0} \int_{\Gamma-\Gamma_{\epsilon}+\Gamma_{\epsilon}^{*}} S_{k i j}\left(\mathbf{x}^{\prime}, \mathbf{x}\right) u_{k}(\mathbf{x}) d \Gamma(\mathbf{x})= \\
& =\lim _{\epsilon \rightarrow 0} \int_{\Gamma_{\epsilon}^{*}} S_{k i j}\left(\mathbf{x}^{\prime}, \mathbf{x}\right)\left[u_{k}(\mathbf{x})-u_{k}\left(\mathbf{x}^{\prime}\right)-u_{k, m}\left(\mathbf{x}^{\prime}\right)\left(x_{m}-x_{m}^{\prime}\right)\right] d \Gamma(\mathbf{x})+
\end{aligned}
$$




$$
\begin{aligned}
& +u_{k}\left(\mathbf{x}^{\prime}\right) \lim _{\epsilon \rightarrow 0} \int_{\Gamma_{\epsilon}^{*}} S_{k i j}\left(\mathbf{x}^{\prime}, \mathbf{x}\right) d \Gamma(\mathbf{x})+ \\
& +u_{k, m}\left(\mathbf{x}^{\prime}\right) \lim _{\epsilon \rightarrow 0} \int_{\Gamma_{\epsilon}^{*}} S_{k i j}\left(\mathbf{x}^{\prime}, \mathbf{x}\right)\left(x_{m}-x_{m}^{\prime}\right) d \Gamma(\mathbf{x})+ \\
& +\lim _{\epsilon \rightarrow 0} \int_{\Gamma-\Gamma_{\epsilon}} S_{k i j}\left(\mathbf{x}^{\prime}, \mathbf{x}\right) u_{k}(\mathbf{x}) d \Gamma(\mathbf{x}) .
\end{aligned}
$$

Assumindo que as derivativas do deslocamento expressas na Eq. (3.37) são contínuas no ponto fonte, o primeiro termo do lado direito da Eq. (3.37) é integrável e desaparece no processo de limite. O segundo termo do lado direito dessa expressão é dado por:

$$
u_{k}\left(\mathbf{x}^{\prime}\right) \lim _{\epsilon \rightarrow 0} \int_{\Gamma_{\epsilon}^{*}} S_{k i j}\left(\mathbf{x}^{\prime}, \mathbf{x}\right) d \Gamma(\mathbf{x})=u_{k}\left(\mathbf{x}^{\prime}\right) \lim _{\epsilon \rightarrow 0} \frac{C_{k i j}\left(\mathbf{x}^{\prime}\right)}{\epsilon}
$$

onde $C_{k i j}$ é uma constante que depende da geometria local e das constantes elásticas. O terceiro termo do lado direito da mesma equação representa um salto das derivativas de deslocamento, denotado por $B_{k i j m}\left(\mathbf{x}^{\prime}\right) u_{k, m}\left(\mathbf{x}^{\prime}\right)$, no qual $B_{k i j m}$ é uma constante que depende das constantes elásticas e das coordenadas de transformação. Finalmente, o quarto termo do lado direito da equação resulta numa integral imprópria que é calculada no sentido do valor principal de Hadamard, representada por:

$$
\begin{aligned}
& \int_{\Gamma} S_{k i j}\left(\mathbf{x}^{\prime}, \mathbf{x}\right) u_{k}(\mathbf{x}) d \Gamma(\mathbf{x})= \\
& =\lim _{\epsilon \rightarrow 0}\left\{\int_{\Gamma-\Gamma_{\epsilon}} S_{k i j}\left(\mathbf{x}^{\prime}, \mathbf{x}\right) u_{k}(\mathbf{x}) d \Gamma(\mathbf{x})+u_{k}\left(\mathbf{x}^{\prime}\right) \int_{\Gamma_{\epsilon}^{*}} S_{k i j}\left(\mathbf{x}^{\prime}, \mathbf{x}\right) d \Gamma(\mathbf{x})\right\}= \\
& =\lim _{\epsilon \rightarrow 0}\left\{\int_{\Gamma-\Gamma_{\epsilon}} S_{k i j}\left(\mathbf{x}^{\prime}, \mathbf{x}\right) u_{k}(\mathbf{x}) d \Gamma(\mathbf{x})+u_{k}\left(\mathbf{x}^{\prime}\right) \frac{C_{k i j}\left(\mathbf{x}^{\prime}\right)}{\epsilon}\right\} .
\end{aligned}
$$

Quando o ponto fonte é aplicado a contornos suaves, as Equações (3.35) e (3.37) permitem demonstrar:

$$
A_{k i j}\left(\mathbf{x}^{\prime}\right) t_{k}\left(\mathbf{x}^{\prime}\right)-B_{k i j m} u_{k, m}\left(\mathbf{x}^{\prime}\right)=\frac{1}{2} \sigma_{i j}\left(\mathbf{x}^{\prime}\right)
$$


Assim, quando o ponto fonte é transportado para o contorno, ou seja, $\epsilon \rightarrow 0$, em um contorno suave, a Eq. (3.34) dá origem à equação integral de contorno de tensão:

$$
\frac{1}{2} \sigma_{i j}\left(\mathbf{x}^{\prime}\right)+\int_{\Gamma} S_{k i j}\left(\mathbf{x}^{\prime}, \mathbf{x}\right) u_{k}(\mathbf{x}) d \Gamma(\mathbf{x})=\int_{\Gamma} D_{k i j}\left(\mathbf{x}^{\prime}, \mathbf{x}\right) t_{k}(\mathbf{x}) d \Gamma(\mathbf{x})
$$

Finalmente, a equação integral de contorno de forças de superfície, ou, Equação Integral de Contorno Hipersingular $(\mathrm{EICH})$ é enunciada como:

$$
\frac{1}{2} t_{j}\left(\mathbf{x}^{\prime}\right)+n_{i}\left(\mathbf{x}^{\prime}\right) \int_{\Gamma} S_{k i j}\left(\mathbf{x}^{\prime}, \mathbf{x}\right) u_{k}(\mathbf{x}) d \Gamma(\mathbf{x})=n_{i}\left(\mathbf{x}^{\prime}\right) \int_{\Gamma} D_{k i j}\left(\mathbf{x}^{\prime}, \mathbf{x}\right) t_{k}(\mathbf{x}) d \Gamma(\mathbf{x}),
$$

onde $n_{i}$ denota o $i$-ésimo componente do vetor normal ao contorno no ponto fonte.

\subsubsection{Formulação Dual}

Conforme demonstrado anteriormente, tanto a equação integral de contorno para os deslocamentos (EICC), quanto a equação para as forças de superfície (EICH), constitui soluções independentes do problema elástico então considerado para domínios não degenerados. Segundo Portela (30), degenerações na geometria de um problema, seja a degeneração expressa no domínio ou contorno, são definidas matematicamente como trincas. Em um domínio trincado, tratar o problema elástico utilizando apenas uma das equações integrais de contorno, seja considerando a EICC ou a $\mathrm{EICH}$, dá origem a um problema mal posto, no qual uma única equação teria de ser aplicada a dois pontos fontes, cada um disposto em uma das faces da trinca. Entretanto, tendo em vista que ambas as equações são independentes, o tratamento de problemas dessa natureza recai no uso de ambas as equações de forma simultânea, em uma formulação chamada dual. Assim, o problema elástico de geometria degenerada, antes mal posto, torna-se passível de ser solucionado pelo equacionamento então apresentado.

Neste trabalho, a formulação dual do Método dos Elementos de Contorno, ou, Método dos Elementos de Contorno Dual (MECD), foi implementada conjuntamente a um algoritmo de refinamento adaptativo a fim de prover soluções a problemas de trincas em chapas metálicas, estendendo-se a quaisquer problemas de geometria 
degenerada definidos dentro do regime linear elástico. Os resultados numéricos obtidos serão apresentados no Capítulo 5 deste trabalho.

\subsection{FORMULAÇÃO DO MEC DISCRETIZADA}

A implementação numérica das equações integrais de contorno começa com a aproximação do contorno $\Gamma$ do problema através de elementos discretos, os chamados elementos de contorno. A cada um destes elementos associam-se um ou mais nós. Os deslocamentos e esforços ao longo de cada elemento são aproximados por funções polinomiais, chamadas funções de forma. Assim, o número de nós de cada elemento dependerá diretamente da escolha da função polinomial responsável pela interpolação da geometria e quantidades nodais que definem o problema.

\subsubsection{Elementos Quadráticos Descontínuos}

Neste trabalho, utilizar-se-ão elementos quadráticos (três nós por elemento) descontínuos (elementos cujos nós das extremidades não são compartilhados pelos elementos vizinhos). A escolha desse tipo de elemento diz respeito à técnica de refinamento adaptativo implementado ao algoritmo de análise numérica. Uma que vez que essa técnica faz uso das próprias descontinuidades ao longo do contorno entre elementos adjacentes para o cálculo do estimador de erro que guiará o refinamento da malha, há a obrigatoriedade de discretizar o contorno em elementos descontínuos. Os elementos quadráticos permitem o modelamento de elementos curvos e são especialmente indicados para problemas com altos gradientes, o que concede certa versatilidade ao programa ora proposto. Ademais, serão utilizados elementos quadráticos descontínuos isoparamétricos, ou seja, será usado exatamente o mesmo tipo de elemento para representar as quantidades físicas e geométricas do problema.

Os deslocamentos e forças de superfície são representados em um elemento quadrático padrão como: 


$$
\begin{aligned}
& \mathbf{u}=\left\{\begin{array}{l}
u_{1} \\
u_{2}
\end{array}\right\}=\left[\begin{array}{cccccc}
N_{d}^{(1)} & 0 & N_{d}^{(2)} & 0 & N_{d}^{(3)} & 0 \\
0 & N_{d}^{(1)} & 0 & N_{d}^{(2)} & 0 & N_{d}^{(3)}
\end{array}\right]\left\{\begin{array}{l}
u_{1}^{(1)} \\
u_{2}^{(1)} \\
u_{1}^{(2)} \\
u_{2}^{(2)} \\
u_{1}^{(3)} \\
u_{1}^{(3)}
\end{array}\right\}=\mathrm{N}_{d} \mathbf{u}^{(n)} \\
& \mathbf{t}=\left\{\begin{array}{l}
t_{1} \\
t_{2}
\end{array}\right\}=\left[\begin{array}{cccccc}
N_{d}^{(1)} & 0 & N_{d}^{(2)} & 0 & N_{d}^{(3)} & 0 \\
0 & N_{d}^{(1)} & 0 & N_{d}^{(2)} & 0 & N_{d}^{(3)}
\end{array}\right]\left\{\begin{array}{l}
t_{1}^{(1)} \\
t_{2}^{(1)} \\
t_{1}^{(2)} \\
t_{2}^{(2)} \\
t_{1}^{(3)} \\
t_{1}^{(3)}
\end{array}\right\}=\mathrm{N}_{d} \mathbf{t}^{(n)}
\end{aligned}
$$

onde $u_{i}^{(n)}$ e $t_{i}^{(n)}$ são os valores nodais de deslocamentos e forças de superfícies, respectivamente e $N_{d}^{(i)}$ são as funções de forma quadráticas descontínuas, definidas por:

$$
\begin{gathered}
N_{d}^{(1)}=\xi\left(\frac{9}{8} \xi-\frac{3}{4}\right), \\
N_{d}^{(2)}=\left(1-\frac{3}{2} \xi\right)\left(1+\frac{3}{2} \xi\right), \\
N_{d}^{(3)}=\xi\left(\frac{9}{8} \xi+\frac{3}{4}\right),
\end{gathered}
$$

onde $\xi$ representa uma coordenada adimensional ao longo do elemento (Figura 3.2).

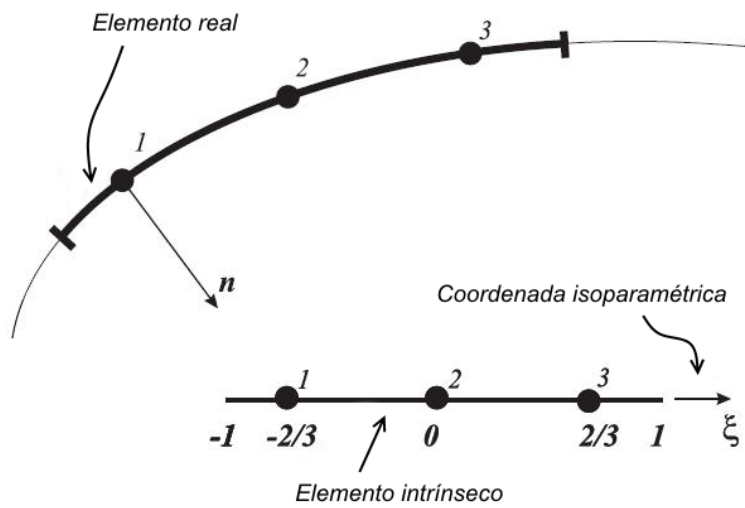

Figura 3.2 Elemento quadrático descontínuo. Fonte: (45) adaptado 
Considere que o contorno tenha sido dividido em $N E$ elementos de contorno. Substituindo as Equações (3.43) e (3.44) na Eq. (3.29), tem-se:

$$
\mathbf{c}^{i} \mathbf{u}^{i}+\sum_{j=1}^{N E}\left\{\int_{\Gamma_{j}} \mathrm{TN} d \Gamma\right\} \mathbf{u}^{j}=\sum_{j=1}^{N E}\left\{\int_{\Gamma_{j}} \mathrm{UNd} \Omega\right\} \mathbf{t}^{j}
$$

Seja,

$$
\int_{\Gamma_{j}} \mathrm{UNd} \Omega=\mathbf{g}
$$

e

$$
\int_{\Gamma_{j}} \mathrm{TN} d \Gamma=\mathbf{h}
$$

Assim, temos:

$$
\sum_{j=1}^{N E} H^{i j} u^{j}=\sum_{j=1}^{N E} G^{i j} t^{j}
$$

ou, na forma matricial:

$$
\mathbf{H u}=\mathbf{G t} \text {. }
$$

\subsubsection{Integração no Espaço}

De forma análoga à representação dos deslocamentos e forças de superfície, a geometria do elemento também pode ser representada pelas coordenadas nodais e as funções de forma $N^{(i)}$. Entretanto, para evitar descontinuidades na geometria, as funções de forma usadas são contínuas:

$$
\mathbf{x}=\left\{\begin{array}{l}
x_{1} \\
x_{2}
\end{array}\right\}=\left[\begin{array}{cccccc}
N_{c}^{(1)} & 0 & N_{c}^{(2)} & 0 & N_{c}^{(3)} & 0 \\
0 & N_{c}^{(1)} & 0 & N_{c}^{(2)} & 0 & N_{c}^{(3)}
\end{array}\right]\left\{\begin{array}{l}
x_{1}^{(1)} \\
x_{2}^{(1)} \\
x_{1}^{(2)} \\
x_{2}^{(2)} \\
x_{1}^{(3)} \\
x_{1}^{(3)}
\end{array}\right\}=\mathrm{N}_{c} \mathbf{x}^{(n)}
$$


onde $N_{c}^{(1)}=1 / 2 \xi(1-\xi), N_{c}^{(2)}=1-\xi^{2}$ e $N_{c}^{(3)}=1 / 2 \xi(1+\xi)$ são as funções de forma quadráticas contínuas.

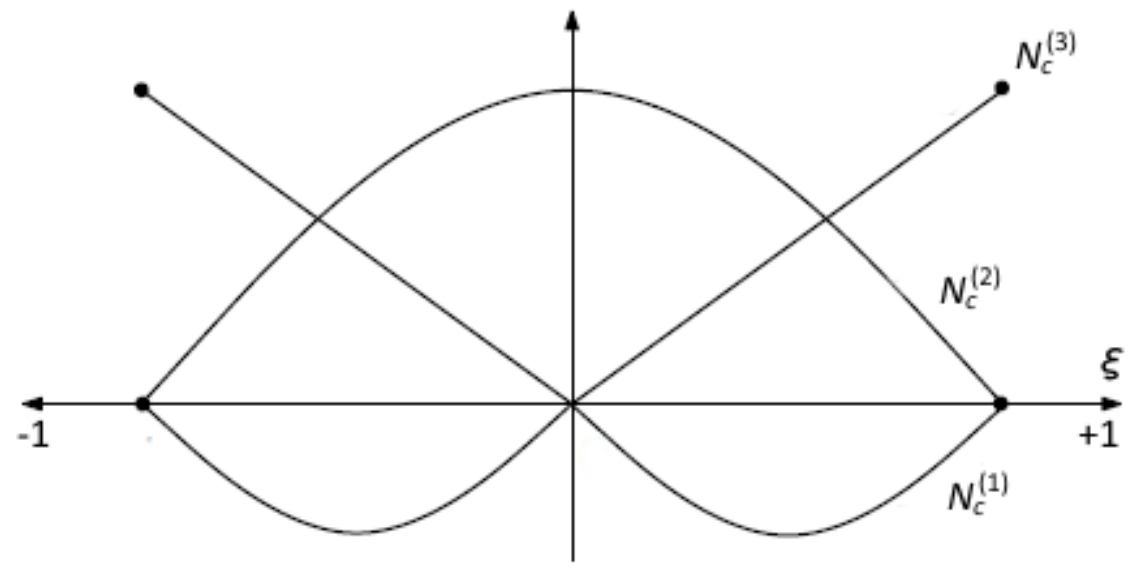

Figura 3.3 Funções de forma quadrática contínuas

As integrais de contorno podem ser escritas da seguinte forma:

$$
\begin{aligned}
& H^{(j)}=\int_{\Gamma_{j}} T_{i k} N^{(j)}=\int_{-1}^{1} T_{i k} N^{(j)}|J| d \xi, \\
& G^{(j)}=\int_{\Gamma_{j}} U_{i k} N^{(j)}=\int_{-1}^{1} U_{i k} N^{(j)}|J| d \xi,
\end{aligned}
$$

onde $|J|$ representa o módulo do Jacobiano da transformação $\left(x_{1}, x_{2}\right) \rightarrow \xi$ :

$$
|J|=\frac{d \Gamma}{d \xi}=\left\{\left(\frac{d x_{1}}{d \xi}\right)^{2}+\left(\frac{d x_{2}}{d \xi}\right)^{2}\right\}^{1 / 2}
$$

Na Eq. (3.56), $d x_{1} / d \xi$ e $d x_{2} / d \xi$ são obtidos ao derivarmos as expressões apresentadas na Eq. (3.53) em relação a $\xi$.

Integrais singulares da ordem $O(\ln r)$ podem ser avaliadas eficientemente pela quadratura de Gauss com uma transformação de variáveis cúbica, conforme proposto por Telles (46), que cancela exatamente a singularidade logarítmica. Uma outra possibilidade é o uso da quadratura logarítmica de Gauss, apresentada por Stroud e Secrest (47). De acordo com esse método, os termos incluindo singularidades logarítmicas podem ser integrados por: 


$$
I=\int_{0}^{1} \ln \left(\frac{1}{\xi}\right) f(\xi) d \xi \cong \sum_{i=1}^{N} w_{i} f(\xi)
$$

onde $N$ representa o número de pontos de Gauss.

Neste trabalho, os termos não singulares das matrizes H e G são integrados por meio da quadratura de Gauss padrão com 10 pontos de integração. Os termos singulares de G são do tipo $\ln (r)$, e serão integrados com a quadratura logarítmica de Gauss com 10 pontos de integração. Já os termos singulares de $\mathbf{H}$ são do tipo $1 / r$ e precisam ser calculados no sentido do valor principal de Cauchy. Uma maneira bastante simples de se tratar essa singularidade é através da consideração de corpos rígidos (48). Assumindo que um corpo rígido tenha todos os seus pontos do contorno deslocados de um valor unitário e que não existam forças de corpo $\left(b_{i}=0\right)$ aplicadas na direção de um dos eixos coordenados, as forças de superfície em qualquer ponto do contorno desse corpo devem ser nulas. Dessa forma, a Eq. (3.52) se torna:

$$
\mathbf{H v} \mathbf{v}^{q}=0,
$$

onde $\mathbf{v}^{q}$ é um vetor que possui deslocamentos unitários para todos os nós ao longo da direção $q$ e zero na outra direção. Para satisfazer a Eq. (3.58), aplica-se:

$$
H_{i i}=\sum_{j=1}^{N} H_{i j} \quad j \neq i
$$

sendo $j$ o número do j-ésimo elemento.

A Eq. (3.59) mostra que o termo da diagonal da matriz $\mathbf{H}$ é igual à soma de todos os outros termos fora da diagonal, correspondentes ao grau de liberdade em consideração.

\subsubsection{Cálculo das Tensões no Contorno}

Apresenta-se, a seguir, o equacionamento necessário à obtenção do tensor das tensões em um nó qualquer do contorno. Inicialmente, considere um nó em que as direções dos vetores normal e tangente ao contorno não coincidam com as direções dos eixos geométricos $x_{1}$ e $x_{2}$, conforme Fig. 3.4 abaixo. 


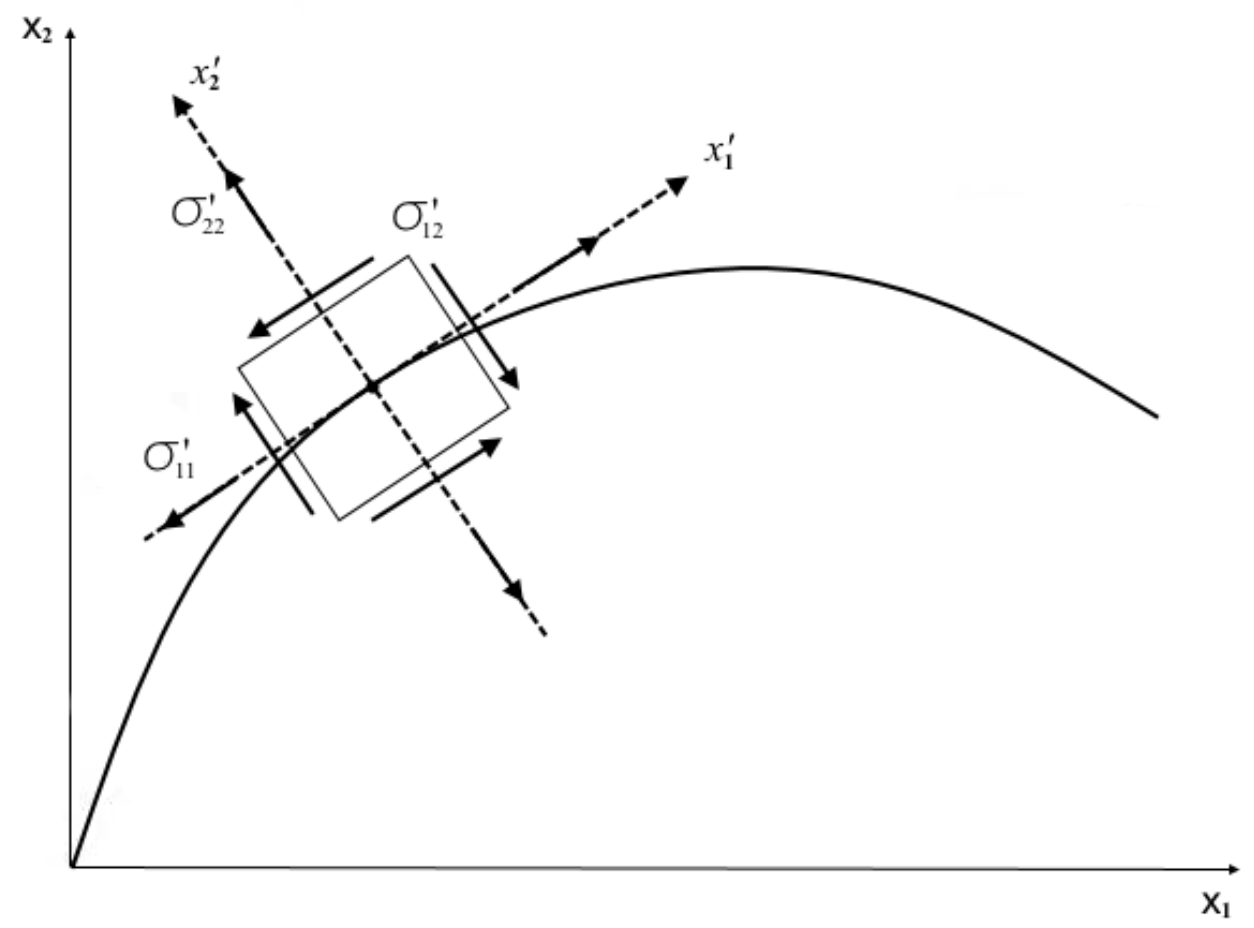

Figura 3.4 Tensões no Contorno

No sistema local, temos a seguinte relação:

$$
\begin{aligned}
& \sigma_{22}^{\prime}=t_{2}^{\prime}, \\
& \sigma_{12}^{\prime}=t_{1}^{\prime} .
\end{aligned}
$$

A deformação $\varepsilon_{11}^{\prime}$ pode ser calculado pela relação:

$$
\varepsilon_{11}^{\prime}=\frac{1}{2}\left(u_{1,1}^{\prime}+u_{1,1}^{\prime}\right)=u_{1,1}^{\prime}
$$

onde,

$$
u_{1,1}^{\prime}=\frac{d u_{1}^{\prime}}{d x_{1}^{\prime}}=\frac{d u_{1}^{\prime}}{d \xi} \frac{d \xi}{d x_{1}^{\prime}}
$$

Usando preceitos de geometria diferencial, a Eq. (3.63) nos mostra que a direção local $x_{1}^{\prime}$ é tangente ao comprimento infinitesimal do arco $d s$, dado por:

$$
d s=\sqrt{d x_{1}^{\prime 2}+d x_{2}^{\prime 2}}=\sqrt{\left(\frac{d x_{1}^{\prime}}{d \xi}\right)^{2}+\left(\frac{d x_{2}^{\prime}}{d \xi}\right)^{2}} d \xi \therefore \frac{d s}{d \xi}=J
$$

Um pequeno movimento ao longo de $s$ corresponde a um pequeno movimento em $x_{1}^{\prime}$. Isso permite que o termo $x_{1}^{\prime}$ na Eq. (3.63) seja substituído pela Eq. (3.64): 


$$
\varepsilon_{11}^{\prime}=\frac{d u_{1}^{\prime}}{d \xi} \frac{d \xi}{d s} \quad \therefore \quad \varepsilon_{11}^{\prime}=\frac{d u_{1}^{\prime}}{d \xi} J^{-1}
$$

sendo,

$$
\begin{gathered}
u_{1}=\sum_{i=1}^{3} N^{(i)} u_{1}^{(i)}, \\
\frac{d u_{1}}{d \xi}=\sum_{i=1}^{3} \frac{d N^{(i)}}{d \xi} u_{1}^{(i)},
\end{gathered}
$$

onde $N^{(i)}$ são as funções de forma definidas de acordo com a Equações (3.45), (3.46) e (3.47). A deformação, por conseguinte, é determinada pela relação:

$$
\varepsilon_{11}^{\prime}=\sum_{i=1}^{3} \frac{d N^{(i)}}{d \xi} u_{1}^{(i)} J^{-1}
$$

Da relação tensão-deformação, vem:

$$
\left\{\begin{array}{l}
\sigma_{11}^{\prime} \\
\sigma_{22}^{\prime} \\
\sigma_{12}^{\prime}
\end{array}\right\}=\frac{E}{1-v^{2}}\left[\begin{array}{ccc}
1 & v & 0 \\
v & 1 & 0 \\
0 & 0 & 1-v
\end{array}\right]\left\{\begin{array}{l}
\varepsilon_{11}^{\prime} \\
\varepsilon_{22}^{\prime} \\
\varepsilon_{12}^{\prime}
\end{array}\right\}
$$

onde $E$ é o módulo de elasticidade e $v$ é a razão de Poisson. As quantidades denotadas por $\sigma_{11}^{\prime}, \varepsilon_{22}^{\prime}$ e $\varepsilon_{12}^{\prime}$ agora podem ser calculadas para o estado plano de tensão.

Finalmente, as tensões devem ser escritas no referencial global $x_{1}-x_{2}$, ou seja:

$$
\left\{\begin{array}{l}
\sigma_{11} \\
\sigma_{22} \\
\sigma_{12}
\end{array}\right\}=\mathbf{T}^{-1}\left\{\begin{array}{l}
\sigma_{11}^{\prime} \\
\sigma_{22}^{\prime} \\
\sigma_{12}^{\prime}
\end{array}\right\}
$$

onde T é a matriz de transformação de coordenadas, dada por:

$$
\mathbf{T}=\left[\begin{array}{ccc}
m^{2} & n^{2} & 2 m n \\
n^{2} & m^{2} & -2 m n \\
-m n & m n & m^{2}-n^{2}
\end{array}\right]
$$

onde $m=\cos \theta$ e $n=\operatorname{sen} \theta$. 


\section{ESTIMATIVA DE ERRO E ADAPTATIVIDADE}

\subsection{INTRODUÇÃO}

O conceito de erro emerge do exercício de se calcular alguma quantidade matemática qualquer por técnicas de aproximação. Nesse caso, é correto afirmar que a natureza do erro está intrinsecamente ligada à própria definição de análise numérica. Quando implementado em um sistema de análise computacional, um conjunto de equações diferenciais parciais ou equações integrais perde informações à medida que as soluções são geradas, tendo em vista a divergência entre o modelo discreto das aproximações numéricas e o modelo contínuo do problema.

A aferição do distanciamento entre a solução obtida por meio da análise numérica e o valor exato de um problema qualquer é definida como erro da solução. A convergência da solução cresce conforme o erro diminui. Isto posto, faz-se necessário considerar métodos que possibilitem o monitoramento do erro durante um processo iterativo de solução.

O cálculo do erro em cada etapa do processo iterativo possibilitará, entre outras coisas, estabelecer um critério de parada desse cálculo ao se considerar um valor de incerteza aceitável. As soluções obtidas por um método numérico como o MEC normalmente estão associadas com erros cuja origem é evidenciada diante dos fatores descritos conforme se segue (49):

a) Imprecisão no modelo matemático que descreve o problema físico analisado. Nesse caso, o erro proveniente da solução numérica obtida se estabelece devido ao modelo matemático empregado na solução do problema, tendo em vista as quase inevitáveis simplificações necessárias à obtenção da solução.

b) Incertezas relacionadas à definição do problema propriamente dito. Erro devido às incongruências na informação inicial (entrada de dados), seja no que concerne às propriedades do material, à geometria ou às condições de contorno. 
c) Erro de discretização (ou de truncamento). É o erro relacionado à discretização do contorno do problema (50), ou seja, devido à aplicação das equações governantes em um número específico de nós ao longo do contorno. Frente a tal dinâmica, introduzse o conceito de refinamento de "malha", que consiste em aumentar o número de nós da "malha" que define o problema com o intuito de reduzir o erro e melhorar, consequentemente, a convergência da solução numérica.

d) Erro de arredondamento. Ocorre devido à representação finita dos números reais nas computações de resultados. Está relacionado ao nível de precisão dos computadores.

e) Erro de iteração. Se define como sendo a diferença entre a solução exata das equações discretizadas e a solução numérica em uma determinada iteração.

f) Erro de programação. Considera o erro humano causado no momento da implementação das equações e linhas de código do programa computacional responsável pela análise numérica do problema.

Neste trabalho, apenas o erro cujo tipo é descrito na alínea (c) é considerado. Assim, um método de estimativa de erro será definido a seguir com o objetivo de monitorar a quantificação das incertezas relacionadas à estratégia de solução do problema, para, em um segundo momento, interferirmos diretamente na discretização do problema, e melhorar, por conseguinte, a convergência da solução numérica gerada.

\subsection{ESTIMATIVA DE ERRO}

As estimativas de erro de discretização possuem duas naturezas básicas:

a) Estimativas a priori. Têm por base o conhecimento das características da solução, prestando informação qualitativa sobre a razão de convergência (49). Com esse tipo de estimativa é possível avaliar, antes mesmo da obtenção da solução do problema, qual o efeito do tipo de aproximação numérica usada e qual o impacto da redução do 
tamanho dos elementos da malha sobre o erro de discretização propriamente dito (51).

b) Estimativas a posteriori. São usadas para estimar a magnitude do erro de truncamento. Consideram a diferença entre o valor da solução obtida através da análise numérica e o valor exato da solução analítica do problema sob investigação.

Para efeitos práticos, este trabalho se concentrará na técnica de estimativa de erro a posteriori. Assim sendo, o estado da arte desse processo de estimativa de erro aplicado ao MEC será apresentado a seguir e, posteriormente, será definido, no Capítulo 5 deste trabalho, o modelo de estimativa de erro utilizado para obtenção dos resultados apresentados.

\subsubsection{Tipos de Estimadores de Erro a posteriori}

O uso de um estimador de erro eficiente possibilita uma predição muito próxima do erro real, mesmo quando a solução analítica de um determinado problema é desconhecida. A aferição precisa do erro em determinada solução guiará, de forma efetiva e confiável, o refinamento adaptativo da malha do problema, desencadeando, por sua vez, soluções mais precisas.

Estimadores de erro a posteriori aplicados ao MEC têm sido objeto de extensa investigação por parte da comunidade científica ao longo dos anos, conforme se observa segundo as revisões bibliográficas de Liapis (52) e Kita e Kamiya (53). Conforme dispõe Portela (54), estimadores de erro são normalmente classificados dentre cinco tipos distintos:

\subsubsection{Residual}

Considere o sistema $A x=b$, no qual $A \in \mathbb{R}^{n x n}$ (invertível) e $b \in \mathbb{R}^{n}$. Tomando $\bar{x}$ como a solução exata e $\tilde{x}$ como solução aproximada, definem-se (55):

- $\quad$ Erro da solução aproximada: $e=\bar{x}-\tilde{x}$

- Resíduo da solução aproximada: $r=b-A \tilde{x}$

Abe (56) apresentou um novo método para a estimativa do resíduo, calculandoo, exclusivamente, nos pontos de colocação. Chen, Yu e Schnack (57) analisaram o resíduo proveniente da $\mathrm{EICH}$, propondo um método de estimativa de erro baseado na diferença entre as duas soluções para tensões no contorno, considerando a 
formulação elástica do MEC. Martínez-Castro (58) trabalhou com derivativas tangenciais para estimar o erro. $O$ processo residual de estimativa de erro também está presente nos trabalhos de Parreira; Rank; Paulino; Liang, Chen e Yang e Jorge (59-63).

\subsubsection{Interpolação}

Estimadores de erro de interpolação possuem como característica a estimativa do erro através da diferença entre aproximações por polinômios de ordens distintas. Esse tipo de estimador de erro foi utilizado nos trabalhos de Rencis e Mullen (64) e Kita e Kamiya (65). Em (65), por exemplo, uma aproximação cúbica é aplicada à tangente da linha do contorno, sendo utilizada para prover uma solução mais precisa, se comparada com a solução originalmente obtida. O erro é então calculado através da diferença entre as soluções geradas. Segundo Portela (54), uma das desvantagens desse tipo de estimador de erro está relacionada à possível incerteza decorrente da imprecisão computacional.

\subsubsection{Erro da Equação Integral de Contorno}

Esse estimador de erro considera a relação entre o erro da solução e o resíduo proveniente da equação integral de contorno. Alarcon e Reverter (66) utilizou esse tipo de estimador de erro em um algoritmo do MEC adaptativo tipo $p$, técnica de adaptatividade que consiste, basicamente, em refinar a malha aumentando a ordem do polinômio interpolador. Cerrolaza (67) e Alarcón (68) também utilizaram a mesma técnica de adaptatividade, expandindo os conceitos de Alarcón e Reverter (66) para problemas em três dimensões.

\subsubsection{Sensitividade Nodal}

Nesse caso, o erro é estimado como a solução de um sistema de equações diferenciais auxiliar, o que pode resultar em um aumento do esforço computacional. A sensitividade nodal que dá nome à técnica considera a derivada da solução, na direção tangencial à linha de contorno, de cada ponto de colocação. Essa técnica foi apresentada por Guiggiani e Massimo (69), sendo usada posteriormente por Bonnet (70) e Paulino et al. (71). 


\subsubsection{Diferença entre Soluções}

Esse tipo de estimador de erro considera a diferença entre dois tipos diferentes de análises, o que acaba tornando a técnica por demais custosa, já que a solução tem de ser obtida duas vezes. Essa técnica foi amplamente usada, podendo ser encontrada nos trabalhos de Mullen e Rencis; Charafi, Neves e Wrobel; Paulino, Gray e Zarikian, Muci-Kuchler, Riranda-Valenzuela e Soriano-Soriano e Jorge, Ribeiro e Fisher (72-76).

\subsubsection{Estimador de Erro para Elementos de Contorno Descontínuos}

Embora, como demonstrado anteriormente, o uso de estimadores de erro e técnicas de refinamento adaptativo esteja sendo integrado a diferentes formulações do MEC ao longo do tempo, segundo Portela (54), tal estratégia não teve muita aplicação no que concerne formulações do MEC para elementos de contorno descontínuos. Assim, foi apresentado em (54) uma técnica de estimativa de erro e refinamento adaptativo integrado à formulação potencial 2D do MECD, para formulações com esse tipo de elemento.

Naquela publicação, foi introduzida uma nova forma de obter os estimadores de erro das soluções do problema. Essa nova técnica de estimativa de erro possui a vantagem de depender unicamente das descontinuidades da solução obtida ao longo do contorno entre elementos adjacentes. Cumpre registrar que tal estimador não se encaixa em nenhuma das categorias anteriormente apresentadas.

Diante do exposto, o presente trabalho tem como objetivo expandir a aplicação do estimador de erro apresentado em (54), a fim de tratar problemas elásticos em duas dimensões, utilizando a formulação tradicional do MEC e sua formulação dual.

\subsubsection{Equacionamento}

No que tange a análise pelo Método dos Elementos de Contorno (MEC), é sabido que a principal fonte de erro está intimamente relacionada com a discretização do contorno (54). A exatidão da solução cresce, portanto, conforme a malha é refinada. Esse tipo de erro surge ao tentarmos aproximar as variáveis de estado fazendo uso de polinômios que, normalmente, não traduzem de forma fiel o comportamento físico do problema, tornando o modelo matemático usado na modelagem numérica ineficiente. 
Neste contexto, o erro das variáveis de estado para um problema elástico 2D pode ser definido da forma como se segue.

$$
e_{j}^{u}=u_{j}^{0}-u_{j}=\delta u_{j}
$$

para o deslocamento, no qual $j$ representa as direções 1 e 2 e

$$
e_{j}^{t}=t_{j}^{0}-t_{j}=\delta t_{j}
$$

para força de superfície, onde $u_{i}^{0}, t_{i}^{0}$ e $u_{i}, t_{i}$ representam, respectivamente, as soluções exata e aproximada das variáveis de estado ao longo do contorno. Os erros $e_{j}^{u}$ e $e_{j}^{t}$ serão sempre nulos quando calculados para elementos de contorno que apresentarem condição de contorno de deslocamento e força de superfície, respectivamente, prescritas. A norma $L_{2}$ para os erros das variáveis de estado apresentados anteriormente pode ser calculada da forma:

$$
\left\|e_{j}^{u}\right\|=\left[\int_{\Gamma} \delta u_{j}^{2} \mathrm{~d} \Gamma\right]^{1 / 2}
$$

para o deslocamento e

$$
\left\|e_{j}^{t}\right\|=\left[\int_{\Gamma} \delta t_{j}^{2} \mathrm{~d} \Gamma\right]^{1 / 2}
$$

para força de superfície. A norma do erro global pode ser escrita da forma:

$$
\|e\|=\left\|e_{j}^{u}\right\|+\left\|e_{j}^{t}\right\|
$$

As normas representam a exatidão com que as variáveis de estado são modeladas pelos elementos de contorno, e são usadas para associar as estimativas dos respectivos erros de discretização (54). As normas são computadas como um somatório sobre todos os elementos do contorno.

$$
\left\|e_{j}^{u}\right\|=\sum_{i=1}^{N}\left\|e_{j}^{u}\right\|_{i}
$$

e 


$$
\left\|e_{j}^{t}\right\|=\sum_{i=1}^{N}\left\|e_{j}^{t}\right\|_{i}
$$

onde $N$ representa o número de elementos do contorno, $\left\|e_{j}^{u}\right\|$ e $\left\|e_{j}^{t}\right\|$ são os estimadores de erro globais das variáveis de estado, para o deslocamento e força de superfície, respectivamente; $\left\|e_{j}^{u}\right\|_{i}$ e $\left\|e_{j}^{t}\right\|_{i}$ são os estimadores de erro locais, responsáveis por mostrar a contribuição de cada elemento $i$ no cálculo da estimativa de erro global.

\subsubsection{Indicadores de Erro}

No intuito de proceder com o refinamento da malha para prover soluções mais precisas e confiáveis, os indicadores de erro possuem como característica a indicação do elemento de contorno que deverá ser refinado. A técnica consiste em calcular o indicador de erro por elemento, realizando, em seguida, uma verificação quanto ao valor do indicador, na medida em que o elemento que possuir o maior indicador associado possuirá o maior erro calculado e, por sua vez, deverá ser refinado. $O$ algoritmo é então reiniciado com a nova malha e a solução é gerada novamente. $A$ técnica é reempregada até obedecer um critério de parada, qual seja um valor dentro de um limite de tolerância. $O$ detalhamento da técnica de refinamento da malha será minuciosamente explicitado posteriormente.

Normalmente, a solução exata de um problema em análise é desconhecida. Assim, os erros das variáveis de estado conforme definidos pelas Equações (4.1) e (4.2) não podem ser calculados dessa forma. Portela (54) introduziu um procedimento que associa diretamente esses erros às descontinuidades da solução ao longo dos elementos de contorno descontínuos. Como já mencionado, tal técnica foi utilizada na solução de problemas potenciais em duas dimensões; aqui, usaremos a mesma técnica, com suas devidas adaptações, para solucionar problemas elásticos em duas dimensões.

Considere que o contorno de um problema qualquer é discretizado com elementos de contorno descontínuos de qualquer ordem. Nesse caso, a solução do problema elástico na vizinhança em que um ponto $p$ do contorno pertença, simultaneamente, aos elementos $i$ e $i+1$, adjacentes, pode ser expressa como: 


$$
\bar{u}=\bar{u}(t)_{i} \quad \text { para } t \leq t_{p}
$$

e

$$
\bar{u}=\bar{u}(t)_{i+1} \quad \text { para } t \geq t_{p}
$$

ou, simplesmente,

$$
\bar{u}=\bar{u}(t)_{i}+H\left(t-t_{p}\right) u(t)_{t+1}
$$

onde $t$ é uma coordenada qualquer do contorno, $t_{p}$ é a coordenada do ponto $p$, comum aos elementos adjacentes para qual a solução em ambas as direções 1 e 2 é representada, respectivamente, pelos vetores $\bar{u}(t)_{i}$ e $\bar{u}(t)_{i+1}$ e $H\left(t-t_{p}\right)$ é a função degrau de Heaviside, tomado com o valor unitário em $t=t_{p}$. Considerando que 0 contorno é discretizado com elementos descontínuos, é possível que a solução de descontinuidade $\Delta \bar{u}$ ocorra no ponto $t_{p}$, levando à seguinte expressão:

$$
\bar{u}\left(t_{p}\right)_{i+1}=\bar{u}\left(t_{p}\right)_{i}+\Delta \bar{u}
$$

assim, quando a Eq. (4.1) é aplicada ao ponto $t_{p}$, temos o seguinte erro de discretização:

$$
\bar{e}_{u}=\bar{u}_{0}-\bar{u}=\bar{u}_{0}-\bar{u}_{i}-\Delta \bar{u} .
$$

No ponto $t_{p}$, o erro de discretização definido pela Eq. (4.12), pode ser convenientemente decomposto em duas componentes complementares e independentes:

$$
\bar{e}_{u}=\bar{e}_{u c}+\bar{e}_{u n c},
$$

onde $\bar{e}_{u c}$ e $\bar{e}_{u n c}$ são definidos, respectivamente, por:

$$
\bar{e}_{u c}=\bar{u}_{0}-\bar{u}_{i}
$$

e

$$
\bar{e}_{u n c}=\bar{u}_{0}-\Delta \bar{u},
$$


que representam os erros de discretização relacionados aos elementos contínuos e descontínuos para a solução de deslocamento. Assim, a Eq. (4.13) pode ser reescrita como:

$$
\bar{e}_{u}=\bar{u}_{0}-\bar{u}_{i}+\bar{u}_{0}-\Delta \bar{u}=2 \bar{u}_{0}-\bar{u}_{i}-\Delta \bar{u} .
$$

De forma análoga, a análise conforme demonstrada em epígrafe também pode ser aplicada para a solução de força de superfície, conduzindo à uma expressão semelhante:

$$
\bar{e}_{t}=\bar{e}_{t c}+\bar{e}_{t n c}
$$

onde $\bar{e}_{t c}$ e $\bar{e}_{t n c}$ são definidos, respectivamente, por:

$$
\bar{e}_{t c}=\bar{t}_{0}-\bar{t}_{i}
$$

e

$$
\bar{e}_{t n c}=\bar{t}_{0}-\Delta \bar{t},
$$

que representam os erros de discretização relacionados aos elementos contínuos e descontínuos para a solução de força de superfície.

Quando a discretização por elementos de contorno do modelo a ser simulado não é acurado o bastante para simular o comportamento exato das variáveis de estado do problema, a solução obtida da análise pelo MEC trará descontinuidades ao longo do contorno de elementos adjacentes, que, via de regra, crescem à medida que a ordem do polinômio usado na aproximação decresce. Isto posto, podemos concluir que, ao reduzirmos tais descontinuidades, obteremos uma análise mais precisa e, por conseguinte, soluções mais confiáveis. Essa conclusão se define como uma vantagem per se à técnica apresentada anteriormente, uma vez que as descontinuidades são um resultado direto da aplicação do equacionamento proposto, em contraste com análises por elementos de contorno contínuos (54).

Os indicadores de erro como sendo unicamente as descontinuidades da solução ao longo do contorno entre elementos adjacentes têm sua aferição apresentada na forma como se segue. 
Como já explicitado nos capítulos anteriores, neste trabalho utilizamos um algoritmo de análise pelo MEC e MECD com elementos quadráticos descontínuos; cada elemento possui, portanto, três nós geométricos que o definem. Inicialmente, solucionamos o problema tomando o valor das variáveis de estado para todos os três nós de cada elemento. Em seguida, aplicamos a função de forma para elementos quadráticos descontínuos $N$, juntamente às soluções geradas para cada nó, obtendo um valor ponderado das variáveis de estado nos nós extremos de cada elemento, para cada uma das direções $j=1$ e $j=2$ :

$$
u_{j}(\xi=-1)=N_{1}(\xi=-1) u_{j 1}+N_{2}(\xi=-1) u_{j 2}+N_{3}(\xi=-1) u_{j 3}
$$

e

$$
u_{j}(\xi=1)=N_{1}(\xi=1) u_{j 1}+N_{2}(\xi=1) u_{j 2}+N_{3}(\xi=1) u_{j 3}
$$

onde $u_{j}$ é o deslocamento nas direções $j=1,2, N$ é a função de forma para elementos quadráticos descontínuos, e $u_{j 1}, u_{j 2}$ e $u_{j 3}$ representam os valores do deslocamentos para cada nó do elemento.

Analogamente, para força de superfície, temos:

$$
t_{j}(\xi=-1)=N_{1}(\xi=-1) t_{j 1}+N_{2}(\xi=-1) t_{j 2}+N_{3}(\xi=-1) t_{j 3}
$$

e

$$
t_{j}(\xi=1)=N_{1}(\xi=1) t_{j 1}+N_{2}(\xi=1) t_{j 2}+N_{3}(\xi=1) t_{j 3}
$$

onde $t_{j}$ é o deslocamento nas direções $j=1,2$, e $t_{j 1}, t_{j 2}$ e $t_{j 3}$ representam os valores das forças de superfície para cada nó do elemento. As Equações (4.20), (4.21), (4.22) e (4.23) são aplicadas para cada um dos elementos do contorno.

Os indicadores de erro são então obtidos por intermédio dos saltos da solução calculada pelo MEC ou MECD, nos nós entre elementos adjacentes, para cada elemento de contorno. Os saltos da solução são definidos por vetores que contém os valores de ambas as direções 1 e 2 , da seguinte forma:

$$
\bar{J}_{1}^{u}=\bar{u}(\xi=-1)
$$




$$
\bar{J}_{3}^{u}=-\bar{u}(\xi=1)
$$

para o deslocamento, onde $\bar{J}_{1}^{u}$ e $\bar{J}_{3}^{u}$ são os vetores contendo os saltos da solução de deslocamento nos nós 1 e 3 da extremidade do elemento, para ambas as direções do problema 2D. Analogamente, para as soluções de força de superfície, teremos:

$$
\bar{J}_{1}^{t}=\bar{t}(\xi=-1)
$$

e

$$
\bar{J}_{3}^{t}=-\bar{t}(\xi=1)
$$

para força de superfície, onde $\bar{J}_{1}^{t}$ e $\bar{J}_{3}^{t}$ são os vetores contendo os saltos da solução de força de superfície nos nós 1 e 3 da extremidade do elemento, para ambas as direções 1 e 2.

Os saltos da solução de deslocamento e força de superfície, para análise de problemas elásticos em 2D pelo MEC ou MECD, são então definidos, respectivamente, da seguinte forma:

$$
\bar{J}_{u}=\bar{J}_{1}^{u}+\bar{J}_{3}^{u}
$$

e

$$
\bar{J}_{t}=\bar{J}_{1}^{t}+\bar{J}_{3}^{t}
$$

As Equações (4.6) e (4.7) agora podem ser usadas para definir os indicadores de erro das soluções de deslocamento e força de superfície, respectivamente, para cada elemento de contorno:

$$
\left\|\bar{e}_{u}\right\|_{i}=\left[\int_{\Gamma_{i}} \bar{J}_{u}^{2} \mathrm{~d} \Gamma\right]^{1 / 2}=\frac{h_{i}}{2}\left(\bar{J}_{1}^{u^{2}}+\bar{J}_{3}^{u^{2}}\right)
$$

e

$$
\left\|\bar{e}_{t}\right\|_{i}=\left[\int_{\Gamma_{i}} \bar{J}_{t}^{2} \mathrm{~d} \Gamma\right]^{1 / 2}=\frac{h_{i}}{2}\left(\bar{J}_{1}^{t}+\bar{J}_{3}^{t}\right)
$$

onde $h_{i}$ é o comprimento de cada elemento $\Gamma_{i}$. 


\subsubsection{Porcentagem de Erros}

O último passo para o refinamento da malha consiste em calcular a porcentagem de erro por elemento, o que nos permitirá identificar objetivamente o elemento que possui a maior parcela de erro frente ao erro total da solução numérica gerada, erro este que provém, como já demonstrado anteriormente, das descontinuidades ao longo do contorno entre elementos adjacentes.

A porcentagem local dos erros produzidos pela análise numérica em pauta pode ser definida, para a solução de deslocamento e força de superfície, respectivamente, como sendo:

$$
\left(\lambda_{j}^{u}\right)_{i}=\left[\frac{\left\|e_{j}^{u}\right\|_{i}^{2}}{\|u\|^{2}+\left\|e_{j}^{u}\right\|^{2}}\right]^{1 / 2},
$$

e

$$
\left(\lambda_{j}^{t}\right)_{i}=\left[\frac{\left\|e_{j}^{t}\right\|_{i}^{2}}{\|t\|^{2}+\left\|e_{j}^{t}\right\|^{2}}\right]^{1 / 2},
$$

onde $\left\|e_{j}^{u}\right\|_{i}$ e $\left\|e_{j}^{t}\right\|_{i}$ são os indicadores de erro definidos nas Equações (4.29) e (4.30), respectivamente, $e_{j}^{u}$ e $e_{j}^{t}$ são os valores dos erros globais, definidos nas Equações (4.1) e (4.2), respectivamente e $\|u\|$ e $\|t\|$ são as normas da solução de deslocamento e força de superfície gerados pela análise do MEC ou MECD, respectivamente. As porcentagens locais dos erros das soluções de deslocamento e força de superfície, em cada direção 1 e 2, são, então, somadas.

$$
\lambda_{u i}=\lambda_{1_{i}}^{u}+\lambda_{2}^{u}
$$

para o deslocamento e

$$
\lambda_{t i}=\lambda_{1_{i}}^{t}+\lambda_{2 i}^{t}
$$

para força de superfície.

O estimador global de erro, ou, simplesmente, erro global da solução, é definido percentualmente como: 


$$
\eta=\eta_{u}+\eta_{t}
$$

onde $\eta_{u}$ e $\eta_{t}$ representam as contribuições dos erros relacionados à solução de deslocamento e força de superfície, respectivamente. Para a discretização em $N$ elementos de contorno, essas contribuições complementares são definidas como:

$$
\eta_{u}=\left[\sum_{i=1}^{N} \lambda_{u i}^{2}\right]^{1 / 2}
$$

para o deslocamento e

$$
\eta_{t}=\left[\sum_{i=1}^{N} \lambda_{t i}^{2}\right]^{1 / 2}
$$

para força de superfície.

\subsection{REFINAMENTO ADAPTATIVO}

A adaptatividade se define como o processo pelo qual algumas das configurações iniciais do algoritmo responsável pela análise numérica, expressas na fase de préprocessamento, se alteram após a obtenção da solução do problema. Tais alterações possuem o objetivo de produzir soluções mais precisas, ao reduzir, indefinidamente, os erros associados à própria técnica de solução.

\subsubsection{Tipos de Refinamento Adaptativo}

Qualquer que seja o tipo de refinamento usado na solução de um problema, a técnica de adaptatividade depende exclusivamente das informações contidas nos indicadores de erro calculados em etapa anterior. Como já explicitado no subitem 4.2, os indicadores de erro são responsáveis por aferir a contribuição do erro local associado à solução obtida em cada elemento de contorno frente ao erro global da análise numérica. Assim, torna-se possível a identificação do elemento que possui o maior erro relativo para, em um segundo momento, atuarmos exclusivamente sobre esse 
elemento, utilizando um tipo de refinamento adaptativo que terá o objetivo de atenuar as descontinuidades relacionadas às soluções ali obtidas.

No que concerne aos tipos de refinamento adaptativo, é correto afirmar que as alterações às configurações iniciais do algoritmo responsável pela análise numérica podem ocorrer (77):

a) nas equações que caracterizam o modelo matemático de aproximação, objetivamente aumentando a ordem do polinômio interpolador - técnica conhecida como refinamento tipo $p$;

b) na malha usada para efetuar os cálculos da solução, objetivamente aumentando o número de elementos nas zonas de maior índice de erro - técnica conhecida como refinamento tipo $h$;

c) em um processo misto que contemple as duas estratégias definidas nas alíneas anteriores - técnica conhecida como refinamento tipo $p-h$.

\subsubsection{Refinamento Adaptativo Implementado}

Neste trabalho, o processo adaptativo implementado atuará apenas no refinamento da malha. Conforme descrito na alínea (b) acima, o refinamento tipo $h$ atua sobre as zonas com maior índice de erro, em contraposição ao refinamento uniforme, que apenas permite um refinamento global, ou seja, sobre todos os elementos do contorno. O uso desse tipo de refinamento adaptativo permite obter soluções mais precisas frente a um menor esforço computacional, conforme será demonstrado no capítulo seguinte.

O processo de refinamento adaptativo como um todo, compreendendo todas as etapas desde o cálculo dos estimadores de erro até o refinamento da malha, está resumido a seguir.

i. Para uma discretização inicial de elementos de contorno, as soluções são obtidas com a formulação elástica do MEC ou MECD;

ii. O processo de refinamento adaptativo começa, de fato, com o cálculo dos saltos da solução ao longo do contorno entre elementos descontínuos adjacentes, através das Equações (4.24), (4.25), (4.26) e (4.27); 
iii. Os indicadores de erro $\left\|\bar{e}_{u}\right\|_{i}$ e $\left\|\bar{e}_{t}\right\|_{i}$, obtidos através das Equações (4.30) e (4.30) são calculados para cada elemento do contorno;

iv. Com esses indicadores, são computadas as porcentagens de erro $\left(\lambda_{j}^{u}\right)_{i}$ e $\left(\lambda_{j}^{t}\right)_{i}$, através das Equações (4.32) e (4.33) para cada elemento, em ambas as direções 1 e 2. As porcentagens de erro em cada direção são então somadas através das Equações (4.34) e (4.35);

v. É identificado o elemento que possui a maior porcentagem de erro $\lambda_{\max }$, dentre todos os $\lambda_{u i}$ e $\lambda_{t i}$ calculados;

vi. Finalmente, o estimador global de erro $\eta$ é computado através da Eq. (4.36), após o cálculo das contribuições dos erros relacionados à solução de deslocamento e força de superfície $\eta_{u}$ e $\eta_{t}$, respectivamente, através das Equações (4.37) e (4.38);

vii. Todas as etapas anteriores são repetidas em um processo iterativo, até que a solução convirja, obedecendo um critério de parada.

Normalmente, o critério de parada é definido da seguinte forma:

$$
\lambda_{\max } \leq \bar{\lambda}
$$

ou

$$
\eta \leq \bar{\eta},
$$

onde $\lambda_{\max }$ é o erro percentual máximo local, $\eta$ é o erro global, $\bar{\lambda}$ e $\bar{\eta}$ são os limites prescritos para os erros locais e globais, respectivamente. Entretanto, a depender da natureza do problema a ser resolvido, outros critérios de parada poderão ser adotados.

A seguir serão apresentados os problemas resolvidos com a técnica proposta neste capítulo, responsáveis pela validação do algoritmo de refinamento adaptativo implementado às formulações do MEC e MECD. 


\section{RESULTADOS NUMÉRICOS}

\subsection{INTRODUÇÃO}

Foram selecionados dois problemas clássicos de elasticidade plana e dois exemplos tradicionais de Mecânica da Fratura para serem resolvidos com a técnica de refinamento adaptativo descrita no Capítulo 4 deste trabalho. Os problemas definidos a seguir foram escolhidos de forma a permitirem a validação do algoritmo de adaptatividade desenvolvido, cujas rotinas escritas em linguagem Matlab estão disponíveis no Apêndice.

Os dois primeiros exemplos possuem solução analítica conhecida; assim, os critérios de parada do processo iterativo inerente à rotina de refinamento adaptativo deverão associar as soluções calculadas segundo essa técnica à própria solução analítica do problema, observando o erro relativo entre ambas, além de apresentar uma análise comparativa entre o comportamento da formulação clássica do MEC e o MEC adaptativo.

Os exemplos de Mecânica da Fratura serão resolvidos com a formulação dual do MEC, tendo as soluções numéricas comparadas com soluções empíricas encontradas na literatura.

\subsection{PROBLEMAS CLÁSSICOS DE ELASTICIDADE PLANA}

\subsubsection{A Viga Fina de Timoshenko}

\subsubsection{Introdução}

A viga fina de Timoshenko representa um dos problemas clássicos de elasticidade plana, tendo solução analítica conhecida desde meados do século passado (78). Para fins de validação do algoritmo de refinamento adaptativo proposto neste trabalho, a 
solução numérica gerada pelo MEC para o deslocamento será comparada à solução analítica do problema, calculada por intermédio da expressão a ser enunciada a seguir.

No que concerne às formulações tradicionais do Método dos Elementos de Contorno (MEC), a viga fina de Timoshenko não se define como um problema de fácil solução, uma vez que se enquadra na classe de problemas elásticos de corpos finos (ou parede fina), cuja geometria apresenta uma patologia bem particular (79): a chamada quase-singularidade. Inicialmente, o MEC tradicional se mostrou tão ineficaz para o tratamento de problemas desse tipo, que, segundoKrishnasamy, Rizzo e Liu (80), problemas de parede fina haviam sido relegados ao efetivo tratamento numérico pelo Método dos Elementos Finitos (MEF). Desde então, técnicas especiais para o tratamento analítico do fenômeno matemático de quase-singularidade têm sido desenvolvidas para tornar a formulação do MEC eficaz perante problemas dessa natureza.

Estruturas constituídas de corpos finos desempenham um importante papel na atual conjectura da engenharia, estando presentes em carenagens de aeronaves, cascos de navios, e estruturas de pontes. Possuem aplicação extremamente diversificada, tendo em vista seu baixo peso e incomum capacidade de adaptação de forma, compreendendo estruturas em arco, placas, vigas esbeltas, entre muitas outras.

Segundo Zhang, Gu e Chen (81), formulações tradicionais do MEC que usam quadratura de Gauss como técnica de integração numérica possuem dificuldades em gerar resultados confiáveis para problemas de corpos finos. A principal razão para a não convergência da solução diz respeito ao fato de as integrais apresentarem núcleos quase-singulares, estabelecidos diante da situação em que o ponto fonte se encontra muito próximo do ponto campo, conforme se observa pelo esquema retratado na Fig. 5.1 abaixo.

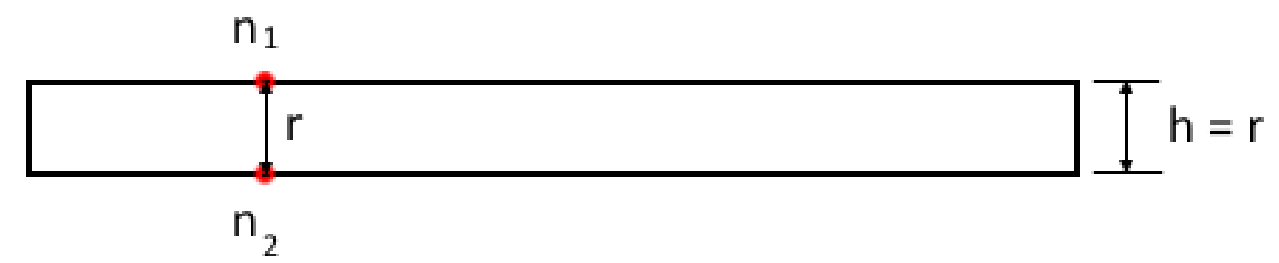

Figura 5.10 problema matemático de quase-singularidade 
Quando o ponto fonte $n_{1}$ está muito próximo do ponto campo $n_{2}$, ou seja, quando $r \rightarrow 0$, o núcleo da integral na equação integral de contorno se define como quase-singular. Embora integrais quase-singulares sejam matematicamente diferentes de integrais singulares, ambas representam um obstáculo para o uso de quadraturas numéricas convencionais, uma vez que o integrando oscila profusamente dentro do intervalo de integração.

Muitos algoritmos foram desenvolvidos para o tratamento analítico de integrais singulares, dos quais podemos citar, por exemplo: Brebbia, Tells e Wrobel (82), Hong e Chen(18), Liu (83), Liu e Rizzo (84), Sladek e Sladek (85) e Granados e Galego (86). Outros inúmeros algoritmos foram desenvolvidos, tanto pelo método direto quanto indireto, para o tratamento analítico de integrais quase-singulares, tais como: Krishnasamy, Rizzo e Liu (80), Granados e Galego (86), Mukherjee (87) e Zhang, Gu e Chen (81)

Conforme se observa em Kane (79), que resolveu um problema de viga fina com razão de aspecto 1:20, utilizando a formulação de multi-regiões do MEC, fica claro que quanto melhor for a técnica de integração, mais rápida será a convergência da solução, daí a necessidade de se utilizar algoritmos para tratar as integrais quasesingulares de forma analítica. Reboredo, Costa e Albuquerque (88) analisaram um problema semelhante, porém com razão de aspecto de 1:100, utilizando a formulação tradicional do MEC. Além de análise por multi-regiões, foi realizado um procedimento de refinamento da malha e variação do número de pontos usados para a integração numérica por quadratura de Gauss. Foi demonstrado naquele artigo que a solução desse problema através de formulações tradicionais do MEC pode produzir resultados confiáveis.

Frente ao exposto, propõe-se a solução do problema de viga fina de Timoshenko através da técnica de refinamento adaptativo tipo $h$, proposta neste trabalho, aplicada à formulação de elasticidade plana do MEC, com vistas a validar o algoritmo desenvolvido e, concomitantemente, propor uma nova técnica de solução para problemas de natureza quase-singular. 


\subsubsection{Definição do Problema}

Segundo demonstrado em Timoshenko (78), a solução analítica para o deslocamento do problema da viga fina em duas dimensões é dada pelas equações a seguir:

$$
\begin{aligned}
& u_{x}(x, y)=\frac{-P y}{6 E I}\left[(v+2)\left(y^{2}-\frac{h^{2}}{4}\right)+(6 L-3 x) x\right], \\
& u_{y}(x, y)=\frac{P y}{6 E I}\left[\frac{h^{2}}{4}(5 v+4) x+3 v(L-x) y^{2}+(3 L-x) x^{2}\right],
\end{aligned}
$$

onde $E$ é o módulo de elasticidade, $v$ é a razão de Poisson e $I$ é o segundo momento de área da seção.

A Fig. 5.2 sintetiza o problema em análise. Para $E=10^{6}$ e $v=0,3$, o deslocamento máximo na direção 2 é dado por:

$$
u_{y}=4,0003
$$
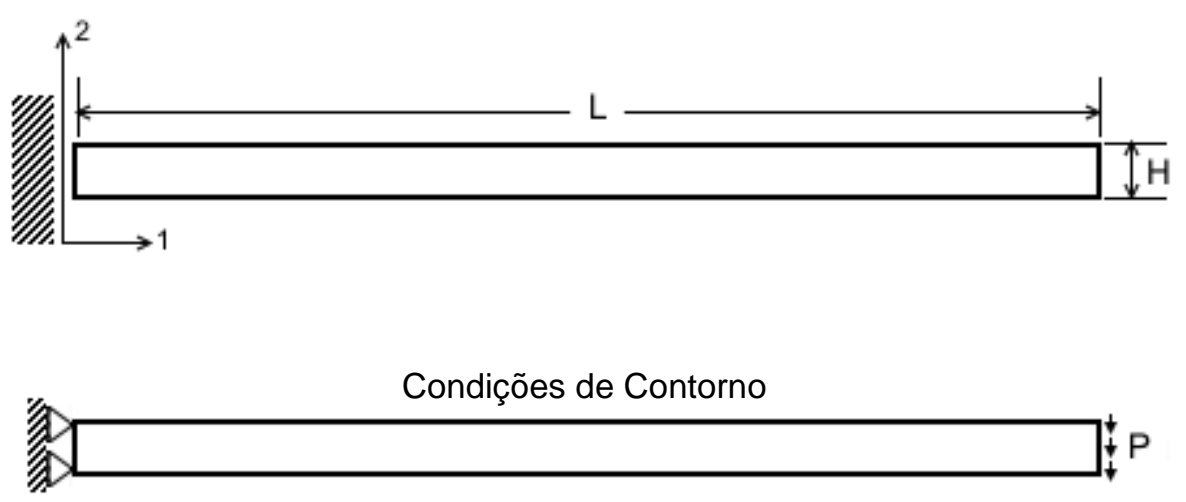

Largura $L=100 \mathrm{~mm}$ Altura $H=1 \mathrm{~mm}$ Força $P=1 N$

Figura 5.2 Problema da viga fina de Timoshenko

\subsubsection{Resultados Numéricos}

Inicialmente, o problema foi discretizado em uma malha de 28 elementos de contorno quadráticos descontínuos, conforme se observa pela Fig. 5.3 a seguir, tendo sido resolvido para o deslocamento máximo na direção 2. Foi aplicado em todo o contorno a EICC, com 10 pontos de integração para quadratura de Gauss.

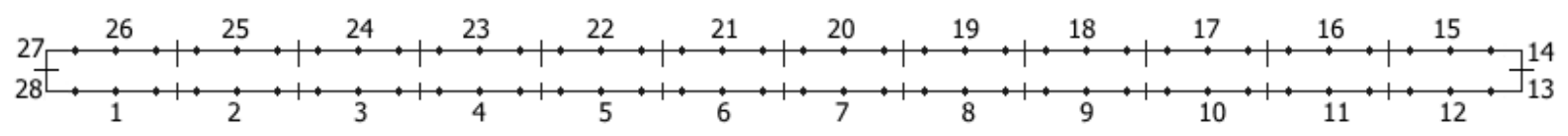

Figura 5.3 Malha inicial para o problema de viga fina 
O algoritmo de refinamento adaptativo proposto neste trabalho indica, inicialmente, as descontinuidades das soluções de deslocamento e forças de superfície calculadas no contorno entre elementos adjacentes. Assim, o indicador de erro aponta o elemento com a maior descontinuidade do modelo; esse elemento é, então, refinado. $O$ processo se repete indefinidamente até que a solução numérica convirja, respeitando um critério de parada previamente definido. Nesse caso, tendo em vista que a solução analítica é conhecida, conforme enunciada pela Eq. (5.3), o critério de parada estipulado foi baseado no cálculo do erro relativo entre as soluções numérica e analítica. Assim, o modelo foi refinado até que a solução se mantivesse abaixo do limite de $0,5 \%$ de erro relativo. Os resultados são apresentados na Tabela 5.1 .

Com o intuito de demonstrar a efetividade da técnica de refinamento adaptativo, o mesmo problema foi resolvido considerando refinamento contínuo do contorno, até que a solução numérica convergisse considerando um erro relativo inferior a $2 \%$, os resultados estão presentes na Fig. 5.2. As soluções foram obtidas usando algoritmos escritos em linguagem Matlab.

Tabela 5.1 Resultados para o deslocamento vertical máximo - MEC convencional

\begin{tabular}{cccc}
\hline $\begin{array}{c}\text { Número de Pontos } \\
\text { de Colocação }\end{array}$ & $\begin{array}{c}\text { Deslocamento Vertical } \\
\text { Máximo (mm) }\end{array}$ & Erro Relativo (\%) & Tempo (s) \\
\hline 84 & 3,4613 & 13,47 & 7,52 \\
165 & 3,5845 & 10,39 & 25,39 \\
246 & 3,707 & 7,33 & 53,97 \\
405 & 3,8347 & 4,13 & 141,54 \\
606 & 3,8915 & 2,72 & 315,31 \\
810 & 3,9225 & 1,94 & 556,49 \\
\hline
\end{tabular}

Tabela 5.2 Resultados para o deslocamento vertical máximo - MEC adaptativo

\begin{tabular}{ccccc}
\hline Iteração & $\begin{array}{c}\text { Número de Pontos } \\
\text { de Colocação }\end{array}$ & $\begin{array}{c}\text { Deslocamento Vertical } \\
\text { Máximo (mm) }\end{array}$ & Erro Relativo (\%) & Tempo (s) \\
\hline 0 & 84 & 3,4613 & 13,47 & 7,52 \\
1 & 126 & 3,7400 & 6,51 & 15,06 \\
2 & 165 & 4,1157 & 2,88 & 26,10 \\
3 & 246 & 4,0730 & 1,82 & 53,94 \\
4 & 324 & 3,9975 & 0,0687 & 93,39 \\
\hline
\end{tabular}


A Fig. 5.4 mostra os resultados para o deslocamento vertical máximo $u_{y}$ em função do número de pontos de colocação para análise pelo MEC convencional e MEC adaptativo. Desta forma, é possível notar que as soluções geradas pelo MEC adaptativo se aproximam mais rapidamente da solução analítica do que as produzidas pelo MEC convencional.

A Fig. 5.5 mostra o erro relativo das soluções produzidas por ambas as formulações em função do tempo de processamento necessário para resolver o problema. As curvas obtidas demonstram que a solução obtida pelo MEC adaptativo atinge menor erro relativo, ou seja, obtém uma resposta mais precisa, frente a um menor tempo de processamento quando comparada à análise pelo MEC convencional.

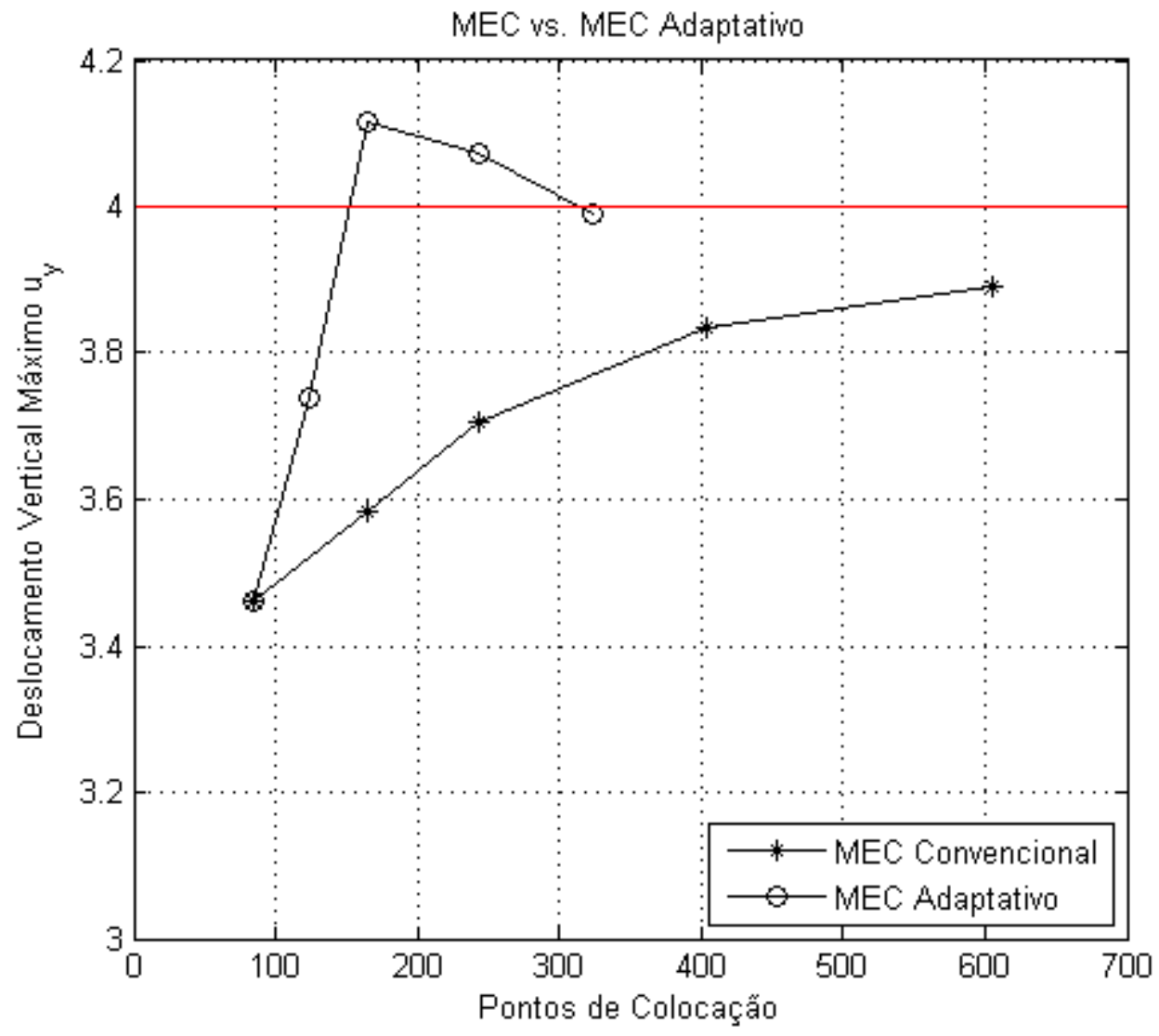

Figura 5.4 Análise de convergência das soluções obtidas com o MEC Convencional e MEC Adaptativo (dimensões em $\mathrm{mm}$ ) 


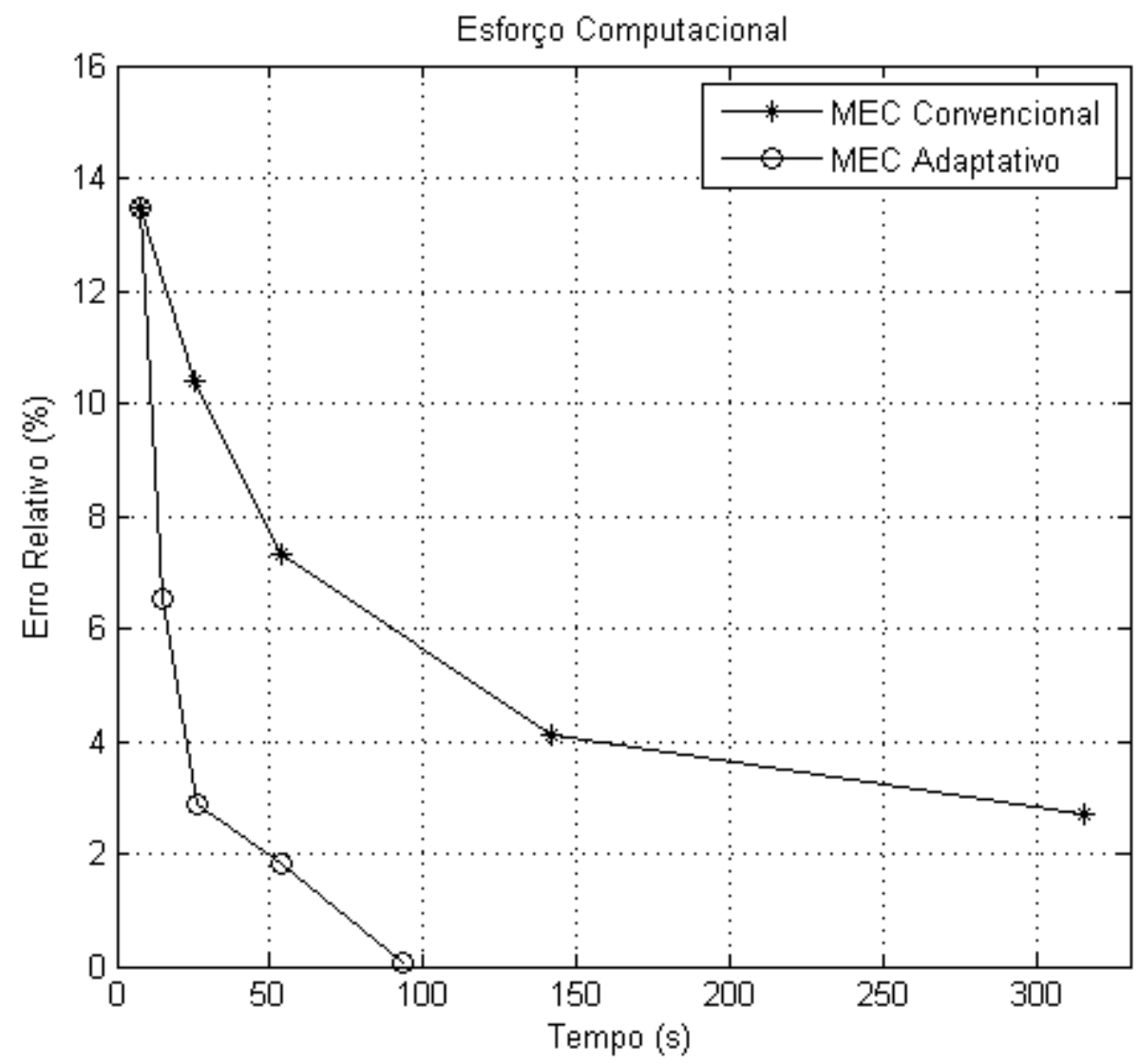

Figura 5.5 Análise de esforço computacional entre os dois métodos de solução

Frente aos resultados obtidos, fica claro a efetividade do MEC adaptativo. Em uma análise comparativa entre ambos os métodos de solução, o refinamento adaptativo além de gerar uma solução mais exata (apenas $0,07 \%$ de erro relativo), faz uso de um esforço computacional menor, com convergência para a solução analítica aproximadamente $90 \%$ mais rápida do que a produzida pela formulação tradicional do MEC.

A solução numérica produzida pelo MEC adaptativo necessitou de apenas 4 iterações e 324 pontos de colocação para produzir uma solução aceitável dentro do critério de parada especificado previamente. $\mathrm{O}$ algoritmo indicou, desde a primeira iteração, uma necessidade de refinamento dos elementos próximos ao engaste, o que demonstra coerência por parte da análise numérica no que se refere ao comportamento mecânico do corpo em análise.

Ademais, o refinamento adaptativo atenuou as oscilações provocadas pelas integrais quase-singulares, provando que mesmo a formulação elástica do MEC, 
juntamente ao refinamento de locais específicos do contorno, produz soluções confiáveis e tecnicamente viáveis.

\subsubsection{Placa Finita com Furo Circular sob Tração}

\subsubsection{Introdução}

O segundo problema escolhido consiste na aferição da tensão máxima em uma placa finita com furo circular sob tração. Esse problema também possui solução analítica conhecida, conforme definida em Timoshenko (78) e enunciada a seguir.

Segundo Umetani (89), a aferição da distribuição de tensões sobre uma placa com furo circular sob tensão possui considerável relevância prática. Nesse caso, o furo causa um concentrador de tensão que varia em função do ângulo que o diâmetro faz com o sentido da força de tração nos extremos da placa, tendo seu valor máximo na extremidade (ponto 1 da Fig. 5.6).

Analogamente à estratégia definida em 5.2.1, e no intuito de reforçar a relevância da técnica de refinamento adaptativo então apresentada, será empreendida uma análise comparativa entre as soluções produzidas pela formulação tradicional do MEC e pelo MEC adaptativo.

\subsubsection{Definição do Problema}

A solução analítica para a tensão máxima em uma placa finita com furo central sob tração foi demonstrada por Timoshenko (78). O problema está definido conforme parâmetros expressos na Fig. 5.6. Para o caso de uma placa finita, a solução analítica para a tensão no ponto 1 para a situação em que $B=2 D$ foi obtida por Howland (90) e está enunciada a seguir.

$$
\sigma_{22}^{1}=4,3 P
$$

onde $P$ é a força de tração aplicada nas extremidades da placa.

Para os dados definidos na Fig. 5.6, temos:

$$
\sigma_{22}^{1}=43
$$

Os resultados numéricos obtidos para a tensão máxima na placa deverão ser comparados, pois, com a solução analítica do problema, apresentada na Eq. (5.5). 


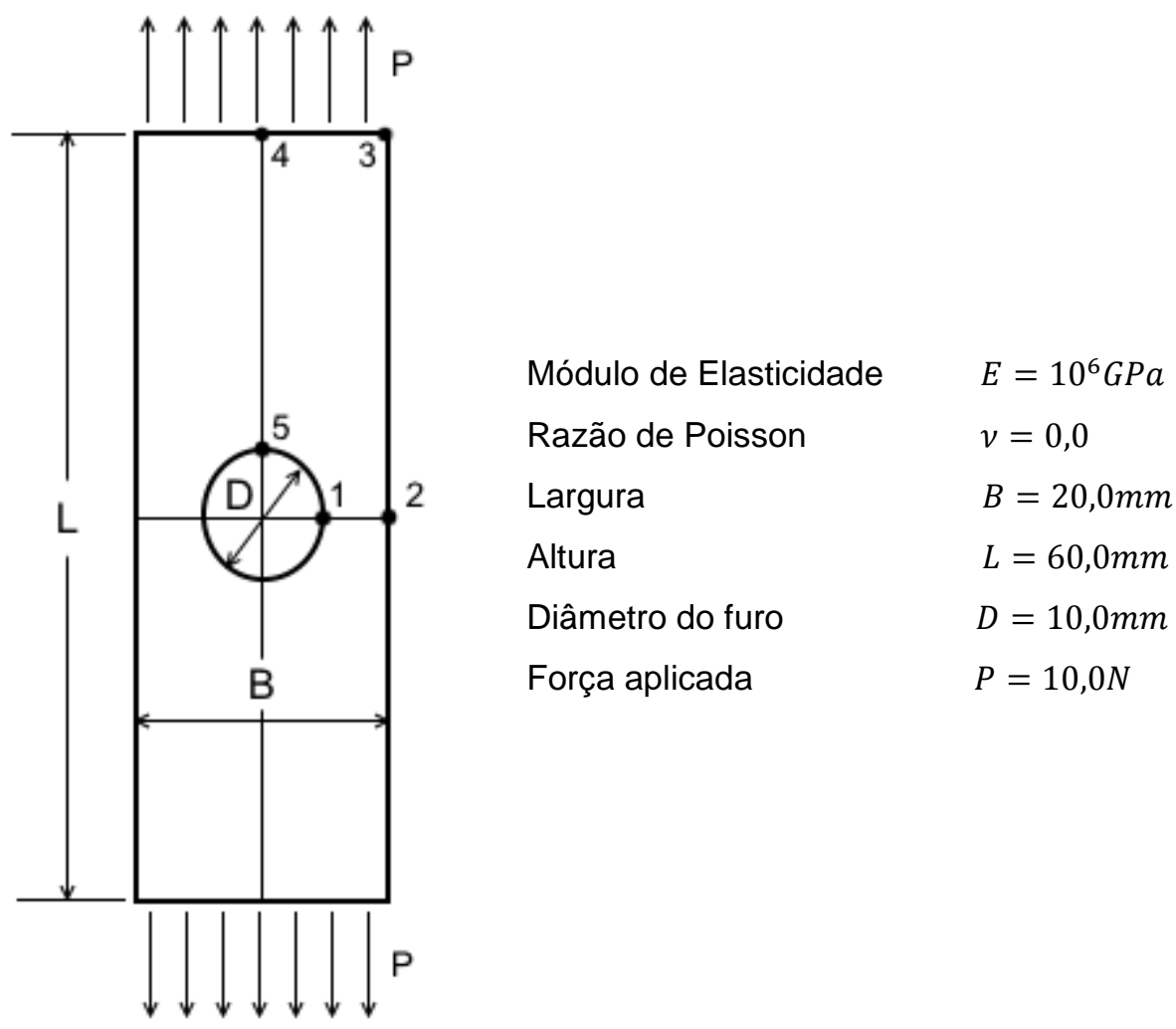

Figura 5.6 O problema da placa com furo circular sob tração

\subsubsection{Resultados Numéricos}

A técnica de refinamento adaptativo supõe a utilização de uma malha inicial grosseira, na medida em que seja possível a solução numérica do problema, embora sejam considerados valores altos de erro relativo. Dessa forma, é possível aferirmos os elementos com as maiores descontinuidades e procedermos com o refinamento localizado, o que, conforme mostrado no exemplo numérico anterior 5.2.1, nos garantirá soluções mais precisas frente a um menor esforço computacional.

O exemplo da placa com furo central sob tração é normalmente resolvido com a discretização de um quarto da placa apenas, tendo em vista a natureza simétrica do problema, como evidenciado em Umetani (89). Assim, começamos com uma malha inicial de 7 elementos e 21 pontos de colocação, conforme se observa na Fig. 5.7. A solução do problema será obtida pela aplicação da EICC, com 10 pontos de integração para quadratura de Gauss. À medida que a malha for sendo refinada, as linhas numeradas na Fig. 5.7 poderão conter mais de um elemento, ao contrário do que demonstra a discretização inicial do problema. 


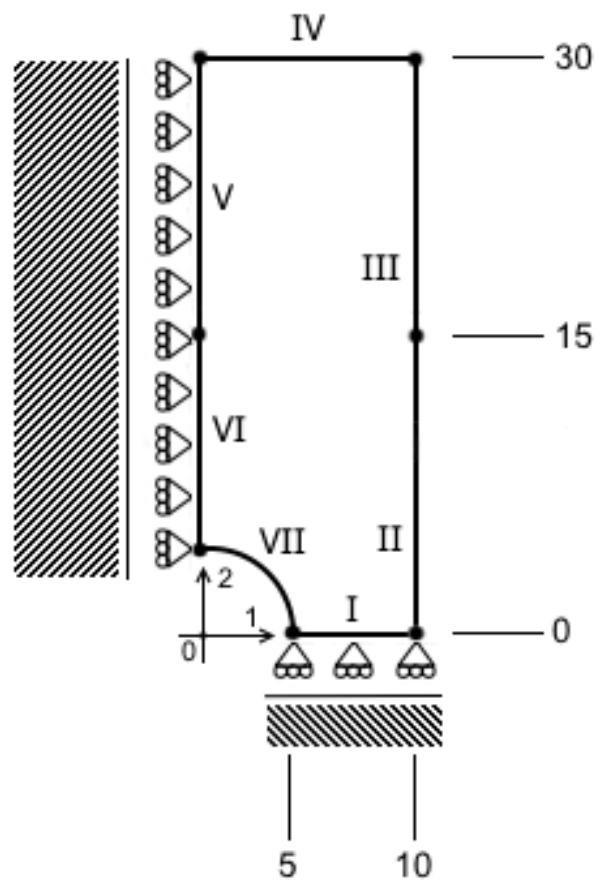

Figura 5.7 Malha inicial do problema da placa com furo central sob tração

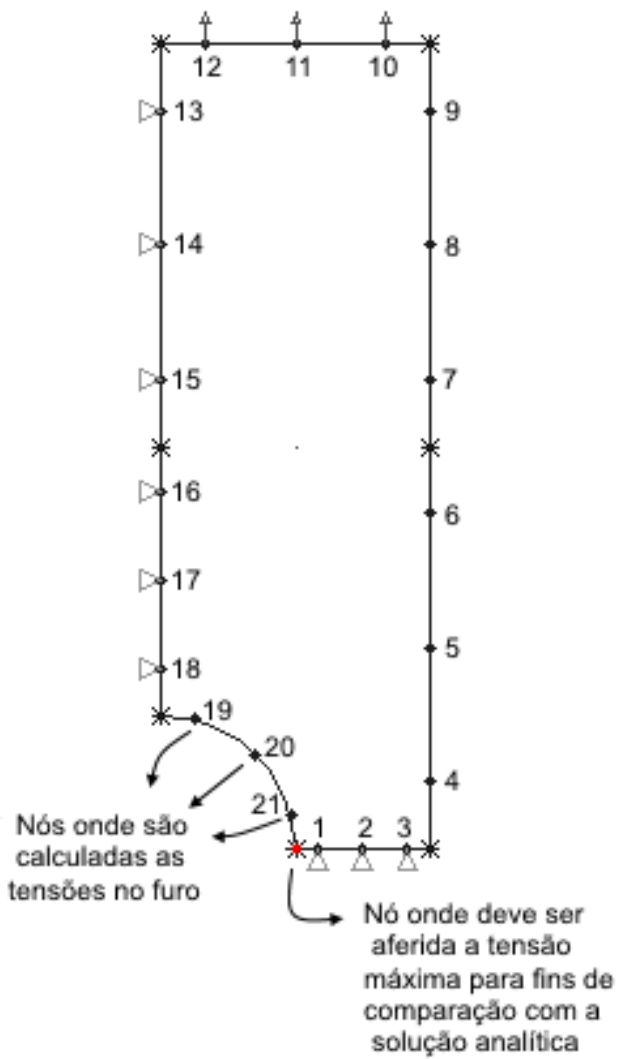

Figura 5.8 Locais de aferição das tensões no furo da placa 
Porquanto a técnica de adaptatividade apresentada requer a utilização de elementos de contorno descontínuos, no intuito de aferir as descontinuidades entre as soluções do contorno, a aferição direta da máxima tensão no furo fica impossibilitada. Isso acontece porque os elementos descontínuos não compartilham nós entre si. Assim, a aferição da tensão no nó da extremidade do furo, indicado na Fig. 5.8, deve ser feita mediante interpolação das tensões aferidas nos nós 19, 20 e 21, através das funções de forma quadráticas descontínuas. Isto posto, calcularemos, durante todo o processo de solução do problema, as tensões nos nós do último elemento que discretiza o furo, aplicando as funções de forma para obter a tensão máxima na placa, comparando-a, em seguida, com a solução analítica apresentada na Eq. (5.5).

A exemplo do problema anterior, para o caso da solução pelo MEC Adaptativo, o critério de parada estipulado foi baseado no cálculo do erro relativo entre as soluções numérica e analítica. Assim, o modelo foi refinado até que a solução se mantivesse abaixo do limite de $0,5 \%$ de erro relativo.

Tabela 5.3 Resultados para a tensão máxima na placa - MEC convencional

\begin{tabular}{cccccc}
\hline Iteração & $\begin{array}{c}\text { Pontos de } \\
\text { Colocação }\end{array}$ & Tensão Máxima & Erro (\%) & Tempo (s) & Refinamento \\
\hline $\mathbf{0}$ & 21 & 35,41 & 17,65 & 0,48 & - \\
$\mathbf{1}$ & 42 & 38,58 & 10,28 & 0,78 & Todos \\
$\mathbf{2}$ & 63 & 42,70 & 0,70 & 1,15 & Todos \\
$\mathbf{3}$ & 84 & 43,04 & 0,093 & 1,58 & Todos \\
\hline
\end{tabular}

Tabela 5.4 Resultados para a tensão máxima na placa - MEC adaptativo

\begin{tabular}{ccccccc}
\hline Iteração & $\begin{array}{c}\text { Pontos de } \\
\text { Colocação }\end{array}$ & $\begin{array}{c}\text { Tensão } \\
\text { Máxima }\end{array}$ & Erro (\%) & Tempo (s) & Refinamento & $\begin{array}{c}\text { Elementos por } \\
\text { Linha }\end{array}$ \\
\hline $\mathbf{0}$ & 21 & 35,41 & 17,65 & 0,48 & - & - \\
$\mathbf{1}$ & 24 & 35,48 & 17,50 & 0,55 & Linha II & 2 \\
$\mathbf{2}$ & 27 & 38,55 & 10,35 & 0,57 & Linha VII & 2 \\
$\mathbf{3}$ & 30 & 38,71 & 9,98 & 0,60 & Linha I & 2 \\
$\mathbf{4}$ & 33 & 42,25 & 1,74 & 0,66 & Linha VII & 3 \\
$\mathbf{5}$ & 36 & 42,05 & 2,21 & 0,70 & Linha VI & 2 \\
$\mathbf{6}$ & 39 & 42,94 & 0,14 & 0,73 & Linha I & 3 \\
\hline
\end{tabular}




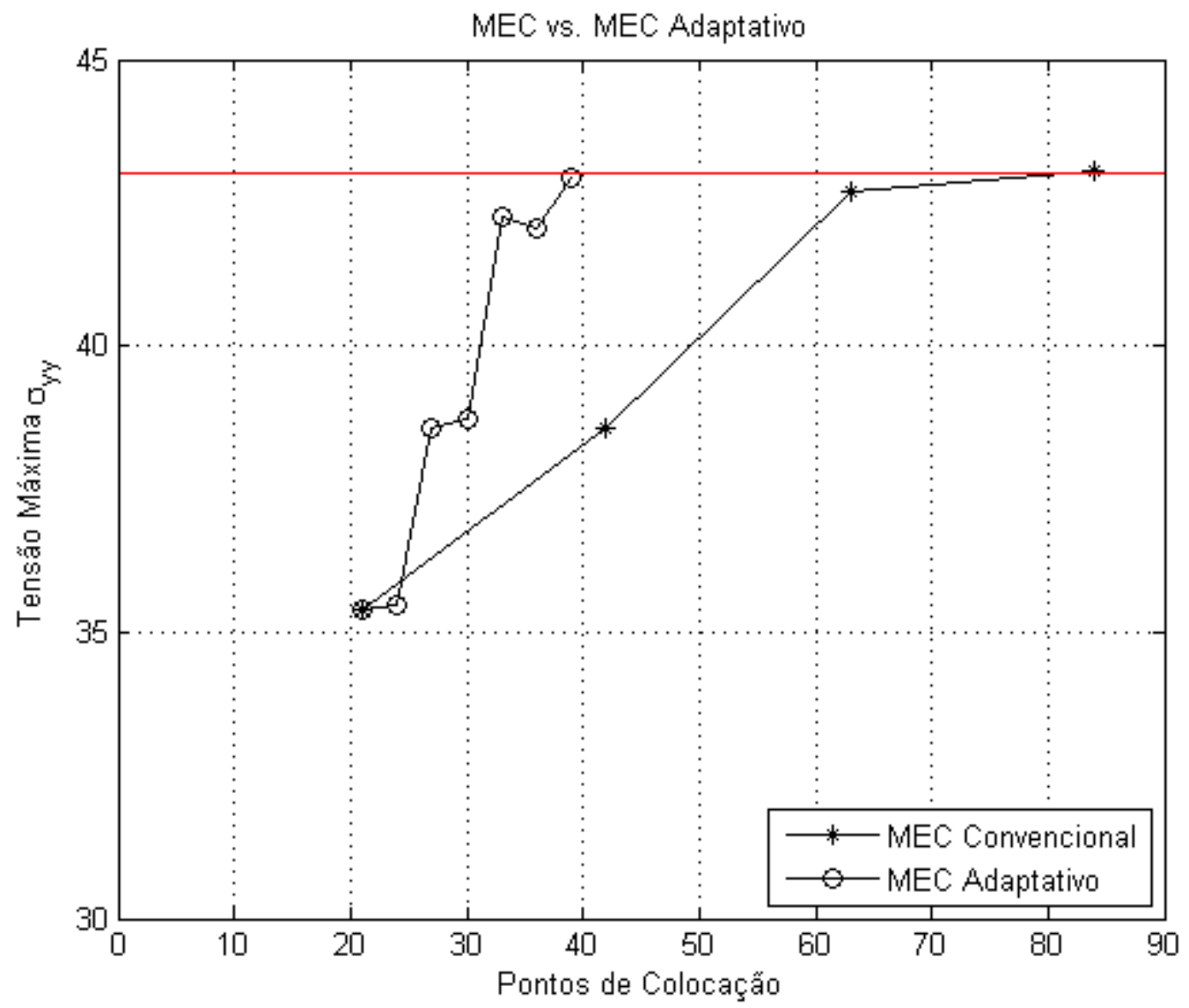

Figura 5.9 Análise de convergência das soluções obtidas com o MEC Convencional e MEC Adaptativo 


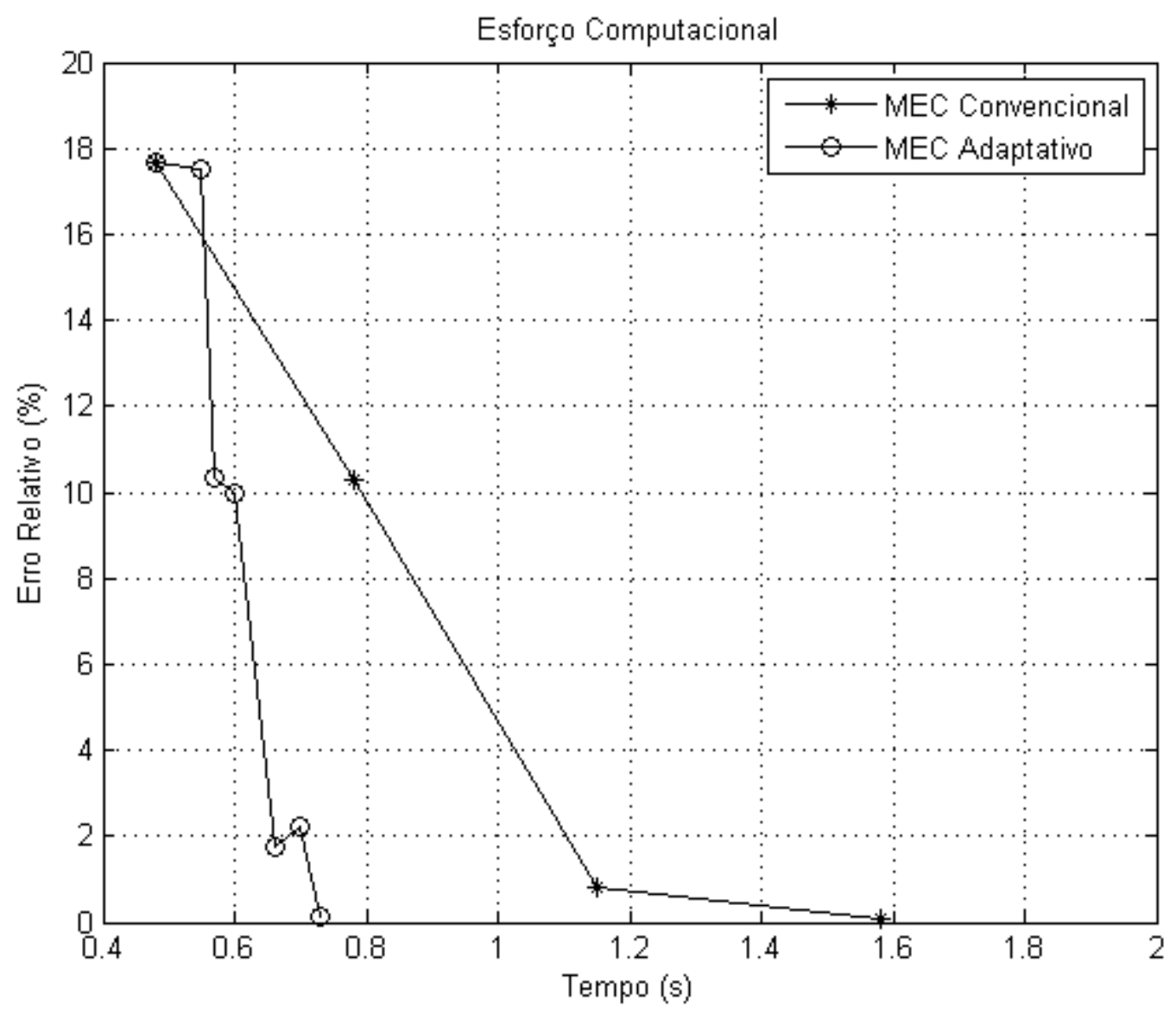

Figura 5.10 Análise de esforço computacional entre os dois métodos de solução

Em análise aos resultados apresentados, podemos perceber, mais uma vez, a efetividade do algoritmo de refinamento adaptativo proposto. A Tabela 5.4 revela as linhas da Fig. 5.7 que foram refinadas segundo as indicações dos indicadores de erro definidos nas Equações (4.31) e (4.32). Percebemos a tendência de refinamento nas intermediações do ponto de maior concentrador de tensão, qual seja a extremidade do furo (ponto 1 da Fig. 5.6). A Fig. 5.9 mostra como o resultado numérico se aproxima da solução analítica no MEC convencional e MEC adaptativo, enquanto que a Fig. 5.10 mostra essa aproximação em termos do erro relativo. Com apenas 6 iterações e 39 pontos de colocação, a solução numérica atingiu a convergência com erro relativo de apenas $0,14 \%$. Se comparadas, percebemos que, embora a solução produzida pela formulação tradicional do MEC seja mais precisa (apenas 0,09\% de erro), o MEC adaptativo consegue produzir uma solução numérica que ainda se mantém abaixo do limite de erro aceitável ( $0,5 \%$ de erro), diante de um tempo de processamento muito menor, aproximadamente $46 \%$ se comparado ao MEC tradicional. 


\subsection{PROBLEMAS CLÁSSICOS DE MECÂNICA DA FRATURA}

\subsubsection{Placa Infinita com Trinca Central}

\subsubsection{Introdução}

O problema de uma placa infinita com trinca central sob tração foi amplamente estudado pela comunidade científica ao longo dos anos, sendo um problema clássico de Mecânica da Fratura. Nesse problema, o campo de tensões e deslocamentos se relaciona com o chamado fator de intensidade de tensões $K$ e, para o caso de tração pura, considera-se apenas o $K_{I}$, ou seja, o fator de intensidade de tensões em modo I (abertura).

Tendo em vista que se trata de um exemplo simétrico, a formulação clássica do MEC poderia ser aplicada para solucionar apenas 1/4 da placa de modo muito eficiente, semelhantemente ao empreendido no problema 5.2.2. Entrementes, este problema será resolvido com a formulação dual do MEC, o MECD, juntamente com o algoritmo de refinamento adaptativo objeto deste trabalho. Aqui, estaremos interessados em comparar o valor do $K_{I}$ entre a formulação clássica do MECD, o MECD adaptativo e a solução empírica obtida por Koiter (39) em 1965, cuja expressão será enunciada a seguir. O fator de intensidade de tensões será calculado pela técnica da integral $J$, conforme elucidado no Capítulo 2 deste trabalho.

\subsubsection{Definição do Problema}

Considere uma placa de comprimento infinito, de largura $B$ e com uma trinca central de comprimento $2 a$, sob os efeitos de uma força trativa de intensidade $P$, conforme ilustrado pela Fig. 5.11. Para tal, a investigação desse problema será por intermédio de parâmetros adimensionais. Assim, trabalharemos com a seguinte relação:

$$
K_{\text {norm }}=\frac{K_{I}}{K_{0}}=\frac{K_{I}}{\sigma_{0} \sqrt{\pi a}},
$$

o que faz com que o fator de intensidade de tensões dependa unicamente dos fatores geométricos do problema. O exemplo será resolvido para diferentes valores de $a / B$, sendo comparados com a solução empírica de Koiter: 


$$
K_{\text {norm_Koiter }}=\frac{1-0,5(a / b)+0,370(a / b)^{2}-0,044(a / b)^{3}}{\sqrt{1-a / b}} .
$$

A solução por aproximação assintótica de Koiter garante um erro relativo máximo igual a $1 \%$ para qualquer valor de $a / B$.

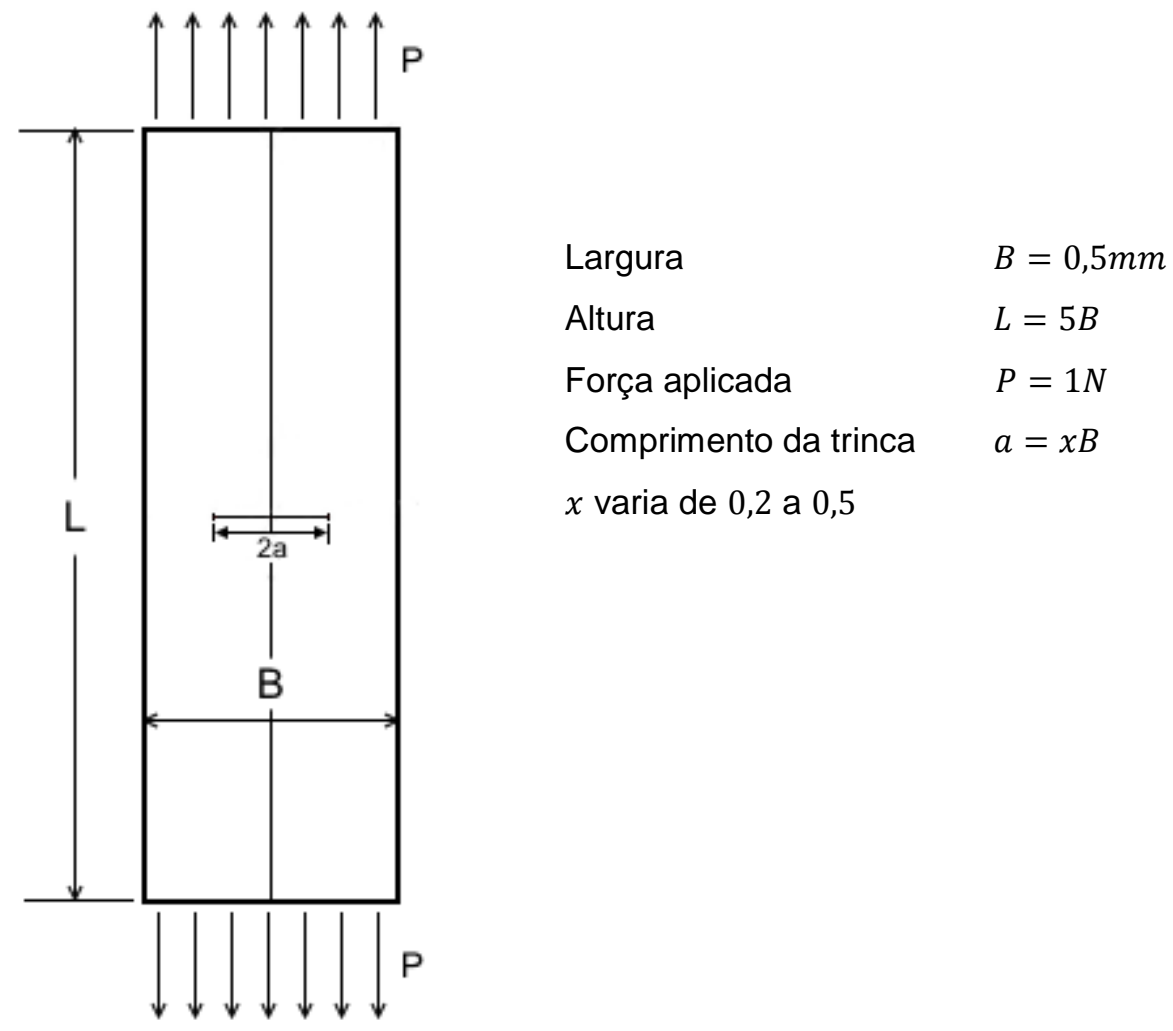

Figura 5.11 O problema da placa com trinca central

\subsubsection{Resultados Numéricos}

Conforme exposto no Capítulo 3 deste trabalho, a utilização de apenas uma equação integral para solucionar o exemplo em epígrafe dá origem a um problema mal posto, uma vez que a formulação do MEC se depara com uma degeneração matemática expressa pelo surgimento de dois pontos fontes na trinca. Dessa forma, problemas de geometria degenerada são normalmente resolvidos pelo MECD. Aqui, a EICC será aplicada em uma das faces da trinca, enquanto que a $\mathrm{EICH}$ solucionará para os elementos da face oposta.

O contorno do problema foi discretizado, inicialmente, com 24 elementos de contorno quadráticos descontínuos. A formulação tradicional do MECD foi aplicada, tendo a malha sido refinada de forma igual até que a solução para o fator de 
intensidade de tensões atingisse a convergência. Em comparação, o MECD adaptativo foi utilizado com o mesmo propósito, no qual os indicadores de erro apontaram os elementos com as maiores descontinuidades do problema, permitindo um refinamento localizado, e, consequentemente, a obtenção de uma solução mais precisa e de forma mais eficiente, como será demonstrada por meio dos resultados então obtidos.

Há de se observar que, ante a primeira iteração da solução pelo MECD adaptativo para $a / B=0,5$, os indicadores de erros dos elementos que discretizam a trinca apresentaram exatamente o mesmo valor (Tabela 5.5a), como era de se esperar, dada a natureza simétrica do problema. Assim, todos os elementos da trinca foram refinados por igual. Embora a solução numérica tenha atingido a convergência na primeira iteração, os indicadores de erro calculados para a eventual continuidade do processo de refinamento adaptativo têm seus valores dispostos na Tabela 5.5b. Percebe-se que, conquanto o elemento 27 (Fig. 5.12) apresente o maior indicador de erro calculado, este valor diverge do calculado para o elemento 22 apenas na nona casa decimal. Assim, faz-se importante informar que os valores relacionados aos indicadores de erro foram considerados apenas até a sétima casa decimal, tendo em vista que diferenciações das últimas casas decimais estão relacionadas a erros de truncamento, que são intrínsecos à própria análise numérica.

Tabela 5.5 Valores para os indicadores de erro nas (a) $1^{\text {a}}$ iteração e (b) $2^{\underline{a}}$ iteração

\begin{tabular}{|c|c|}
\hline \multicolumn{2}{|c|}{$\mathbf{1}^{\text {a }}$ Iteração } \\
\hline Elemento & Indicador de Erro \\
\hline 21 & 0,000344108931894 \\
\hline 22 & 0,000344108931894 \\
\hline 23 & 0,000344108931894 \\
\hline 24 & 0,000344108931894 \\
\hline
\end{tabular}

\begin{tabular}{|c|c|}
\hline \multicolumn{2}{|c|}{$\mathbf{2}^{\mathbf{a}}$ Iteração } \\
\hline Elemento & Indicador de Erro \\
\hline 21 & 0,000363015271660 \\
\hline 22 & 0,000488506726590 \\
\hline 23 & 0,000133516495825 \\
\hline 24 & 0,000008025040895 \\
\hline 25 & 0,000008025040895 \\
\hline 26 & 0,000133516495825 \\
\hline 27 & 0,000488533820628 \\
\hline 28 & 0,000363042365699 \\
\hline
\end{tabular}




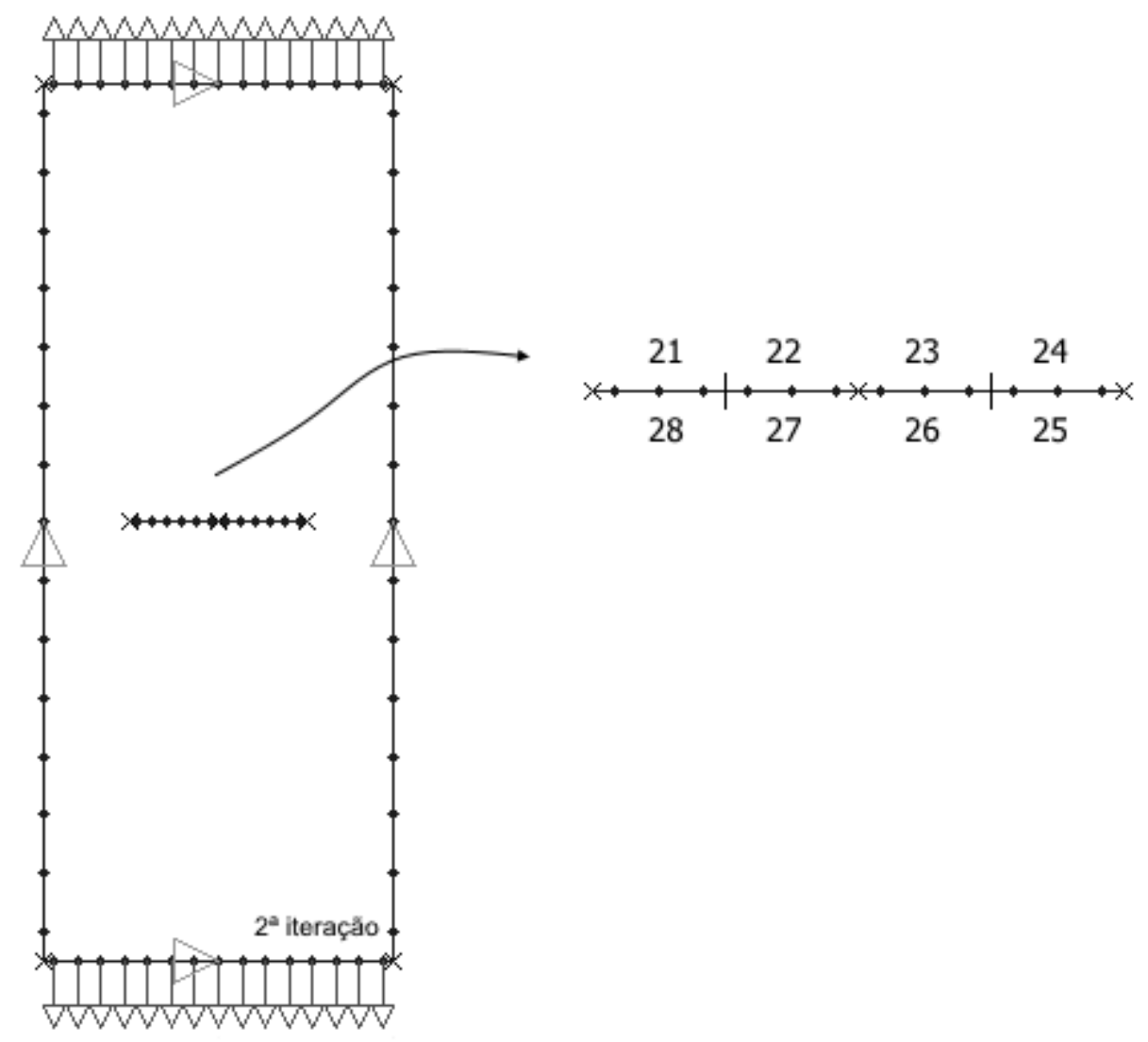

Figura 5.12 Elementos da trinca em detalhe para a $2^{\underline{a}}$ iteração

Tabela 5.6 Resultados para o fator de intensidade de tensão para a/B=0,5 - MECD adaptativo

\begin{tabular}{cccccc}
\hline Iteração & $\begin{array}{c}\text { Pontos de } \\
\text { Colocação }\end{array}$ & K & Erro (\%) & Tempo (s) & Refinamento \\
\hline $\mathbf{0}$ & 72 & 2,1213 & 79,20 & 2,3 & - \\
$\mathbf{1}$ & 84 & 1,1839 & 0,016 & 6,3 & Elementos 21 ao 24 \\
\hline
\end{tabular}

Tabela 5.7 Resultados para o fator de intensidade de tensão para $a / B=0,5-M E C D$ convencional

\begin{tabular}{cccccc}
\hline Iteração & $\begin{array}{c}\text { Pontos de } \\
\text { Colocação }\end{array}$ & K & Erro (\%) & Tempo (s) & Refinamento \\
\hline $\mathbf{0}$ & 72 & 2,1213 & 79,20 & 2,3 & - \\
$\mathbf{1}$ & 120 & 1,1941 & 0,670 & 6,3 & Todos \\
\hline
\end{tabular}

Tabela 5.8 Resultados para o fator de intensidade de tensão para $a / B=0,4-M E C D$ adaptativo

\begin{tabular}{cccccc}
\hline Iteração & $\begin{array}{c}\text { Pontos de } \\
\text { Colocação }\end{array}$ & K & Erro (\%) & Tempo (s) & Refinamento \\
\hline $\mathbf{0}$ & 72 & 1,1522 & 3,86 & 2,36 & - \\
$\mathbf{1}$ & 84 & 1,1161 & 0,60 & 2,76 & Trinca \\
$\mathbf{2}$ & 96 & 1,1125 & 0,28 & 3,60 & Trinca \\
\hline
\end{tabular}


Tabela 5.9 Resultados para o fator de intensidade de tensão para a/B=0,4 - MECD convencional

\begin{tabular}{cccccc}
\hline Iteração & $\begin{array}{c}\text { Pontos de } \\
\text { Colocação }\end{array}$ & K & Erro (\%) & Tempo (s) & Refinamento \\
\hline $\mathbf{0}$ & 72 & 1,1522 & 3,86 & 2,36 & - \\
\hline $\mathbf{1}$ & 120 & 1,1107 & 0,12 & 4,44 & Tudo \\
\hline
\end{tabular}

Tabela 5.10 Resultados para o fator de intensidade de tensão para a/B=0,3 - MECD adaptativo

\begin{tabular}{cccccc}
\hline Iteração & $\begin{array}{c}\text { Pontos de } \\
\text { Colocação }\end{array}$ & K & Erro (\%) & Tempo (s) & Refinamento \\
\hline $\mathbf{0}$ & 72 & 1,2507 & 18,62 & 2,76 & - \\
$\mathbf{1}$ & 84 & 1,0617 & 0,70 & 2,78 & Trinca \\
$\mathbf{2}$ & 96 & 1,0590 & 0,44 & 3,24 & Trinca \\
\hline
\end{tabular}

Tabela 5.11 Resultados para o fator de intensidade de tensão para $a / B=0,3-M E C D$ convencional

\begin{tabular}{cccccc}
\hline Iteração & $\begin{array}{c}\text { Pontos de } \\
\text { Colocação }\end{array}$ & K & Erro (\%) & Tempo (s) & Refinamento \\
\hline $\mathbf{0}$ & 72 & 1,2507 & 18,63 & 2,76 & - \\
\hline $\mathbf{1}$ & 120 & 1,0580 & 0,35 & 4,56 & Tudo \\
\hline
\end{tabular}

Tabela 5.12 Resultados para o fator de intensidade de tensão para $a / B=0,2-M E C D$ adaptativo

\begin{tabular}{cccccc}
\hline Iteração & $\begin{array}{c}\text { Pontos de } \\
\text { Colocação }\end{array}$ & K & Erro (\%) & Tempo (s) & Refinamento \\
\hline $\mathbf{0}$ & 72 & 1,2086 & 18,21 & 2,28 & - \\
\hline $\mathbf{1}$ & 84 & 1,0269 & 0,44 & 3,29 & Trinca \\
\hline
\end{tabular}

Tabela 5.13 Resultados para o fator de intensidade de tensão para $a / B=0,2-M E C D$ convencional

\begin{tabular}{cccccc}
\hline Iteração & $\begin{array}{c}\text { Pontos de } \\
\text { Colocação }\end{array}$ & $\mathbf{K}$ & Erro (\%) & Tempo (s) & Refinamento \\
\hline $\mathbf{0}$ & 72 & 1,2086 & 18,21 & 2,28 & - \\
\hline $\mathbf{1}$ & 120 & 1,0242 & 0,18 & 4,54 & Tudo \\
\hline
\end{tabular}

Conforme demonstram os resultados, a formulação adaptativa do MECD apresenta, de forma geral, resultados mais precisos frente a uma convergência mais rápida. Os gráficos das Figuras 5.13 e 5.14 mostram a situação em que, embora a solução produzida pelo MECD tradicional seja mais precisa do que a encontrada pela técnica de refinamento adaptativo, a convergência dessa última formulação do MECD 
é sensivelmente mais rápida. O gráfico da Fig. 5.15 mostra o contraste entre os melhores resultados do MECD convencional e MECD adaptativo, quando comparados com a solução empírica de Koiter para os valores de $a / B=0,2$ até 0,5 ., demonstrando, ademais, a concordância entre as três curvas.

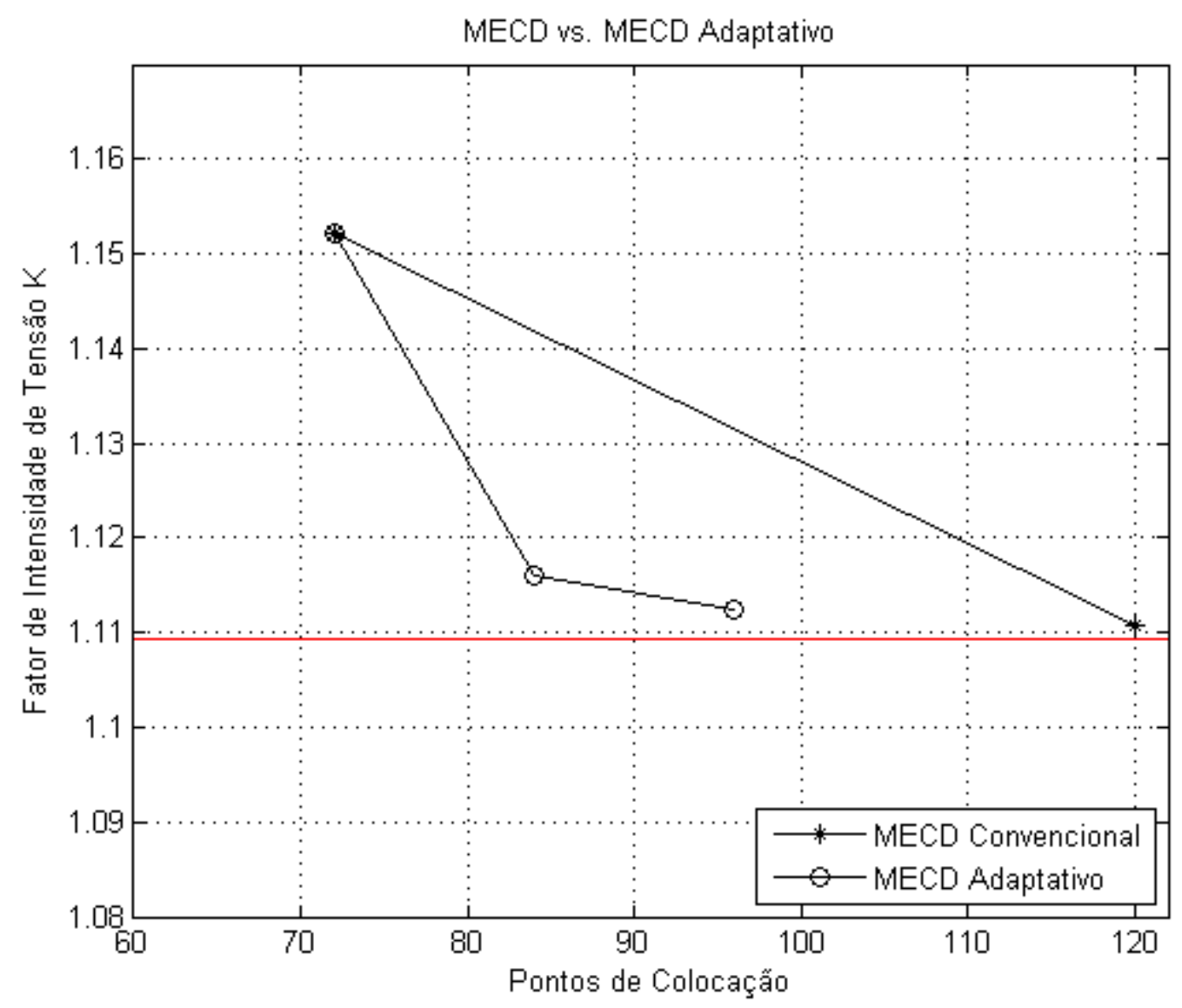

Figura 5.13 Análise de convergência das soluções obtidas com o MECD Convencional e MECD Adaptativo 


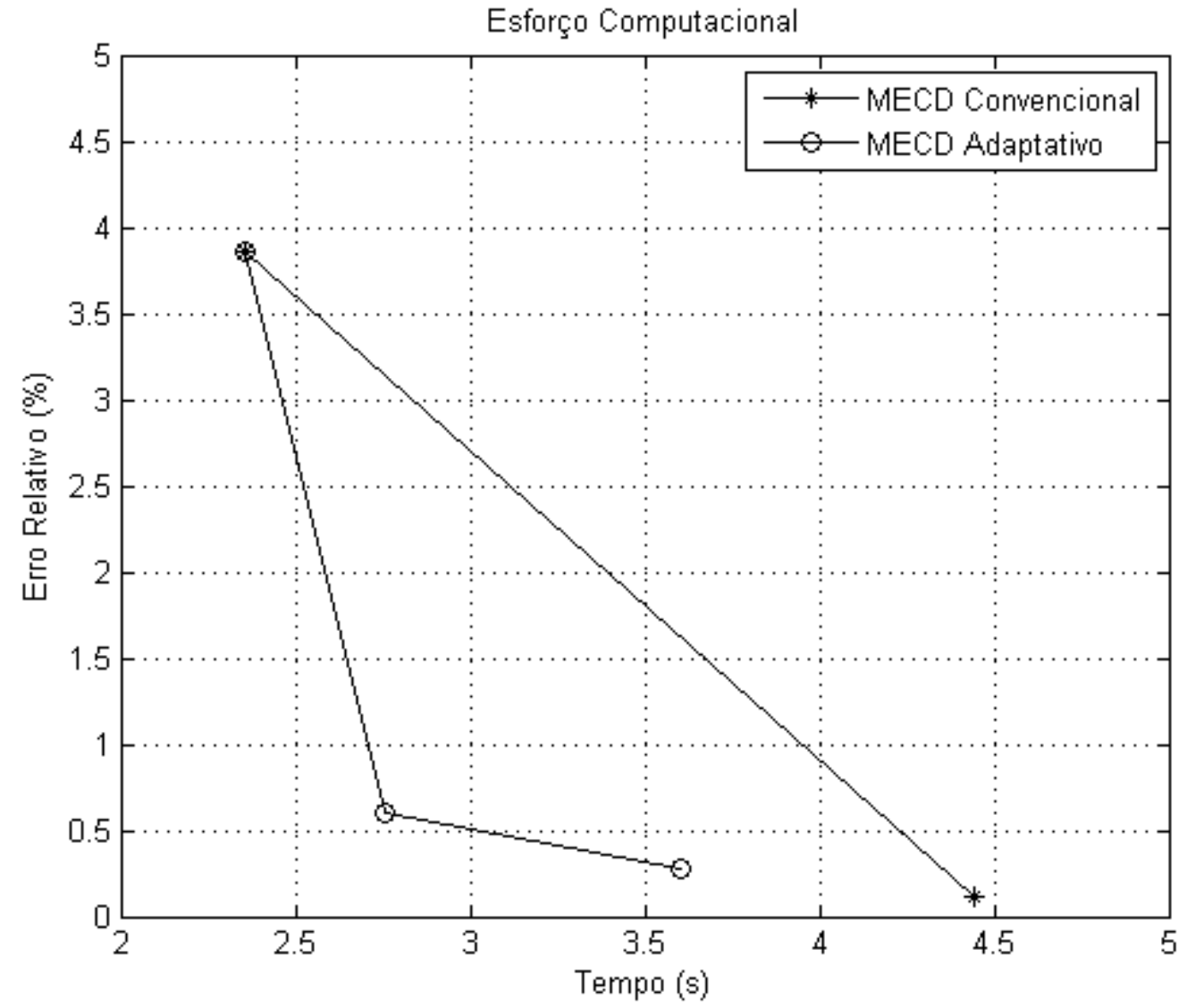

Figura 5.14 Análise de esforço computacional entre os dois métodos de solução 


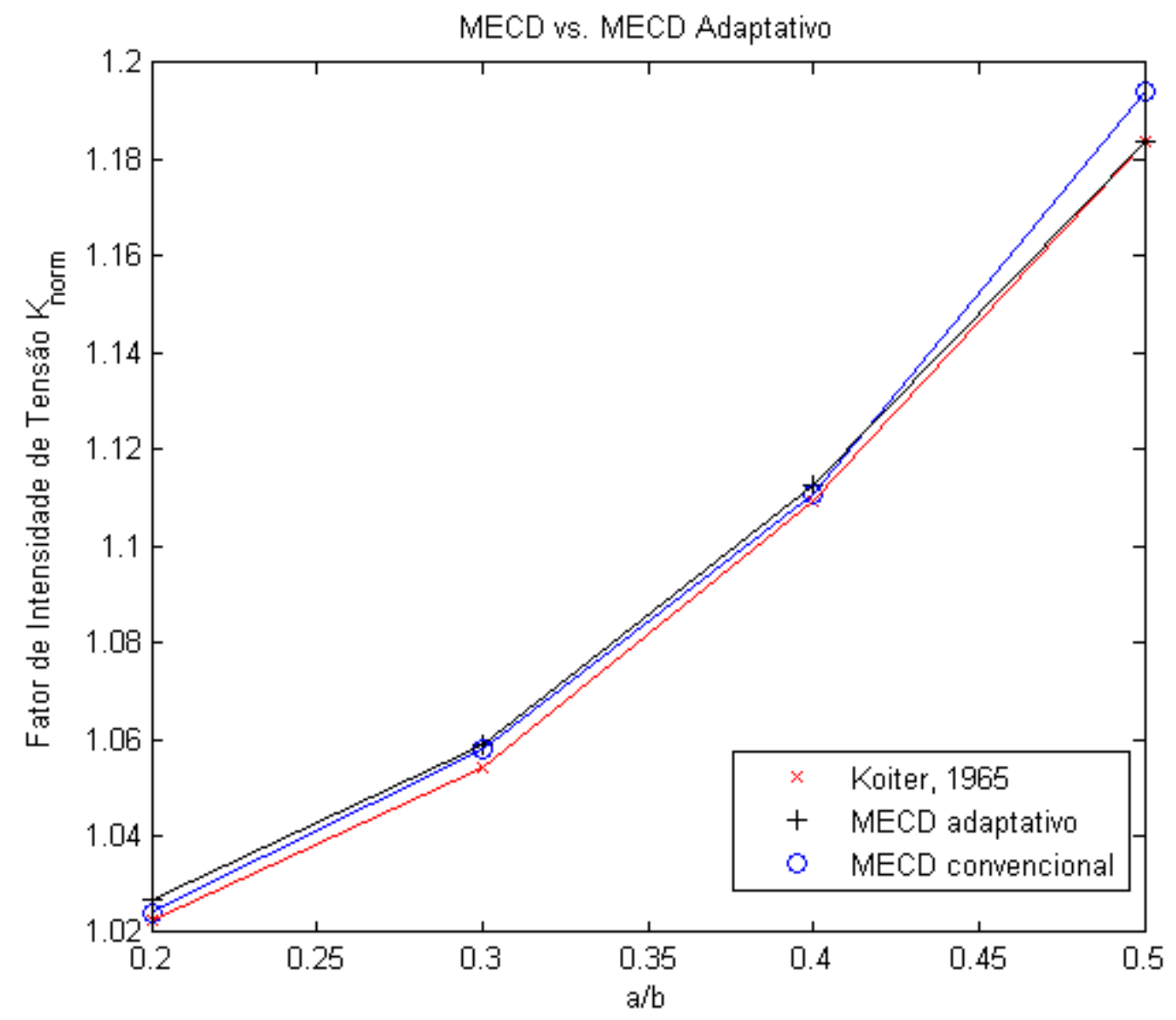

Figura 5.15 Comparação do fator de intensidade de tensão para diferentes valores de a/b

\subsubsection{Placa com Trinca de Borda}

\subsubsection{Introdução}

O último exemplo resolvido com o intuito de validar o algoritmo de refinamento adaptativo incorporado à formulação dual do MEC é o problema da placa com uma trinca de borda. Diferentemente do exemplo apresentado em 5.3.1, a placa com trinca de borda não possui simetria que permita a discretização de apenas parte da placa, tendo o problema de ser resolvido com o MECD.

Nesse exemplo, conforme ilustrado pela Fig. 5.16, o fator de intensidade de tensões em modo de abertura $K_{I}$ ainda influi no campo de tensões e deformações do modelo trincado, considerando que a placa está unicamente sob efeito de força trativa - no sentido de abertura da trinca. As soluções do MECD convencional e MECD adaptativo foram comparadas com a solução empírica obtida por Tada em 1973, que garante erro inferior a $1 \%$ para $a / B<0,2$ e $0,5 \%$ para $a / B \geq 0,2$ (39). 


\subsubsection{Definição do Problema}

Considere uma placa de comprimento infinito, de largura $B$ e com uma trinca de borda de comprimento $a$, sob os efeitos de uma força trativa de intensidade $P$, conforme ilustrado pela Fig. 5.16. A exemplo do disposto em 5.3.1, a investigação desse problema será por intermédio de parâmetros adimensionais.

A solução empírica obtida por Tada (39) consiste na relação:

$K_{\text {norm_tada }}=\sqrt{\frac{2 b}{\pi a} \tan \frac{\pi a}{2 b}} \cdot \frac{0,752+2,02(a / b)+0,37(1-\sin \pi a / 2 b)^{3}}{\cos \frac{\pi a}{2 b}}$.

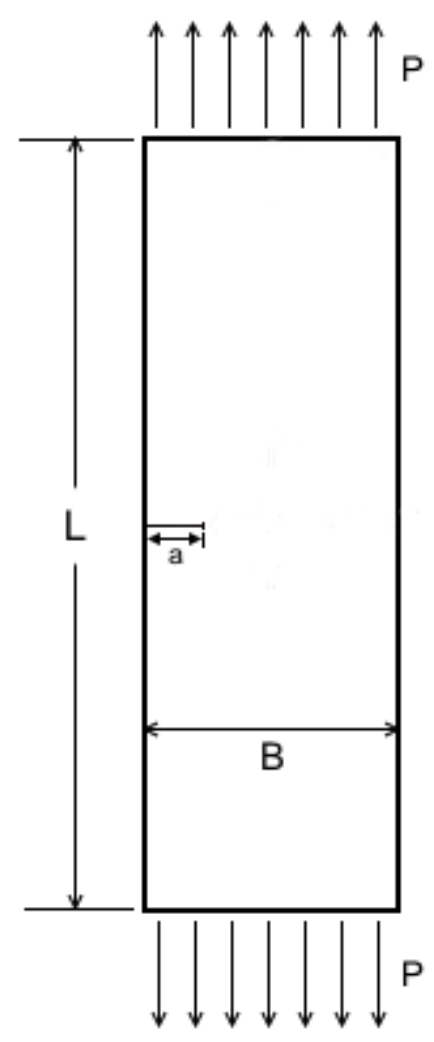

Largura

Altura

Força aplicada

Comprimento da trinca

$x$ varia de 0,4 a 0,7
$B=0,5 \mathrm{~mm}$

$L=5 B$

$P=1 N$

$a=x B$

Figura 5.160 problema da placa com trinca de borda sob tração

\subsubsection{Resultados Numéricos}

O contorno do problema foi discretizado, inicialmente, com 60 elementos de contorno quadráticos descontínuos. A formulação tradicional do MECD foi aplicada, tendo a malha sido refinada de forma igual até que a solução para o fator de intensidade de tensões atingisse a convergência. Em comparação, o MECD adaptativo foi utilizado 
com o mesmo propósito, no qual os indicadores de erro apontaram os elementos com as maiores descontinuidades do problema, permitindo um refinamento localizado, da mesma forma que o realizado para a placa com trinca central sob tração.

Diferentemente do ocorrido no exemplo anterior, os indicadores de erros dos elementos que discretizam a trinca apresentaram valores distintos (Tabela 5.14a), inicialmente. O resultado já era esperado, considerando que o problema em questão não se define como simétrico. De maneira semelhante ao que foi feito em 5.2.1, os elementos 47 e 48 da Fig. 5.17 foram refinados para a primeira iteração. Na segunda iteração, os indicadores de erro apontaram os elementos 49 e 50 como os possuidores de maior descontinuidade (Tabela 5.14b). A tendência de refinamento assinala para os elementos mais próximos da extremidade direita da ponta da trinca, o que valida 0 algoritmo de adaptatividade no que concerne o comportamento mecânico da trinca definido pelas teorias que compõem a disciplina de Mecânica da Fratura. Refinando esses elementos, a solução atinge a convergência em duas iterações, para uma malha de 198 pontos de colocação, cuja solução possui $0,48 \%$ de erro relativo para a solução empírica de Tada (Eq. 5.8).

Tabela 5.14 Valores para os indicadores de erro nas (a) $1^{\underline{a}}$ iteração e (b) $2^{\underline{a}}$ iteração

\begin{tabular}{|c|c|}
\hline \multicolumn{2}{|c|}{$\mathbf{1}^{\mathbf{a}}$ Iteração } \\
\hline Elemento & Indicador de Erro \\
\hline 46 & 0,000000012610476 \\
\hline 47 & 0,000027013740088 \\
\hline 48 & 0,000027013742529 \\
\hline 49 & 0,00000001260983 \\
\hline
\end{tabular}

\begin{tabular}{|c|c|}
\hline \multicolumn{2}{|c|}{$\mathbf{2}^{\mathbf{a}}$ Iteração } \\
\hline Elemento & Indicador de Erro \\
\hline 46 & 0,000000000167806 \\
\hline 47 & 0,000000000074654 \\
\hline 48 & 0,000000003737000 \\
\hline 49 & 0,000006676613952 \\
\hline 50 & 0,000006676614373 \\
\hline 51 & 0,000000003737625 \\
\hline 52 & 0,000000000077796 \\
\hline 53 & 0,000000000204731 \\
\hline
\end{tabular}




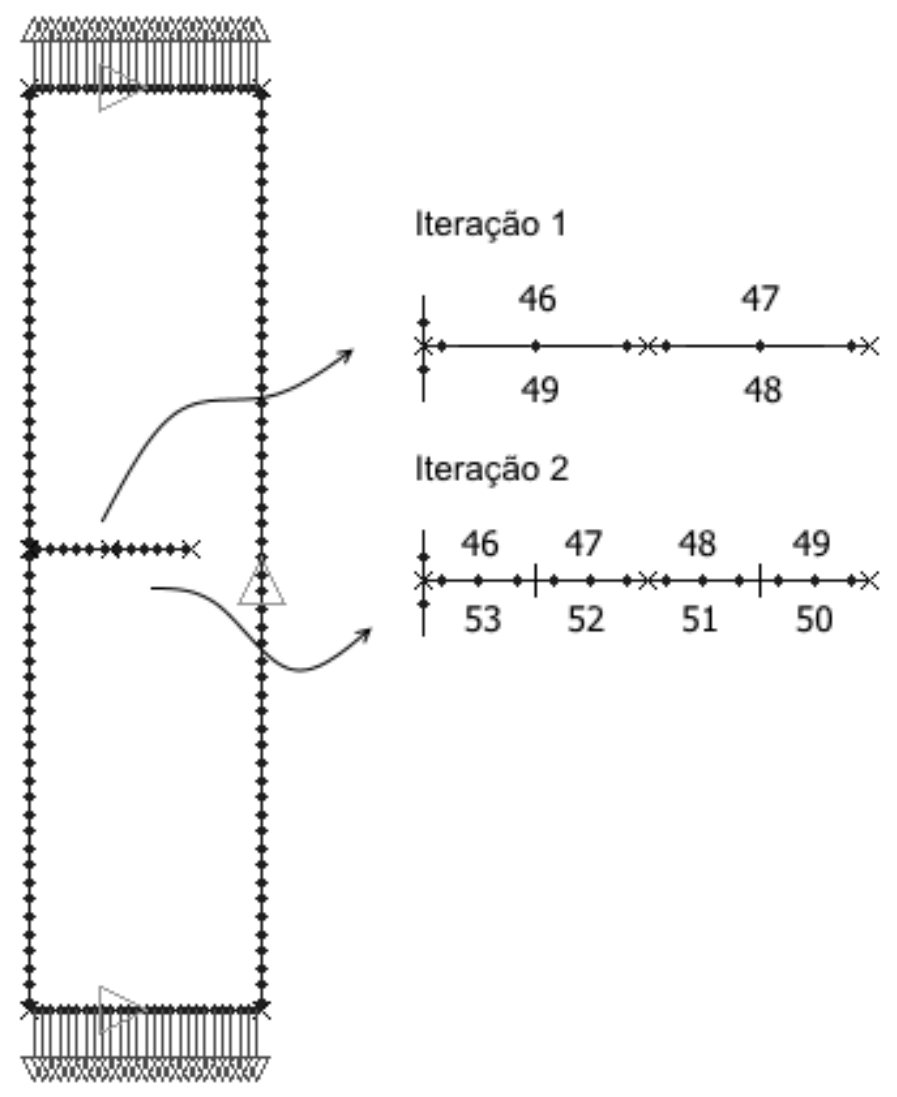

Figura 5.17 Elementos da trinca em detalhe para ambas as iterações

Tabela 5.15 Resultados para o fator de intensidade de tensão para $a / B=0,7-M E C D$ adaptativo

\begin{tabular}{cccccc}
\hline Iteração & $\begin{array}{c}\text { Pontos de } \\
\text { Colocação }\end{array}$ & K & Erro (\%) & Tempo (s) & Refinamento \\
\hline $\mathbf{0}$ & 174 & 5,2348 & 17,89 & 7,03 & - \\
$\mathbf{1}$ & 186 & 6,5636 & 2,95 & 7,66 & Elementos 47 e 48 \\
$\mathbf{2}$ & 198 & 6,3351 & 0,48 & 8,02 & Elementos 49 e 50 \\
\hline
\end{tabular}

Tabela 5.16 Resultados para o fator de intensidade de tensão para $a / B=0,7$ - MECD convencional

\begin{tabular}{cccccc}
\hline Iteração & $\begin{array}{c}\text { Pontos de } \\
\text { Colocação }\end{array}$ & K & Erro (\%) & Tempo (s) & Refinamento \\
\hline $\mathbf{0}$ & 174 & 5,2348 & 17,89 & 7,03 & - \\
$\mathbf{1}$ & 270 & 6,4340 & 0,92 & 14,79 & Tudo \\
\hline
\end{tabular}

Tabela 5.17 Resultados para o fator de intensidade de tensão para a/B=0,6 - MECD adaptativo

\begin{tabular}{cccccc}
\hline Iteração & $\begin{array}{c}\text { Pontos de } \\
\text { Colocação }\end{array}$ & K & Erro (\%) & Tempo (s) & Refinamento \\
\hline $\mathbf{0}$ & 180 & 3,9771 & 1,63 & 8,12 & - \\
$\mathbf{1}$ & 186 & 4,0239 & 0,48 & 7,96 & Trinca \\
\hline
\end{tabular}


Tabela 5.18 Resultados para o fator de intensidade de tensão para $a / B=0,6$ - MECD convencional

\begin{tabular}{cccccc}
\hline Iteração & $\begin{array}{c}\text { Pontos de } \\
\text { Colocação }\end{array}$ & K & Erro (\%) & Tempo (s) & Refinamento \\
\hline $\mathbf{0}$ & 180 & 3,9771 & 1,63 & 8,12 & - \\
$\mathbf{1}$ & 270 & 4,0174 & 0,63 & 14,39 & Tudo \\
\hline
\end{tabular}

Tabela 5.19 Resultados para o fator de intensidade de tensão para $a / B=0,5-M E C D$ adaptativo

\begin{tabular}{cccccc}
\hline Iteração & $\begin{array}{c}\text { Pontos de } \\
\text { Colocação }\end{array}$ & K & Erro (\%) & Tempo (s) & Refinamento \\
\hline $\mathbf{0}$ & 180 & 2,9924 & 5,87 & 7,41 & - \\
$\mathbf{1}$ & 186 & 2,8145 & 0,43 & 7,82 & Trinca \\
\hline
\end{tabular}

Tabela 5.20 Resultados para o fator de intensidade de tensão para a/B=0,5 - MECD convencional

\begin{tabular}{cccccc}
\hline Iteração & $\begin{array}{c}\text { Pontos de } \\
\text { Colocação }\end{array}$ & K & Erro (\%) & Tempo (s) & Refinamento \\
\hline $\mathbf{0}$ & 180 & 2,9924 & 5,87 & 7,41 & - \\
$\mathbf{1}$ & 270 & 2,7767 & 1,76 & 4,56 & Tudo \\
\hline
\end{tabular}

Tabela 5.21 Resultados para o fator de intensidade de tensão para a/B=0,4 - MECD adaptativo

\begin{tabular}{cccccc}
\hline Iteração & $\begin{array}{c}\text { Pontos de } \\
\text { Colocação }\end{array}$ & K & Erro (\%) & Tempo (s) & Refinamento \\
\hline $\mathbf{0}$ & 180 & 2,5438 & 20,67 & 8,53 & - \\
$\mathbf{1}$ & 186 & 2,2475 & 6,62 & 7,73 & Trinca \\
$\mathbf{2}$ & 192 & 2,1178 & 0,47 & 8,46 & Trinca \\
\hline
\end{tabular}

Tabela 5.22 Resultados para o fator de intensidade de tensão para a/B=0,4 - MECD convencional

\begin{tabular}{cccccc}
\hline Iteração & $\begin{array}{c}\text { Pontos de } \\
\text { Colocação }\end{array}$ & K & Erro (\%) & Tempo (s) & Refinamento \\
\hline $\mathbf{0}$ & 180 & 2,5438 & 20,67 & 8,53 & - \\
$\mathbf{1}$ & 270 & 2,1159 & 0,37 & 9,54 & Tudo \\
\hline
\end{tabular}

A Fig. (5.18) demonstra que o fator de intensidade de tensão calculado pelo MEC adaptativo converge para a solução empírica de Tada utilizando uma quantidade inferior de pontos de colocação quando comparada à análise pelo MEC convencional. Tal característica se reflete no tempo de processamento também inferior que o MEC adaptativo leva para produzir um resultado com erro relativo sensivelmente inferior ao produzido com o MEC convencional (Fig. 5.19). Ademais, a exemplo do problema anterior, a Fig. (5.20) demonstra a compatibilidade entre as três soluções. 


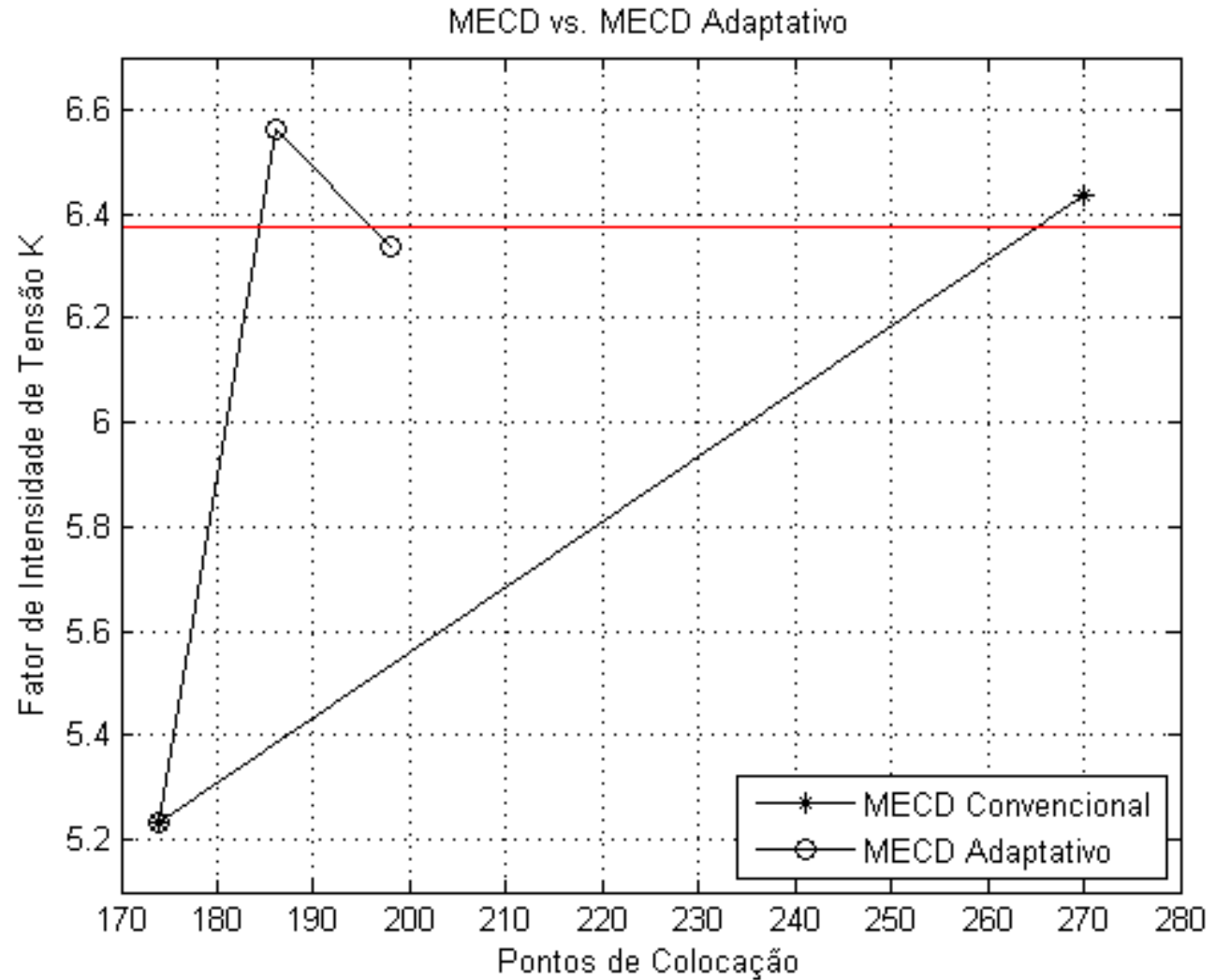

Figura 5.18 Análise de convergência das soluções obtidas com o MECD Convencional e MECD Adaptativo

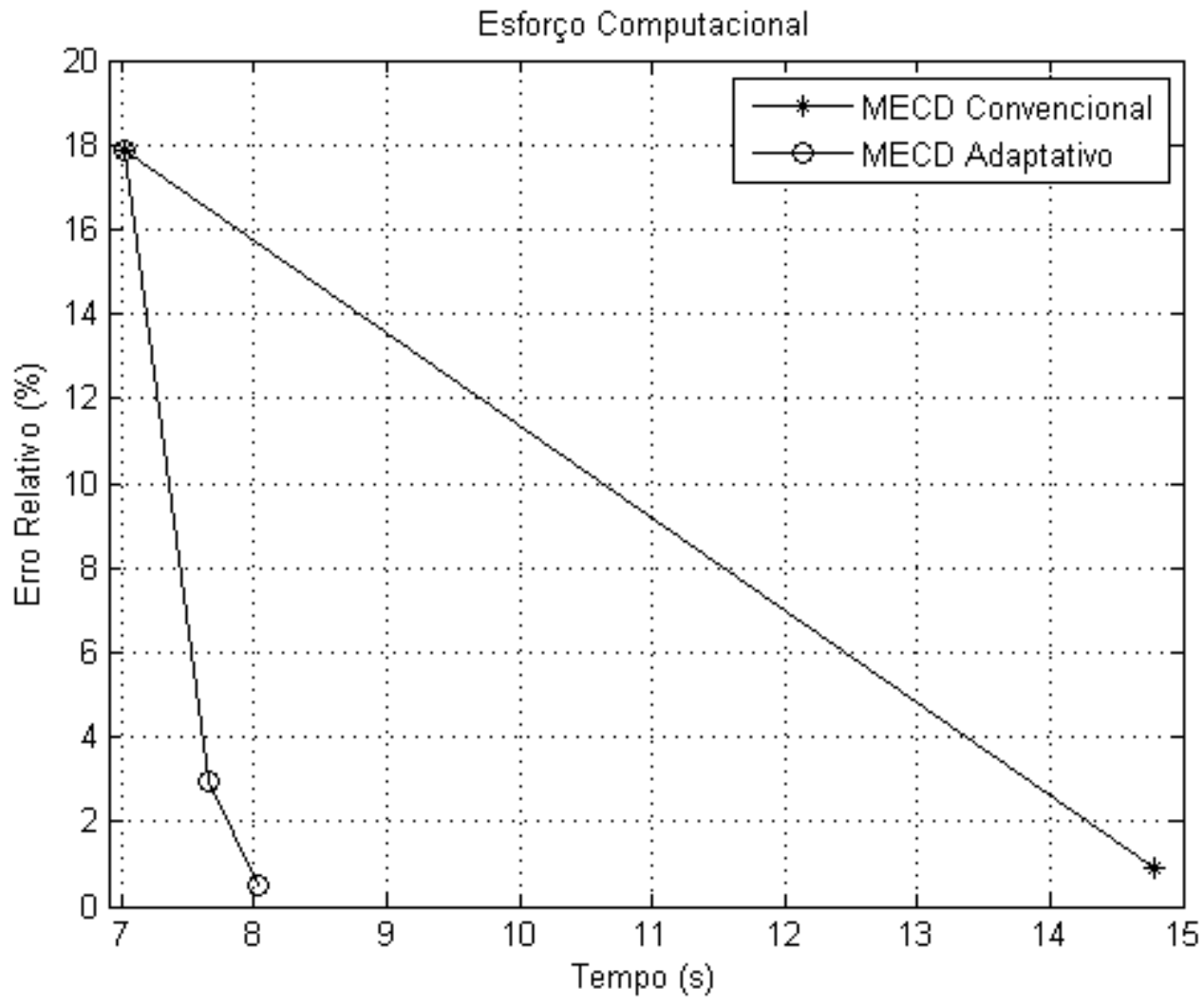

Figura 5.19 Análise de esforço computacional entre os dois métodos de solução 


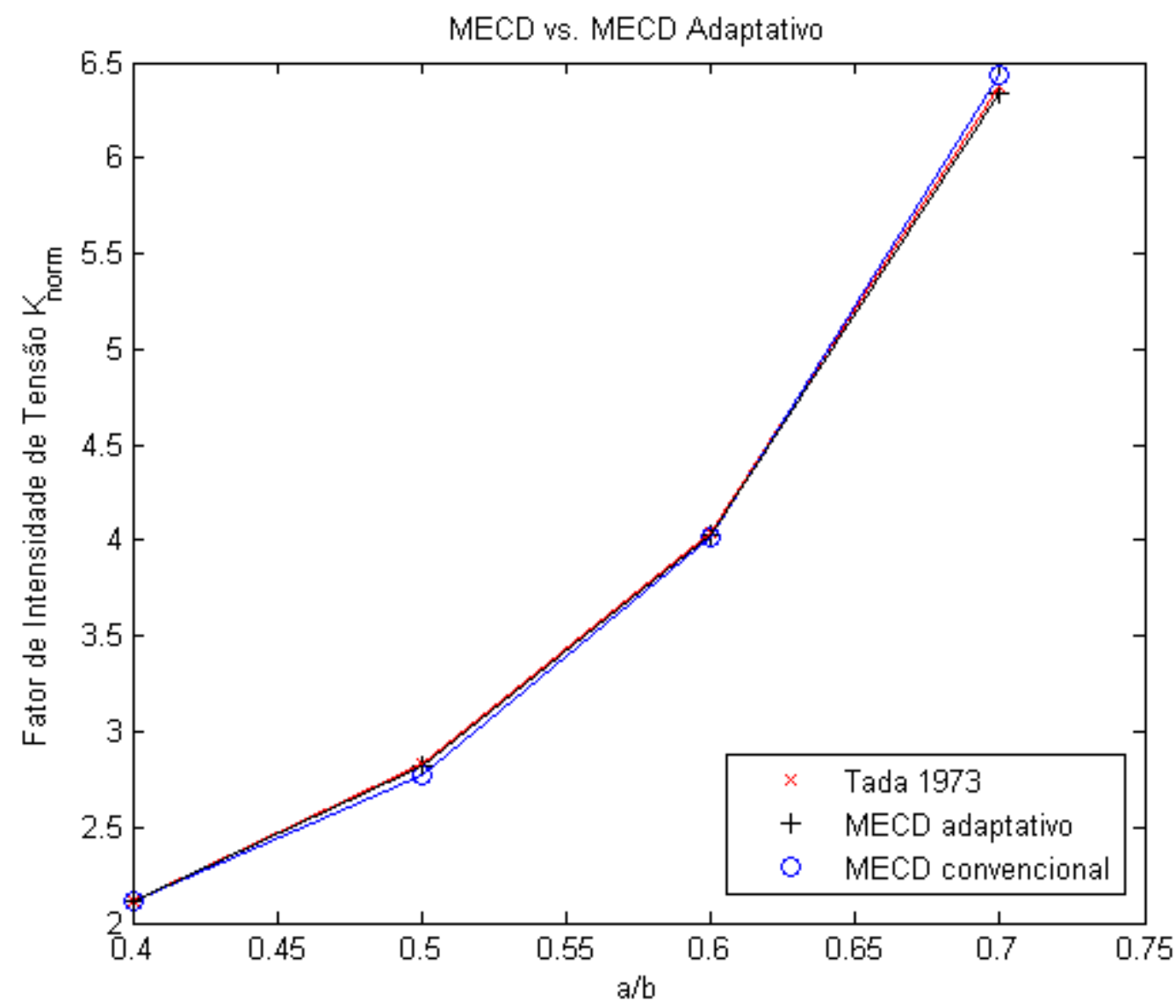

Figura 5.20 Comparação do fator de intensidade de tensão para diferentes valores de a/b 


\section{CONSIDERAÇÕES FINAIS}

\subsection{CONCLUSÕES}

O presente trabalho teve por principal objetivo o desenvolvimento de um algoritmo de refinamento adaptativo tipo $h$, baseado em um processo simples de estimativa de erro, introduzido por Portela (54), que faz uso da própria natureza dos elementos de contorno descontínuos ao computar as descontinuidades das soluções calculadas ao longo do contorno entre elementos adjacentes. Dessa forma, é possível identificar o elemento com a maior porcentagem de erro, permitindo o refinamento localizado da malha.

Esse algoritmo de refinamento adaptativo foi implantado junto à formulação elástica 2D do $M E C$, bem como à sua forma dual (MECD), o que permitiu a solução de problemas elásticos em duas dimensões, além de problemas de geometria degenerada. Os problemas foram escolhidos de modo a permitirem a validação da técnica aqui proposta, mediante a comparação das soluções numéricas às soluções analíticas e empíricas dos problemas resolvidos.

O Capítulo 5 apresentou a solução de quatro problemas. Dentre eles, dois exemplos clássicos da teoria de elasticidade plana: (i)- o problema da viga fina de Timoshenko, que dá origem ao surgimento de núcleos quase-singulares nas equações integrais, dificultando a solução pela formulação elástica tradicional do MEC; (ii)- o problema da placa com furo circular sob tração, cujo campo de tensão é influenciado por um concentrador de tensão que varia em função do ângulo que o diâmetro faz com o sentido da força de tração nos extremos da placa. Além de dois problemas clássicos da mecânica da fratura: (iii)- o exemplo da placa de largura $B$ e comprimento infinito com trinca central, o qual foi solucionado pelo MECD; (iv)- uma placa de largura $B$ e comprimento infinito com trinca de borda, também solucionado pelo MECD. 
A solução dos problemas acima descritos nos permite concluir:

- Problema (i): Os gráficos obtidos demonstram a efetividade da técnica empregada. Em uma análise comparativa entre os métodos de solução desenvolvidos (formulação clássica do MEC e MEC adaptativo), percebemos que a solução produzida com o MEC adaptativo não só é mais precisa (apenas $0,0687 \%$ de erro), como atinge a convergência aproximadamente $90 \%$ mais rápido. Ademais, o refinamento adaptativo atenuou as oscilações provocadas pelas integrais quase-singulares, provando que mesmo a formulação tradicional do MEC, juntamente ao refinamento de locais específicos do contorno, produz soluções confiáveis e tecnicamente viáveis;

- Problema (ii): O problema da placa com furo circular também foi solucionado com rapidez. O algoritmo responsável pelo cálculo das porcentagens de erro por elemento indicou a necessidade de refinamento em elementos nas intermediações do ponto de maior tensão. Com apenas 6 iterações e 39 pontos de colocação, a solução numérica atingiu a convergência com erro relativo de apenas $0,14 \%$;

- Problema (iii): O MECD adaptativo também se mostrou deveras efetivo ao solucionar o problema clássico da placa com trinca central. Os resultados foram obtidos para diferentes valores de $a / B$, quociente que representa a razão entre a metade do comprimento da trinca e a largura da placa. $O$ fator de intensidade de tensão foi calculado por meio da Integral $J$, produzindo resultados abaixo do limite de $0,5 \%$ de erro entre a solução numérica e a solução empírica de Koiter.

- Problema (iv): Para a placa com trinca de borda, o algoritmo de refinamento adaptativo revelou uma tendência de refinamento perto da ponta da trinca, no extremo oposto do limite externo da placa, o que caracteriza compatibilidade com o comportamento mecânico real do material em análise. A simulação com o MECD adaptativo produziu bons resultados, muitas vezes mais precisos do que os produzidos com o MECD convencional diante de uma malha mais refinada. A nível de comparação, para $a / B=0,5$, O MECD adaptativo mostrou apenas 
0,43\% de erro se comparado à solução empírica de Tada, utilizando uma malha com 186 pontos de colocação, frente a uma solução de 1,76\% de erro produzida com o MECD convencional, utilizando uma malha contendo 270 pontos de colocação.

De forma geral, frente a todos os resultados obtidos, concluímos que o algoritmo de refinamento adaptativo proposto neste trabalho foi capaz de gerar soluções mais precisas que as produzidas com refinamento uniforme, fazendo uso de um menor custo computacional, o que torna a técnica extremamente atrativa para aplicação prática.

\subsection{TRABALHOS FUTUROS}

Apontamos, a seguir, algumas sugestões para a continuidade do desenvolvimento da técnica de adaptatividade apresentada neste trabalho.

- Aplicar o algoritmo de refinamento adaptativo a formulações elásticas em 3D do MEC e MECD;

- Desenvolver o refinamento adaptativo tipo $p$, que, juntamente com a técnica de refinamento tipo $h$ proposta, integrará um modo misto de refinamento;

- Aplicar a técnica de refinamento adaptativo a formulações rápidas do MEC, como o Método dos Elementos de Contorno com Expansão em Multipolos;

- Investigar a possibilidade de resolução de problemas de propagação de trincas com o MECD adaptativo. 


\section{REFERÊNCIAS}

(1) CHENG, Alexander H.-D.; CHENG, Daisy T. Heritage and early history of the boundary element method. Engineering Analysis with Boundary Elements, v. 29, n. 3, p. 268-302, 2005.

(2) SOMIGLIANA, Carlo. Sopra l'equilibrio di un corpo elastico isotropo./l Nuovo Cimento (1877-1894), v. 17, n. 1, p. 140-148, 1885.

(3) FREDHOLM, Ivar. Sur une classe d'équations fonctionnelles.Acta mathematica, v. 27, n. 1, p. 365-390, 1903.

(4) MUSKHELISHVILI, Nikolaĭ Ivanovich. Some basic problems of the mathematical theory of elasticity. Springer Science \& Business Media, 1977.

(5) MIKHLIN, S. G. Integral equations. Pergamon Press, Londres, 1957.

(6) SMIRNOV, Vladimir Ivanovitch. Integral equations and partial differential equations. Pergamon Press, 1964.

(7) KUPRADZE, V. K. Potential methods in elasticity theory. Daniel Davey \& Co., New York, 1965.

(8) KELLOGG, Oliver Dimon et al. Foundations of potential theory. New York., 1929.

(9) JASWON, M. A. Integral equation methods in potential theory. I. Proceedings of the Royal Society of London. Series A, Mathematical and Physical Sciences, p. 23-32, 1963.

(10) SYMM, G. T. Integral equation methods in potential theory. II. Proceedings of the Royal Society of London. Series A. Mathematical and Physical Sciences, v. 275, n. 1360, p. 33-46, 1963.

(11) MASSONNET, C. E. Numerical use of integral procedures. Stress analysis, p. 198-235, 1965.

(12) E OLIVEIRA, Arantes. Plane stress analysis by a general integral method. 1968.

(13) RIZZO, Frank J. An integral equation approach to boundary value problems of classical elastostatics. Quart. Appl. Math, v. 25, n. 1, p. 83-95, 1967.

(14) CRUZE T. A., e RIZZO F. J. A direct formulation and numerical solution of the general transient elastodynamic problem - I. Int. J. Math. Anal. Appl., 22 (1968). 
(15) LACHAT, Jean-Claude. A further development of the boundary integral technique for elastostatics. 1975. Tese de Doutorado. University of Southampton.

(16) LACHAT, J. C.; WATSON, J. O. Effective numerical treatment of boundary integral equations: A formulation for three-dimensional elastostatics. International Journal for Numerical Methods in Engineering, v. 10, n. 5, p. 991-1005, 1976.

(17) CRUZE, T. A. Mathematical foundations of the boundary integral equation method in solid mechanics. Report No. AFOSR-TR-1002 Airforce Office of Scientific Research, 1977.

(18) HONG, Hong-Ki; CHEN, Jeng-Tzong. Derivations of integral equations of elasticity. Journal of Engineering Mechanics, v. 114, n. 6, p. 1028-1044, 1988.

(19) ALIABADI, Mohammad H.; ROOKE, David P. Numerical fracture mechanics. Springer Science \& Business Media, 1991.

(20) BREBBIA, C. A.; DOMINGUEZ, J. Boundary element methods for potential problems. Applied Mathematical Modelling, v. 1, n. 7, p. 372-378, 1977.

(21) PORTELA, Artur. Theoretical basis of boundary solutions for the linear theory of structures. Applied Mathematical Modelling, v. 5, n. 1, p. 57-59, 1981.

(22) PORTElA, A.; ALIABADI, M. H.; ROOKE, D. P. The dual boundary element method: effective implementation for crack problems. International Journal for Numerical Methods in Engineering, v. 33, n. 6, p. 1269-1287, 1992.

(23) CHEN, J. T. On Hadamard principal value and boundary integral formulation of fracture mechanics. Master ThesisNational Taiwan University, Institute of Applied Mechanics, 1986.

(24) CHEN J.T. e HONG H. K. On Hadamard principal value and its application to crack problems through BEM, Proc of 11th Natl Conf. on Theoretical and Applied Mechanics, Taipei, Taiwan, 827-837, 1987.

(25) CHEN, W. H.; CHEN, T. C. An efficient dual boundary element technique for a two-dimensional fracture problem with multiple cracks. International Journal for Numerical Methods in Engineering, v. 38, n. 10, p. 1739-1756, 1995.

(26) GRAY, L. J. Boundary element method for regions with thin internal cavities. Engineering Analysis with Boundary Elements, v. 6, n. 4, p. 180-184, 1989. 
(27) GRAY, L. J.; MARTHA, Luiz F.; INGRAFFEA, A. R. Hypersingular integrals in boundary element fracture analysis. International Journal for Numerical Methods in Engineering, v. 29, n. 6, p. 1135-1158, 1990.

(28) MI, Y.; ALIABADI, M. H. Dual boundary element method for three-dimensional fracture mechanics analysis. Engineering Analysis with Boundary Elements, v. 10, n. 2, p. 161-171, 1992.

(29) CHEN, J. T.; HONG, H.-K. Review of dual boundary element methods with emphasis on hypersingular integrals and divergent series. Applied Mechanics Reviews, v. 52, n. 1, p. 17-33, 1999.

(30) PORTELA, Artur. Dual boundary element incremental analysis of crack growth. 1992. Tese de Doutorado. University of Southampton.

(31) BROEK, David. Elementary engineering fracture mechanics. Springer Science \& Business Media, 1982.

(32) INGLIS, Charles Edward. Stresses in a plate due to the presence of cracks and sharp corners. Spie Milestone series MS, v. 137, p. 3-17, 1997.

(33) GRIFFITH, Alan A. The phenomena of rupture and flow in solids. Philosophical transactions of the royal society of london. Series $A$, containing papers of a mathematical or physical character, p. 163-198, 1921.

(34) ANDERSON, Ted L. Fracture mechanics: fundamentals and applications. CRC press, 2005.

(35) IRWIN, G. R. Relation of stresses near a crack to the crack extension force.9th Cong. App. Mech., Brussels, 1957.

(36) WESTERGAARD, H.M. Bearing pressures and cracks. Trans. ASME. J. AppL Mech., 6, No. 2, A49-A53, 1939.

(37) SATO, Marcel. Modelagem de Problemas da Mecânica da Fratura e Propagação de Trincas em Fadiga. Dissertação de mestrado, Universidade Estadual de Campinas, Campinas, São Paulo, 2009.

(38) IRWIN, George R. Analysis of stresses and strains near the end of a crack traversing a plate. SPIE MILESTONE SERIES MS, v. 137, p. 167-170, 1997.

(39) TADA, Hiroshi; PARIS, P. C.; IRWIN, G. R. The analysis of cracks handbook. New York: ASME Press, 2000. 
(40) WELLS, A.A., Unstable Crack Propagation in Metals: Cleavage and Fast Fracture. Proceedings of the Crack Propagation Symposium, Vol. 1, Paper 84. Cranfield. UK, 1961.

(41) RICE, James R. A path independent integral and the approximate analysis of strain concentration by notches and cracks. Journal of applied mechanics 35.2: 379386, 1968.

(42) RUGGiERO, M. A. G., LOPES, V. L. R. Cálculo Numérico - Aspectos Teóricos e Computacionais. 2ª Edição, Pearson Education, 1996.

(43) BREBBIA, C. A. Variational basis of approximate models in continuum mechanics. Variational methods in engineering, p. 1-23, 1985.

(44) BETTI, Enrico. Teoria della elasticitá./l Nuovo Cimento (1869-1876), v. 7, n. 1, p. 69-97, 1872.

(45) DOVAL, P. C. M. Análise de Estabilidade de Placas de Materiais Compósitos Lamindados usando o Método dos Elementos de Contorno. Tese de doutorado, Universidade Estadual de Campinas, Campinas, São Paulo, 2013.

(46) TELLES, J. C. F. A self adaptative coordinate transformation for efficient numerical evaluation of general boundary element integrals. Int. J. for Numerical Methods in Engn., v. 24, p. 959\{973, 1987.

(47) STROUD, A. H.; SECREST, D. Gaussian Quadrature Formulas. New jersey. Englewood Cliffs: Prentice Hall, 1966.

(48) BREBBIA, C.; DOMINGUEZ, J. Boundary Elements: An Introductory Course. Computational Mechanics Publications, 1989.

(49) MADUREIRA, Maria Luísa Romariz. Estudo do erro e processos adaptativos em problemas de enformação pelo método dos elementos finitos. Tese de doutorado, Universidade do Porto, Porto, Portugal, 1996.

(50) ROACHE, Patrick J. Verification and validation in computational science and engineering. Hermosa, 1998.

(51) PLETCHER, Richard H.; TANNEHILL, John C.; ANDERSON, Dale. Computational fluid mechanics and heat transfer. CRC Press, 2012.

(52) LIAPIS, S. A review of error estimation and adaptivity in the boundary element method. Engineering analysis with boundary elements, v. 14, n. 4, p. 315-323, 1994. 
(53) KITA, E.; KAMIYA, N. Recent studies on adaptive boundary element methods. Advances in Engineering Software, v. 19, n. 1, p. 21-32, 1994.

(54) PORTELA, A. Dual boundary-element method: Simple error estimator and adaptivity. International Journal for Numerical Methods in Engineering, v. 86, n. 12, p. 1457-1480, 2011.

(55) BURDEN, Richard L.; FAIRES, J. Douglas. Numerical analysis. PWS. 1989.

(56) ABE, Kazuhisa. A new residue and nodal error evaluation in h-adaptive boundary element method. Advances in Engineering Software, v. 15, n. 3, p. 231-239, 1992.

(57) CHEN, H. B.; YU, D. H.; SCHNACK, E. A simple a-posteriori error estimation for adaptive BEM in elasticity. Computational mechanics, v. 30, n. 5-6, p. 343-354, 2003. (58) MARTíNEZ-CASTRO, Alejandro E.; GALLEGO, Rafael. Tangential residual as error estimator in the boundary element method. Computers \& structures, v. 83, n. 10, p. 685-699, 2005.

(59) PARREIRA, Pedro Guilherme Sampaio Viola. Análise do erro no método dos elementos de fronteira em elasticidade. 1987.

(60) RANK, Ernst. Adaptive h-, p-and hp-versions for boundary integral element methods. International journal for numerical methods in engineering, v. 28, n. 6, p. 1335-1349, 1989.

(61) PAULINO, Glaucio Hermogenes. Novel formulations of the boundary element method for fracture mechanics and error estimation. 1996.

(62) LIANG, Ming-Te; CHEN, Jeng-Tzong; YANG, S. S. Error estimation for boundary element method. Engineering analysis with boundary elements, v. 23, n. 3, p. 257-265, 1999.

(63) JORGE, Ariosto B.; RIBEIRO, Gabriel O.; FISHER, Timothy S. New approaches for error estimation and adaptivity for 2D potential boundary element methods. International journal for numerical methods in engineering, v. 56, n. 1, p. 117-144, 2003.

(64) RENCIS, Joseph J.; MULLEN, Robert L. Solution of elasticity problems by a selfadaptive mesh refinement technique for boundary element computation. International journal for numerical methods in engineering, v. 23, n. 8, p. 1509-1527, 1986.

(65) KITA, E.; KAMIYA, N. A new adaptive boundary mesh refinement based on simple algorithm. Mechanics Research Communications, v. 18, n. 4, p. 177-186, 1991. 
(66) ALARCON, E.; REVERTER, A. p-adaptive boundary elements. International journal for numerical methods in engineering, v. 23, n. 5, p. 801-829, 1986.

(67) CERROLAZA, M. The p-adaptive boundary integral equation method. Advances in Engineering Software, v. 15, n. 3, p. 261-267, 1992.

(68) CERROLAZA, Miguel; ALARCÓN, Enrique. p-adaptive boundary elements for three-dimensional potential problems Communications in applied numerical methods, v. 3, n. 4, p. 335-344, 1987.

(69) GUIGGIANI, MASSIMO. Sensitivity analysis for boundary element error estimation and mesh refinement. International journal for numerical methods in engineering, v. 39, n. 17, p. 2907-2920, 1996.

(70) BONNET, Marc; GUIGGIANI, Massimo. Tangential derivative of singular boundary integrals with respect to the position of collocation points. Int. J. Num. Meth. in Eng., v. 41, p. 1255-1275, 1998.

(71) PAULINO, G. H. et al. Nodal sensitivities as error estimates in computational mechanics. Acta Mechanica, v. 121, n. 1-4, p. 191-213, 1997.

(72) MULLEN, R. L.; RENCIS, J. J. Adaptive mesh refinement techniques for boundary element methods. Advanced topics in boundary element analysis, p. 235-255, 1985.

(73) CHARAFI, Abdellatif; NEVES, A. C.; WROBEL, L. C. h-Hierarchical adaptive boundary element method using local reanalysis. International journal for numerical methods in engineering, v. 38, n. 13, p. 2185-2207, 1995.

(74) PAULINO, Glaucio H.; GRAY, L. J.; ZARIKIAN, V. R. E. J. Hypersingular residuals--A new approach for error estimation in the boundary element method. International Journal for Numerical Methods in Engineering, v. 39, n. 12, p. 2005-2029, 1996.

(75) MUCI-KÜCHLER, K. H.; MIRANDA-VALENZUELA, J. C.; SORIANO-SORIANO, $S$. Use of the tangent derivative boundary integral equations for the efficient computation of stresses and error indicators. International journal for numerical methods in engineering, v. 53, n. 4, p. 797-824, 2002.

(76) JORGE, Ariosto B.; RIBEIRO, Gabriel O.; FISHER, Timothy S. New approaches for error estimation and adaptivity for 2D potential boundary element methods. International journal for numerical methods in engineering, v. 56, n. 1, p. 117-144, 2003. 
(77) KALLINDERIS, Yannis G.; BARON, Judson R. Adaptation methods for a new Navier-Stokes algorithm. AIAA journal, v. 27, n. 1, p. 37-43, 1989.

(78) TIMOSHENKO, S. Theory of Elasticity 3E. Engineering Societies Monographs. McGraw-Hill, 1936.

(79) KANE, James $\mathrm{H}$. Boundary element analysis in engineering continuum mechanics(Book). Englewood Cliffs, NJ: Prentice Hall., 1994.

(80) KRISHNASAMY, Guna; RIZZO, Frank J.; LIU, Yijun. Boundary integral equations for thin bodies. International Journal for Numerical Methods in Engineering, v. 37, n. 1, p. 107-121, 1994.

(81) ZHANG, Y., GU, Y., CHEN, J. Boundary Element Analysis of Thin Structural Problems in 2D Elastostatics. Journal of Marine Science and Technology, Vol. 19, pp. 409-416, 2011

(82) BREBBIA, C. A., TELLS, J. C. F., e WROBEL, L. C. Boundary Element Techniques, Springer-Verlag, Berlin, Alemanha, 1984.

(83) LIU, C. S. A Modified Collocation Trefftz Method for the Inverse Cauchy Problem of Laplace Equation. Engineering Analysis with Boundary Elements, Vol. 32, No. 9, pp. 778-785, 2006.

(84) LIU, Y. J. \& RIZZO, F. J. Scattering of Elastic Waves from Thin Shapes in Three Dimensions Using the Composite Boundary Integral Equation Formulation. J. Acoust. Soc. Am. Vol. 102, pp. 926-932, 1997.

(85) SLADEK, V. e SLADEK, J. Singular Integrals in Boundary Element Methods, Computational Mechanics Publications, Southampton, 1998.

(86) GRANADOS, J. J. e GALLEGO, G. Regularization of Nearly Hypersingular Integrals in the Boundary Element Method. Engineering Analysis with Boundary Elements, Vol. 25, No. 3, pp. 165-184, 2001.

(87) MUKHERJEE, Subrata; CHATI, Mandar K.; SHI, Xiaolan. Evaluation of nearly singular integrals in boundary element contour and node methods for threedimensional linear elasticity. International Journal of Solids and Structures, v. 37, n. 51, p. 7633-7654, 2000.

(88) REBOREDO, R. R., COSTA, D. I. G. e ALBUQUERQUE, E. L. Analysis of thin shaped elastic problems using the Boundary element method. XXXV CILAMCE, Fortaleza, Brasil, 2014. 
(89) UMETANI, S. I. Adaptive Boundary Element Methods in Elastostatics. Topics in Engineering Vol. 5, Computational Mechanics Publications, Southampton (UK) e Boston (EUA), 1988.

(90) HOWLAND, R. C. J. On the stresses in the neighbourhood of a circular hole in a strip under tension. Philosophical Transactions of the Royal Society of London. Series A, Containing Papers of a Mathematical or Physical Character, p. 49-86, 1930. 


\section{APÊNDICE A - ROTINA PARA O CÁLCULO DOS SALTOS ENTRE AS SOLUÇÕES DO CONTORNO}

Este apêndice apresenta a rotina desenvolvida pelo autor, no ambiente de programação do software MATLAB 7.12.0 (R2011a), que tem como função calcular os saltos entre as soluções de deslocamento e forças de superfície ao longo do contorno entre elementos adjacentes.

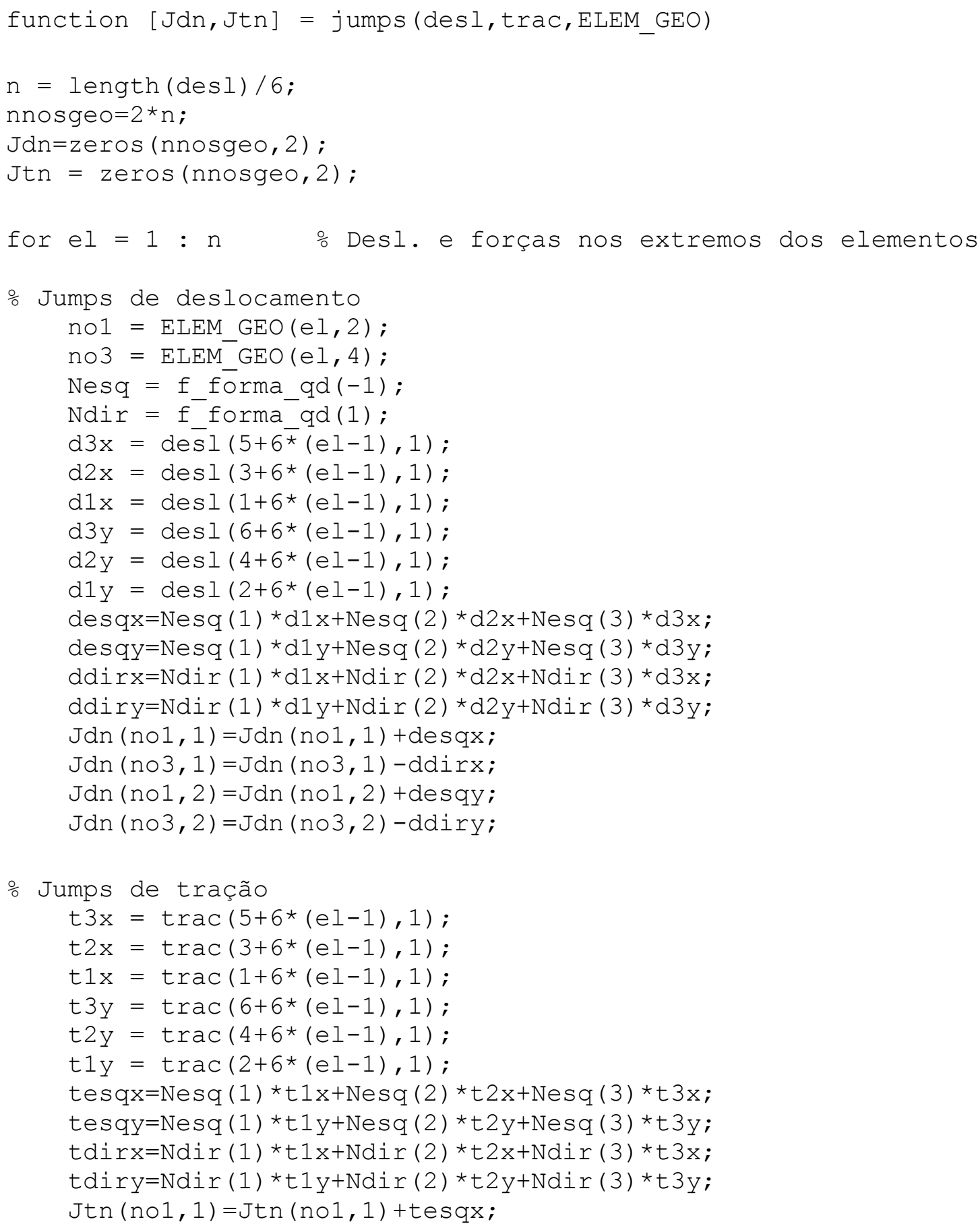


$\operatorname{Jtn}(n \circ 3,1)=\operatorname{Jtn}(n \circ 3,1)-\operatorname{tdirx} ;$

Jtn $(n \circ 1,2)=\operatorname{Jtn}(n \circ 1,2)+$ tesqy;

end

Jtn $(n \circ 3,2)=\operatorname{Jtn}(n \circ 3,2)$-tdiry;

return 


\section{APÊNDICE B - ROTINA PARA O CÁLCULO DOS INDICADORES DE ERRO}

Este apêndice apresenta a rotina desenvolvida pelo autor, no ambiente de programação do software MATLAB 7.12.0 (R2011a), que tem como função calcular os indicadores de erro das soluções de deslocamento e forças de superfície por elemento.

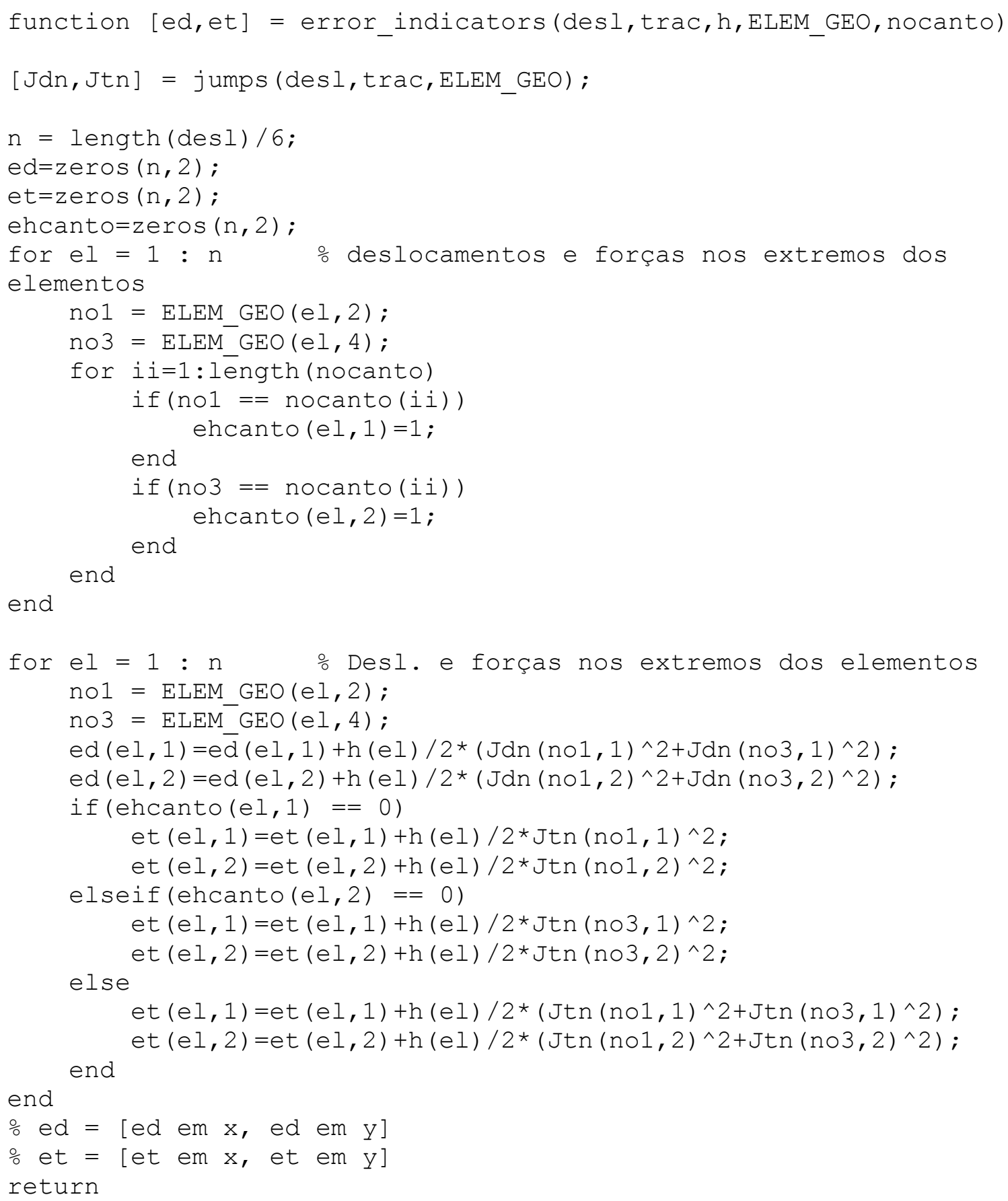




\section{APÊNDICE C - ROTINA PARA O CÁLCULO DAS PORCENTAGENS DE ERRO}

Este apêndice apresenta a rotina desenvolvida pelo autor, no ambiente de programação do software MATLAB 7.12.0 (R2011a), que tem como função calcular as porcentagens de erro das soluções de deslocamento e forças de superfície por elemento.

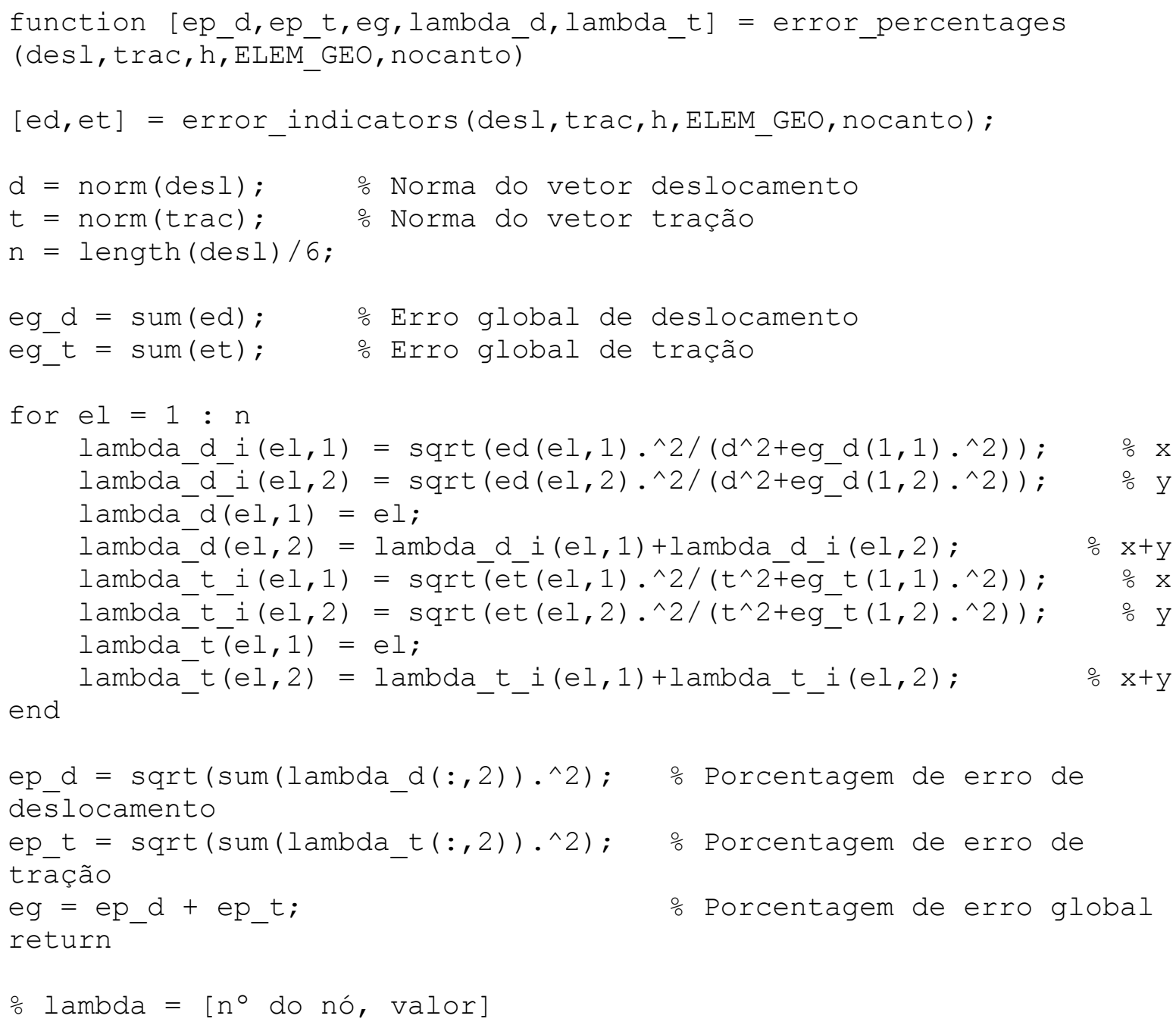




\section{APÊNDICE D - ROTINA PARA EFETUAR O REFINAMENTO}

Este apêndice apresenta a rotina desenvolvida pelo autor, no ambiente de programação do software MATLAB 7.12.0 (R2011a), que tem como função indicar as coordenadas do elemento com a maior porcentagem de erro calculada.

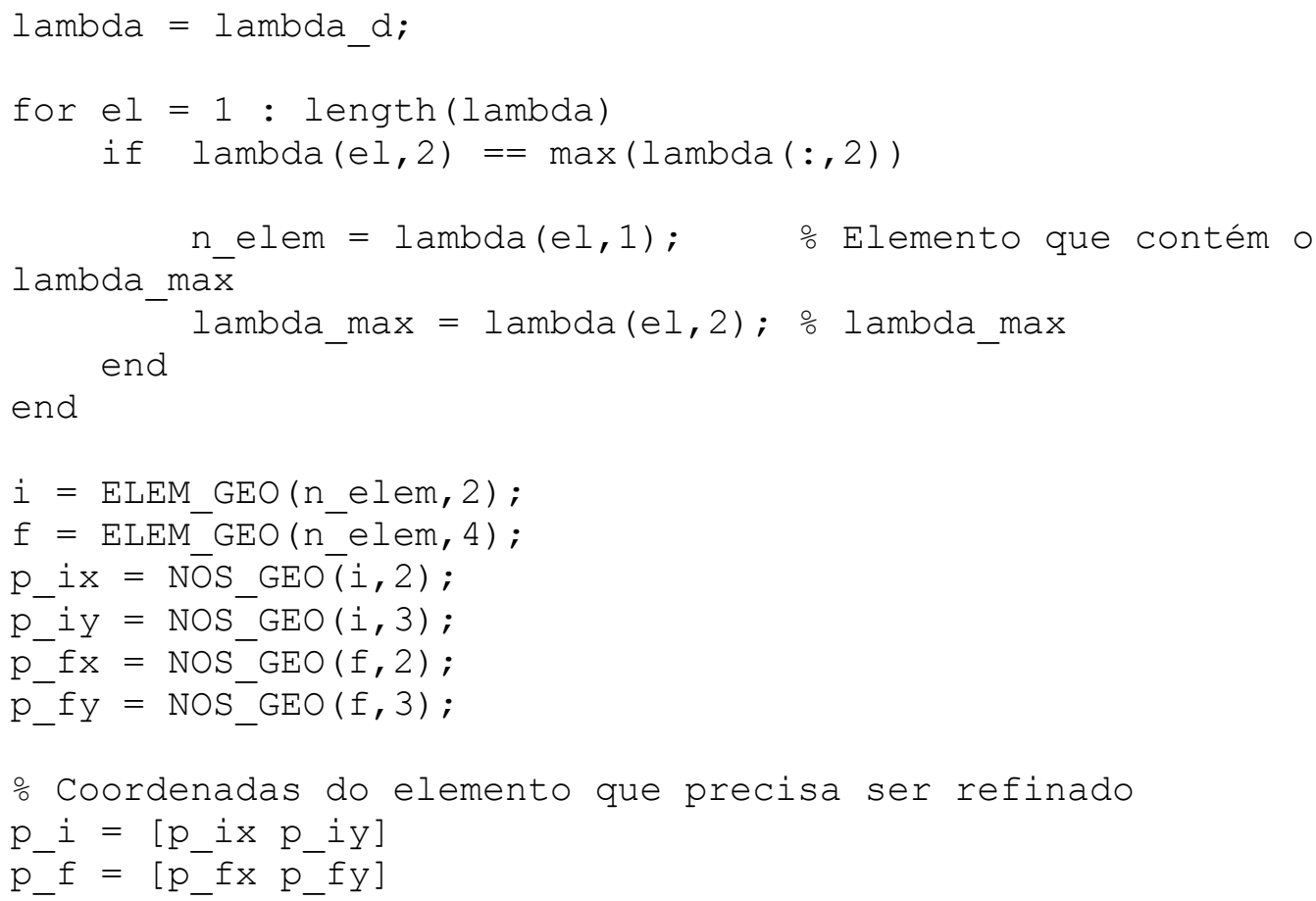

